\title{
Review
}

\section{A Review of Nanocarbon-Based Solutions for the Structural Health Monitoring of Composite Parts Used in Renewable Energies}

\author{
Antoine Lemartinel ${ }^{1,2}$, Mickael Castro ${ }^{1} \mathbb{D}$, Olivier Fouché ${ }^{2}$, Julio-César De-Luca ${ }^{2} \mathbb{D}$ and Jean-François Feller ${ }^{1, * \mathbb{D}}$ \\ 1 Smart Plastics Group, University of South Brittany (UBS), IRDL CNRS 6027, 56100 Lorient, France; \\ antoine.lemartinel@gmail.com (A.L.); mickael.castro@univ-ubs.fr (M.C.) \\ 2 Jules Verne Technological Research Institute (IRT), 44340 Bouguenais, France; \\ olivier.fouche@irt-jules-verne.fr (O.F.); julio-cesar.de-luca@irt-jules-verne.fr (J.-C.D.-L.) \\ * Correspondence: jean-francois.feller@univ-ubs.fr
}

check for updates

Citation: Lemartinel, A.; Castro, M.; Fouché, O.; De-Luca, J.-C.; Feller, J.-F. A Review of Nanocarbon-Based Solutions for the Structural Health Monitoring of Composite Parts Used in Renewable Energies. J. Compos. Sci. 2022, 6, 32. https://doi.org/10.3390/ jcs6020032

Academic Editor: Francesco

Tornabene

Received: 25 November 2021

Accepted: 31 December 2021

Published: 19 January 2022

Publisher's Note: MDPI stays neutral with regard to jurisdictional claims in published maps and institutional affiliations.

Copyright: (c) 2022 by the authors. Licensee MDPI, Basel, Switzerland. This article is an open access article distributed under the terms and conditions of the Creative Commons Attribution (CC BY) license (https:// creativecommons.org/licenses/by/ $4.0 /)$.

\begin{abstract}
The growing demands for electrical energy, especially renewable, is boosting the development of wind turbines equipped with longer composite blades. To reduce the maintenance cost of such huge composite parts, the structural health monitoring (SHM) is an approach to anticipate and/or follow the structural behaviour along time. Apart from the development of traditional non-destructive testing methods, in order to reduce the use of intrusive instrumentation there is a growing interest for the development of "self-sensing materials". An interesting route to achieve this, can be to introduce carbon nanofillers such as nanotubes (CNT) in the composite structures, which enables to create systems that are sensitive to both strain and damage. This review aims at updating the state of the art of this topic so far. A first overview of the existing SHM techniques for thermoset based wind turbine blades composites is presented. Then, the use of self-sensing materials for strain and damage sensing is presented. Different strategies are overviewed and discussed, from the design of conductive composites such as carbon fibres reinforced polymers, to the elaboration of conductive nano-reinforced polymer composites. The origins of sensing mechanisms along with the percolation theory applied to nanofillers dispersed in polymer matrices are also detailed.
\end{abstract}

Keywords: wind turbine blade; composite materials; structural health monitoring (SHM); fibrereinforced plastics (FRP); nano engineered composites; carbon nanotubes (CNT)

\section{Introduction}

Since the first decade of the 21th century the installed wind energy electricity has strongly increased worldwide as clearly seen in Figure 1, with a significant increase per year since 2015 of 11\% for China, 7\% for Europe Union [1] and for United States [2,3]. 


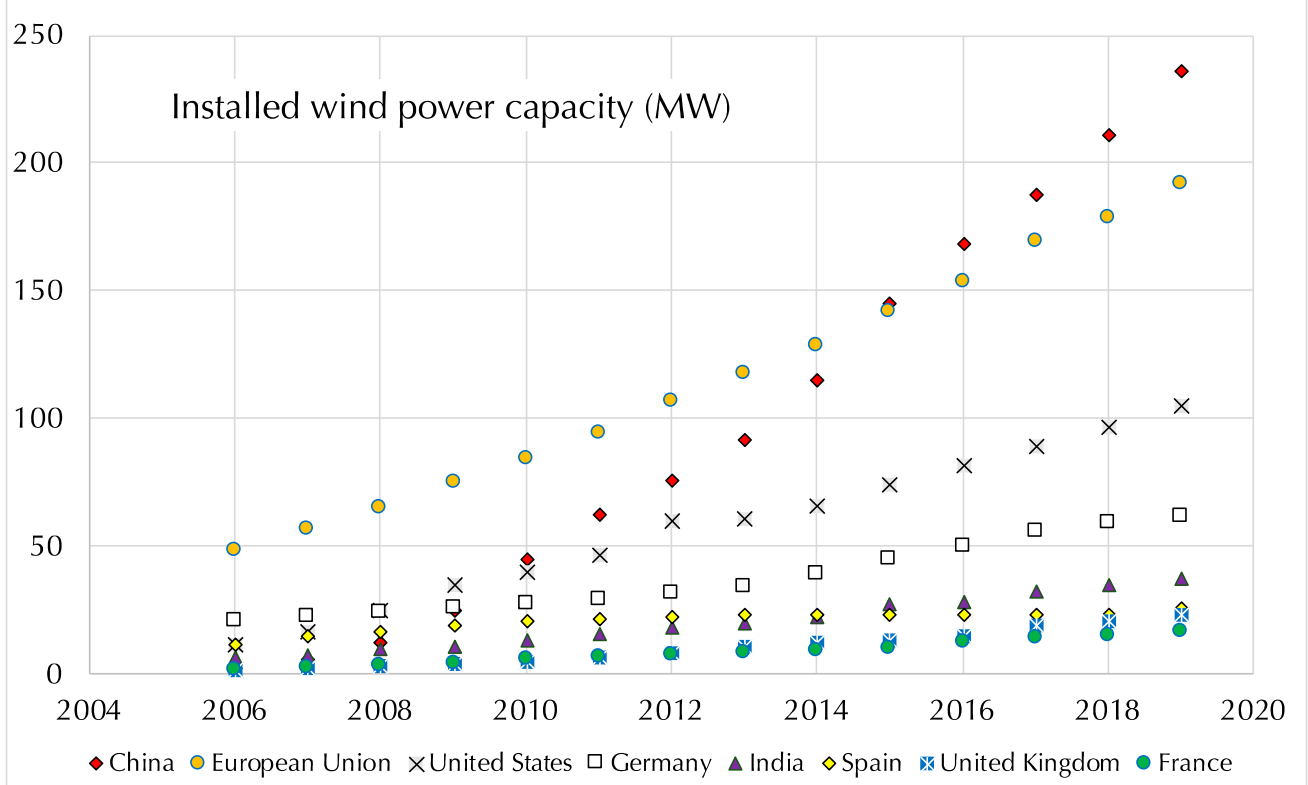

Figure 1. Increase of installed wind power capacity (MW) in the world between 2006 and 2020 [4].

Although, most wind turbines are setup on-shore, there is a strong tendency to develop them off-shore to produce a larger and more constant energy as seen in Figure 2. Indeed, reaching extreme characteristics such as that of a $20 \mathrm{MW}$ turbine, planned to be produced in near future is a true technological challenge. Therefore, to keep on increasing power capacity, several technological improvements are needed to reach more than $20 \%$ production of the US electrical energy with wind energy [5], as well as $20 \%$ by 2020 and $32 \%$ by 2030 of renewable energy in the European Union, according to the recent directive established in 2018 [6].

In this context of fabrication of ever longer wind turbines blades reaching more than $100 \mathrm{~m}$, only composite materials can achieve the highest mechanical performances/weight ratio needed. Usually made of glass fibres assembled with an epoxy matrix composites are anisotropic or orthotropic materials by design, and their failure is a combination of various mechanisms like matrix cracking, delamination, fibre breakage, or interfacial debonding [7]. Therefore, it is important to identify the origin of damage to prevent defects during the manufacturing phase, transportation, and in operation. A good assessment of damage mitigation techniques in wind turbine blades has been made by Shohag et al. [8].

Hence, damage initiation and propagation remain difficult to predict. The detection of damages along with undergone strain could promote a better prediction of the ultimate failure of the structure, thus leading to the reduction of maintenance cost. For instance, among the current total cost of on-shore wind turbines reaching more than $1 \mathrm{M} € \cdot \mathrm{MW}^{-1}$, about $10 \%$ is induced by maintenance [9], and the transition to off-shore plants could increase this cost to nearly $30 \%[10,11]$. 


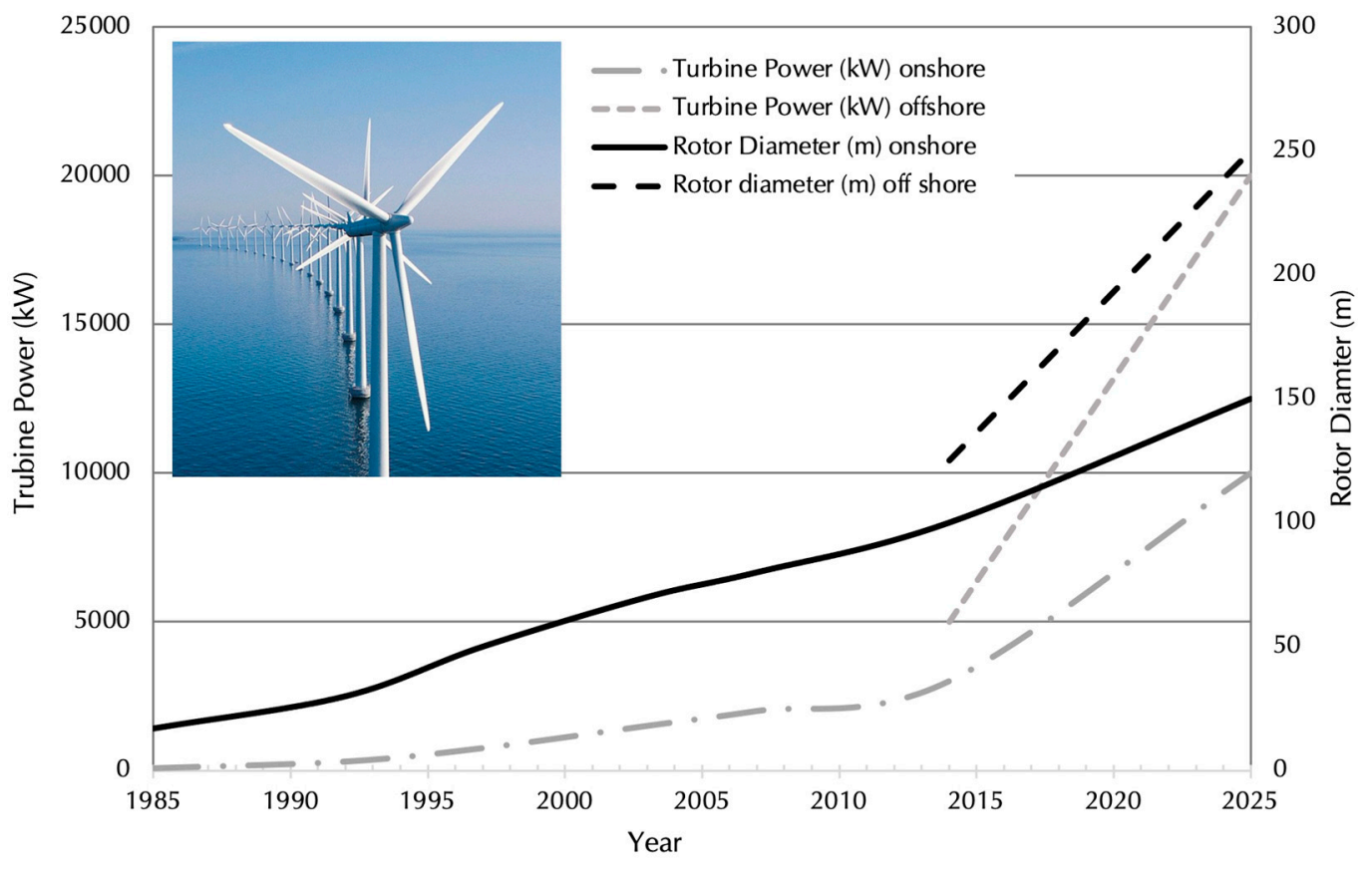

Figure 2. Chronological evolution of wind turbines' rotor size $(\mathrm{m})$ with power $(\mathrm{kW})$ [12].

In this context, a Structural Health Monitoring (SHM) system, which would provide clues about the material's health state, comes out as a very interesting tool [13-16]. SHM systems have multiple objectives, such as allowing an optimal use of the structure, decreasing the downtime, and avoiding catastrophic failure. It should also help to replace the scheduled and periodic maintenances by performance-based inspections; as well as to reduce the human involvement for less labour, human errors, and therefore higher reliability. Structural Health Monitoring (SHM) of wind turbine blades is required, because their failure is one of the main reasons for turbine downtimes [11]. Today's main causes of damages in blades are identified as follows [17]: Firstly, the erosion of the leading edge, mainly close to the tip, caused by abrasive airborne particles, and reduces the aerodynamic efficiency. It can also create delamination along the edge. Secondly, the lightning can induce damages and cracks around the impact point. Then, the accumulation of ice on the blade's surface, due to the combination of climate and temperature conditions, can result in a reduction of the aerodynamic or an increase of the fatigue caused by the additional mass.

Finally, wind turbines have an expected life time of 20 years. The degradation of blades due to fatigue mechanisms is therefore likely to happen before the end of life and requiring reparations after a pertinent diagnosis. The resulting damages proposed by Sørensen et al. [18] are shown in Figure 3.

According to the authors, the different sketches of damage can be classified in 7 types:

- Type 1: Damage formation and growth in the adhesive layer joining skin and main spar flanges (skin/adhesive debonding and/or main spar/adhesive layer debonding),

- Type 2: Damage formation and growth in the adhesive layer joining the up and downwind skins along leading and/or trailing edges (adhesive joint failure between skins),

- Type 3: Damage formation and growth at the interface between face and core in sandwich panels in skins and main spar web (sandwich panel face/core debonding),

- Type 4: Internal damage formation and growth in laminates in skin and/or main spar flanges, under a tensile or compression load (delamination driven by a tensional or a buckling load),

- Type 5: Splitting and fracture of separate fibres in laminates of the skin and main spar (fibre failure in tension; laminate failure in compression), 
- Type 6: Buckling of the skin due to damage formation and growth in the bond between skin and main spar under compressive load (skin/adhesive debonding induced by buckling, a specific type 1 case),

- Type 7: Formation and growth of cracks in the gel-coat; debonding of the gelcoat from the skin (gel-coat cracking and gel-coat/skin debonding).

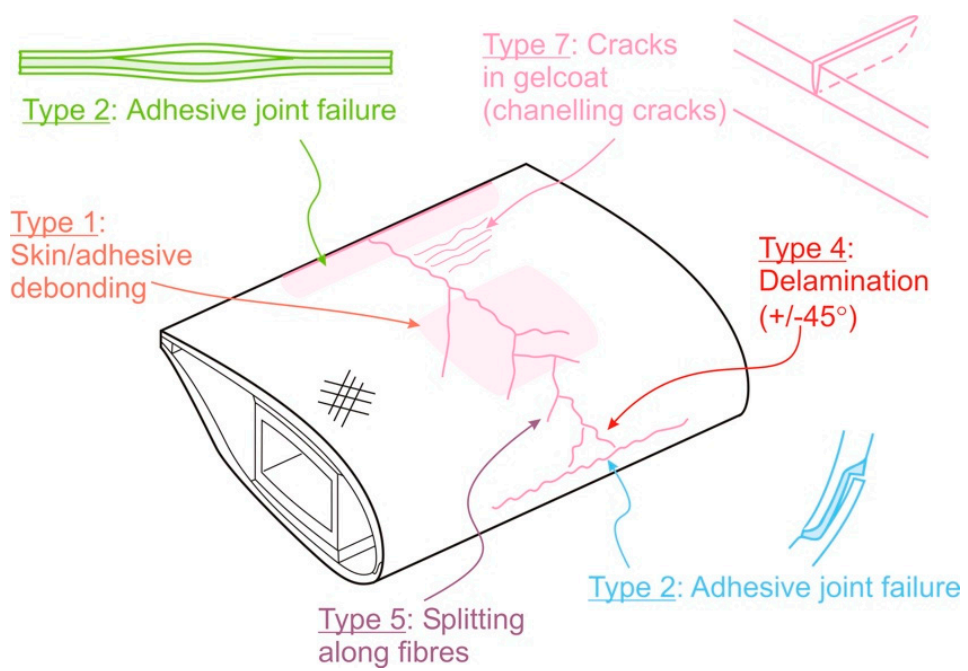

(a)
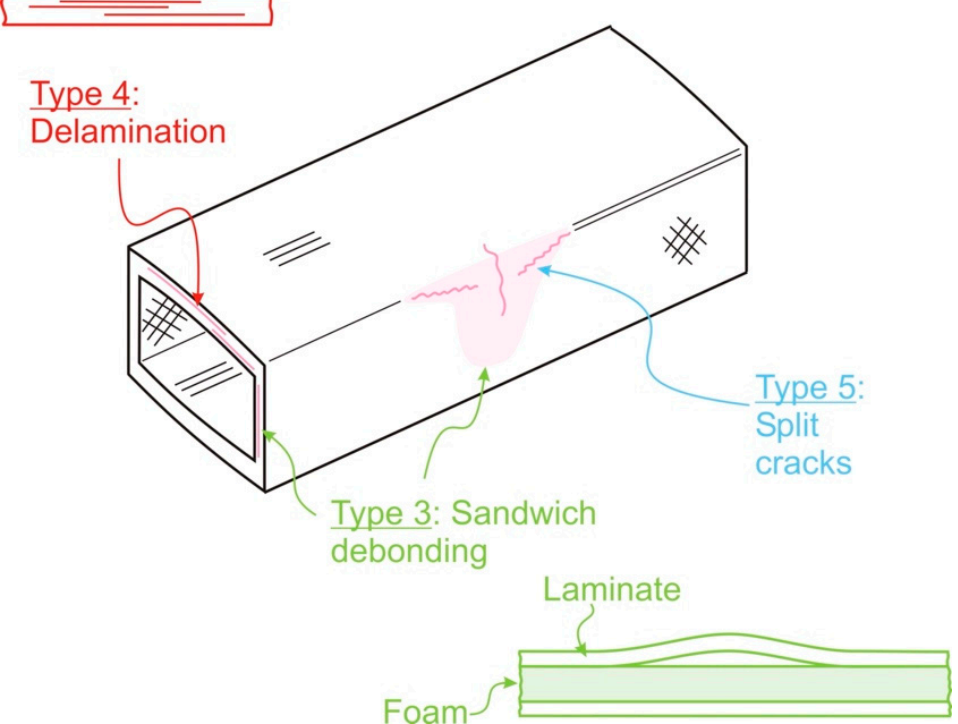

(b)

Figure 3. Sketches of the different types of damage that can occur in a wind turbine blade, (a) by skin-adhesive debonding, (b) delamination [18].

To illustrate the damages localisation during the blade failure, Chen et al. [19] have conducted a destructive bending test on a $52.3 \mathrm{~m}$ long blade. Different sorts of damages resulting from the test are shown in Figure 4, which shows that the damage repartition on the surface and in the core of blade is not homogeneous. For examples, debonding between the core and the skin is observed at several locations, and fibres cracks are visible near the spar cap. Therefore, the detection of the various damage types and their localisation by a SHM technic is required. 


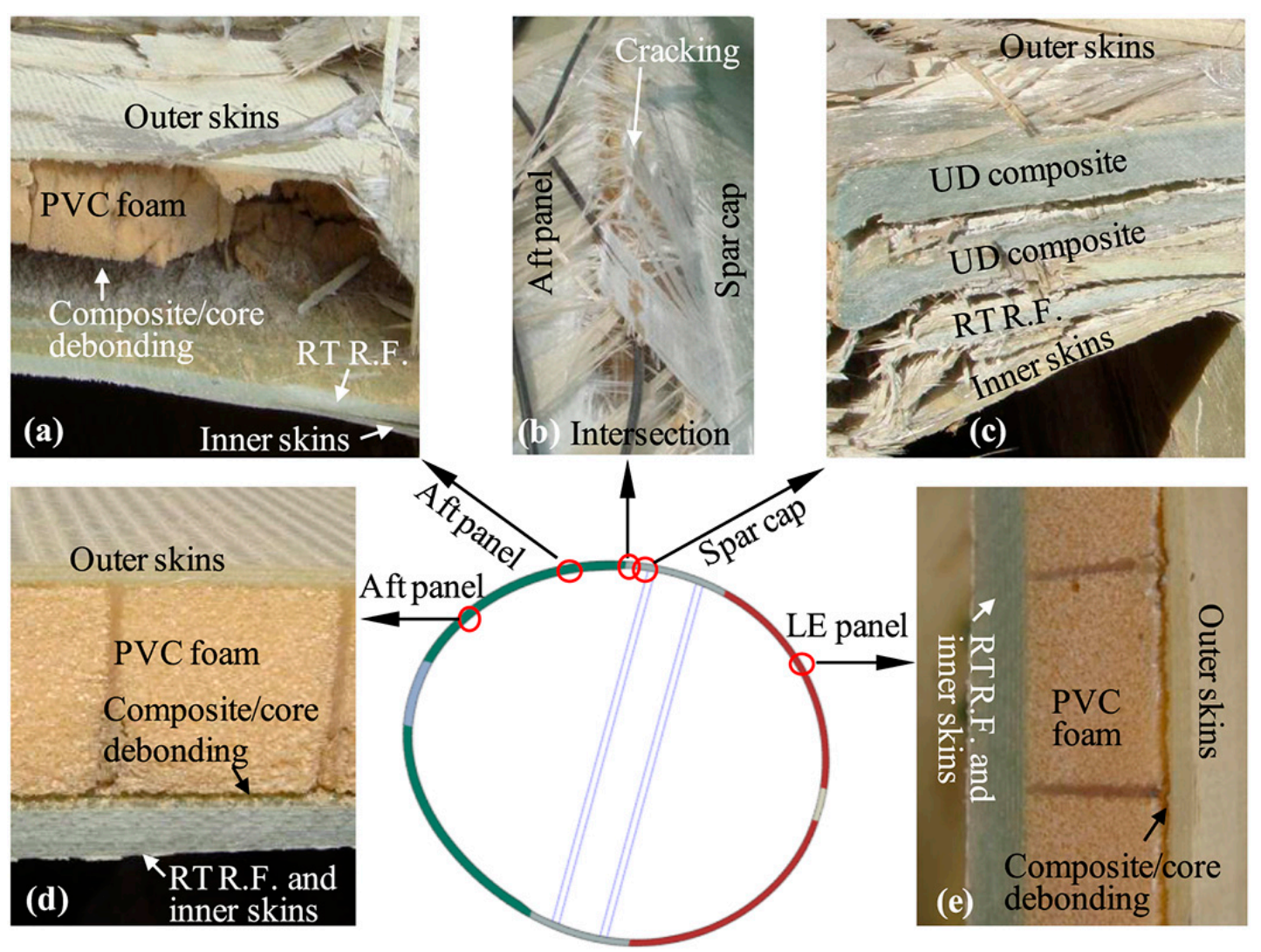

Figure 4. Observed failures around a $52.3 \mathrm{~m}$ long blade after a destructive bending test, (a) the aft panel adjacent to the spar cap is also subject to cracking of the outer composites, (b) the region of intersection between the spar cap and the aft panel shows longitudinal cracking of the skin composites, (c) local buckling and the consequent material failure of the aft panel inevitably affect the adjacent spar cap, which exhibits severe delamination and delamination of the inner composites, (d) Inner skin / composite core debonding, (e) Outer skin/composite core debonding [19].

Furthermore, off-shore wind turbines are exposed to harsh environmental conditions (humidity, salinity, varying temperature ...) and fluctuating load that affect the system's performance and ultimately provoke a failure. A fault is defined as a significant change in the system parameters beyond acceptable/allowed limits leading to a decrease of the system performance. Depending on the fault and the related criticality, the required actions may include corrective maintenance intending to restore the system to its previous (undamaged) state or emergency maintenance targeting to avoid failures of components and systems. To avoid the downtime of the structure, as well as localising failures and predicting the remaining life time of blades, the development of SHM techniques is inevitable, keeping in mind, at the same time, its beneficial impact on the operating and maintenance costs. In a laminate composite material, damage initiates and propagates in zones of high-stress concentrations, such as free edges around cut-outs, joints or delamination edges $[17,19,20]$. Therefore, the estimation and prediction of failure is not trivial. In the case of composites, several standard non-destructive evaluation (NDE) techniques exist for the detection of strain or damage, including ultrasonic inspection, acoustic emission (AE), strain gauges, optical fibre, electrical resistance tomography (ERT) and piezo-resistive sensors. Moreover, the recent development of nanoparticles and nano composites is leading to the emergence of self-sensing materials.

Existing surveys of SHM for wind turbines focus on the monitoring technics available for the different parts of the turbine [1,21-26]. In the case of the blades, Yang and Sun [27] have reported the use of acoustic emission, infrared thermography and X-Ray imaging as inspecting technics of full-scale blades to detect hidden flaws and defects. In the case of 'in 
service' monitoring, Schubel et al. [13] and Cooperman \& Martinez [28] have detailed the available sensors for strain and damage detection such as metallic strain gauges, optical fibres or acoustic emission. Nevertheless, these relevant and well documented surveys only focus on the use of existing SHM technologies and sensors, but do not present new developments of alternative technics to monitor strain and/or damage into composite structures. Thus, the goal of this paper is to provide a comprehensive survey of the self-sensing materials that are proposed or being developed in the scientific community. Firstly, the characteristics of the existing strain or damage technics are discussed. Then, an alternative approach relying on self-sensing thermoset composite materials is presented through the main studies reported in the literature.

\section{Commercially Available Technics Based on Strain \& Damage Monitoring}

The basic principle of strain gauges is to provide the variation of length of the material on defined zones. The damage undergone by a structure is not directly obtained by the strain gauges. Using the resistance laws of materials (Hooke's laws), the stress can be calculated from the deformation, where the sensor is located [13]. The knowledge of the mechanical properties of the material is therefore necessary to use strain gauges. Different types of gauges can be found but their principle is similar: any strain undergone by the gauge is directly converted into an electrical or optical signal as an output. Once a gauge is attached to the structure, its deformation is locally similar to the one encountered by the structure. Thus, the gauge signal recording enables an estimation the structure's deformation. The existing strain gauges mainly rely on capacitance, inductance or resistance of the sensing element, and on transmitted or reflected signals of optical fibres $[13,23,28,29]$.

\subsection{Monitoring Technics Used in Strain Analysis}

\subsubsection{Metallic Strain Gauges}

The elastic deformation of a metal gauge proportionally modifies the value of its resistance. The sensitivity, or gauge factor (GF), of strain gauges is generally in the order of 2 and the initial resistances can vary from $30 \Omega$ to $3 \mathrm{k} \Omega$. The value of the initial resistance, as well as the gauge factor, is precisely set and controlled. The non-linear characteristic of metal gauge usually starts with strains up to $\pm 15 \%$ [30]. For smaller deformation, there is an emergence of new strain gauges with much higher gauge factors, up to 150 [31]. In general, these sensors are preferably positioned on the surface of the structure, possess limited sensitivity towards direction over a defined area [32], and have a flat surface allowing an optimised adhesion. Since the patent of the printed circuit for foil strain gauge in 1952 by Paul Eisler [33] the technic has obviously become mature. It is a precise and affordable technology with a standard deviation of the GF value about 1\% [30], and a price around $10 €$ per direction of measurement [34]. The associated electrical measurement usually relies on a Wheatstone bridge. The measured voltage change in the bridge is precisely linked to the change of resistance of the gauge, and consequently to the strain. External parameters are affecting the metal gauge characteristics, such as temperature, which modifies the gauge factor (GF) about $10^{-2} \% \cdot \mathrm{K}^{-1}$ [35], environmental disturbances like lightning or electromagnetic interference. Yet, such sensors suffer from performance degradation over time which differs their lifetime compared to the structure's lifetime $[15,36]$. Finally, typical commercial metallic strain gauges are made of a $5 \mu \mathrm{m}$ metallic wire stacked on a $45 \mu \mathrm{m}$ poly(imide) film and recovered by a $25 \mu \mathrm{m}$ poly(imide) film [35]. The nature of their components may turn out to be a weak point if considering the embedment of the gauges in laminated composites structures.

\subsubsection{Optical Fibres}

Several technologies based on optical fibres (OF) already exist, with a predominance of fibre Bragg grating (FBG) or Rayleigh scattering [37]. A FBG sensor is a periodic variation of the refractive index in the fibre's core (Figure 5). The change of the core refraction index is between $10^{-5}$ and $10^{-3}$, and the length of a Bragg grating is usually around $10 \mathrm{~mm}$ [38]. 
When an emitted light along the fibre arrives on the sensor, the change of the refraction index induces the creation of a transmitted and a reflected light signal as shown in Figure 5.

a)

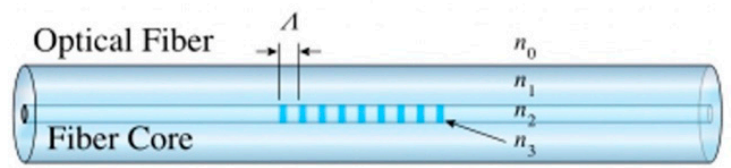

\section{Core Refractive Index}

b)

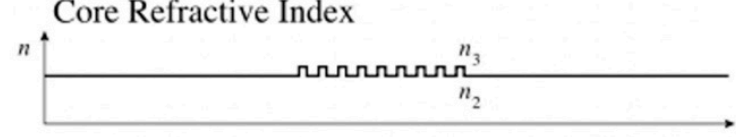

Spectral Response

c)

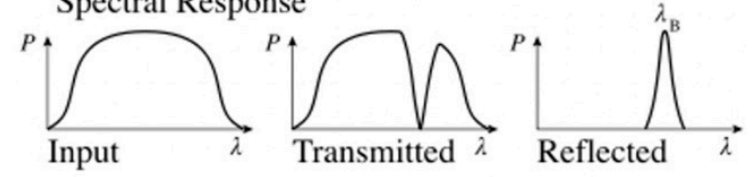

Figure 5. Principle of a FBG sensor [39]. (a) A Fibre Bragg Grating structure with the different refractive index (outer $n_{0}$, fibre $n_{1}$, core $n_{0}$, and grating $n_{3}$ ) and the distance $\Lambda$ between each grating. (b) The refractive core index profile. (c) Illustration of the transmitted and reflected spectral response regarding the input signal.

Any change of the refraction index in the grating modifies the transmitted and reflected signal. External solicitation such as strain, temperature, humidity, vibrations, breaks and delamination can induce a change in the index [23,38-44]. The wavelength shift caused by strain and temperature can be expressed using the Equation (1) [42].

$$
\frac{\Delta \lambda_{F B G}}{\lambda_{F B G}}=\left(1-P_{e}\right) \varepsilon+(\alpha+\xi) \Delta T
$$

where $\lambda_{F B G}$ is the wavelength of the propagating light, $\varepsilon$ the fibre strain, $T$ the fibre temperature, $P_{e}$ the effective opto-mechanical constant, $\alpha$ the coefficient of thermal expansion of the glass fibre, and $\xi$ the fibre thermo-optic coefficient.

Therefore, any local strain or temperature modification can be measured by FBG sensors. Several FBG sensors can be grated along a single OF. A discrete mapping of a structure can therefore be assumed by a unique fibre. In order to discriminate between the strain and the temperature via the wavelength shift, the use of two different optical fibres is requested in practice [45]. Kinet et al. [45] have compared three technics to discriminate the temperature and strain measurements in composite laminates with FBG. The best solution was found with the use of two fibres, one in the core of the sample and one embedded in a capillary to isolate it from strain. The authors reported an uncertainty on strain close to $2 \mu \varepsilon$ and on temperature about $0.1^{\circ} \mathrm{C}$. Compared to metal strain gauge, the usual gauge factor (GF) is usually lower, ranging from 0.7 to $1[46,47]$ with a limit of strain detection of $1 \mu \varepsilon$ [48]. The multiplication of FBG sensors on a structure is ultimately leading to the strain mapping of materials [49]. To date, FBG are already used as SHM devices for civil engineering like bridges [50], and have shown some interest for aeronautic [51] and renewable [44] applications.

Rayleigh scattering optical fibres have a refractive index which varies along the fibre as a function of the presence of defects or non-homogeneities of the material [28]. This index variation allows backscattering of different wavelengths at different points of the fibre. The analysis of the backscattered light makes possible to obtain information on the deformation, the changes in temperature, and the undergone flexion at each point along the fibre. Compared to FBG, the strain deformation can be estimated along the complete fibre, thus inducing a larger amount of data.

FBG or Rayleigh fibres can be surface-applied or integrated in the structure. On the surface, they do not modify the characteristics of the material. Once in the core of 
the composite, the optical fibre size, usually about $100-150 \mu \mathrm{m}$, is much greater than the composites reinforcing fibres, less than $20 \mu \mathrm{m}$ for carbon or glass fibres. It results in the creation of a gap between the optical fibres and the reinforcement fibres, as shown in Figure 6, thus inducing resin rich regions.

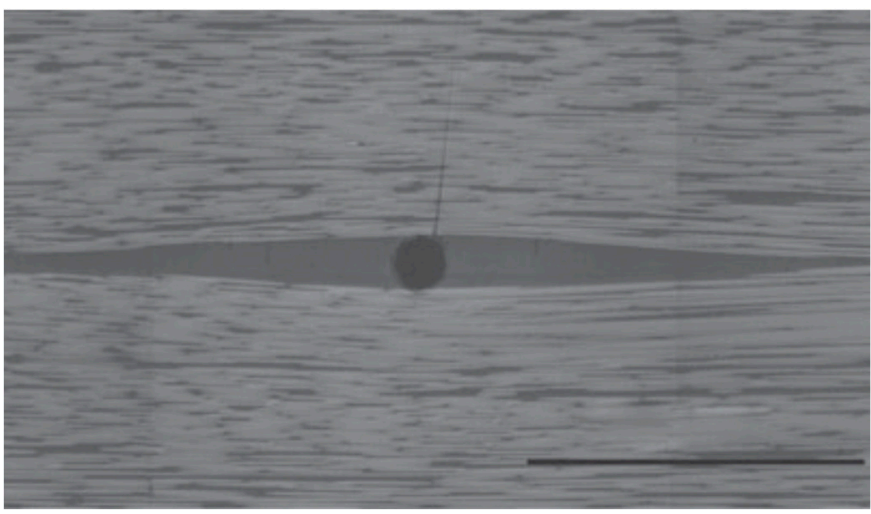

(a)

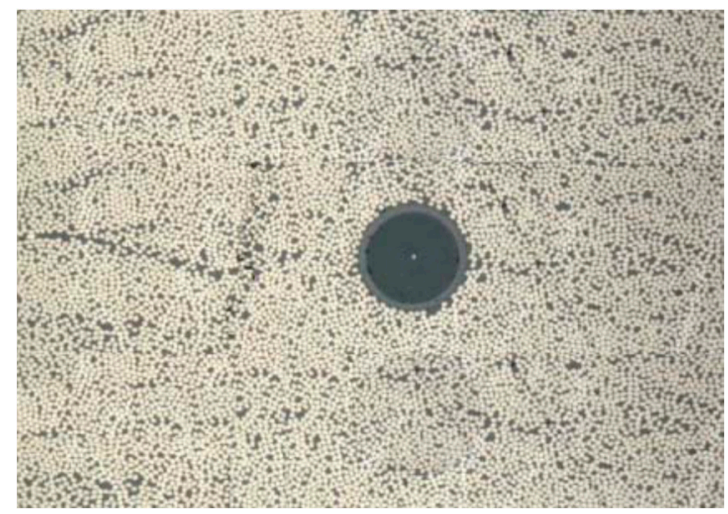

(b)

Figure 6. OF embedded in a composite (a) perpendicularly to the fibres (diameter $80 \mu \mathrm{m}$ and scale bar $500 \mu \mathrm{m}$ ) [52] and (b) in the fibres axis (diameter $125 \mu \mathrm{m}$ ) [53].

Huang et al. [52] have studied carbon fibre reinforced polymer (CFRP) compression behaviour, while stainless steel wires were embedded in the core of the composite. The wires diameter was varying from 80 to $560 \mu \mathrm{m}$. The authors reported a decrease of the failure strength with the diameter, of $1.120 \mathrm{Gpa}$ and $0.393 \mathrm{Gpa}$ for $80 \mu \mathrm{m}$ and $560 \mu \mathrm{m}$, that represented 87 and $30 \%$ respectively of the initial failure strength of the pristine CFRP. Although the OF mechanical properties and their adhesion with the matrix is different from the steel wire, a similar trend can be expected when embedding OF in composites, thus seen as a potential drawback.

\subsection{Monitoring Techniques Used in Failure Analysis}

\subsubsection{Visual Inspection}

To date, the periodic structural health inspection of wind turbine blades is made by professional climbers while the wind turbine is shut down. The inspection is mainly limited to visual inspection and simple manual tapping tests with a hammer [54,55]. It allows detecting surface damages in defined critical areas. For internal damages, the tapping method requires an expertise to distinguish between the damaged and undamaged structure. Nevertheless, some damages cannot be detected by the current technics, being too deep in the core of the structure and thus not responsive to the tapping method.

\subsubsection{Performance Analysis}

A wind turbine structure, working in its optimal state, exhibits a certain level of performance (power, nominal voltage, angle of inclination of the blades, current, speed of the blades, etc.). When the structure degrades, performance is changed despite identical operating conditions [56]. Consequently, the analysis of various operating parameters enables to identify the presence of damages on the structure when deviations are important compared to the optimum performances [23,29]. Performance analysis is an efficient method to determine the integrity level of the structure, despite the lack of estimation of the defect's characteristics (location, concentration, type...) as well as the inability to anticipate their appearance. This technic still remains an indicator of the overall structure's health level. 


\subsubsection{Acoustic Emission (AE)}

Acoustic Emission (AE) is known as the emission of elastic waves with low amplitude ranges and high frequency (from $100 \mathrm{kHz}$ to $1 \mathrm{MHz}$ ) [13,57]. The $\mathrm{AE}$ waves are generated within the material by the release of energy. Therefore, $\mathrm{AE}$ is a passive non-destructive evaluation technic (NDE) because the excitation source is the core material without any additional external source. Typical sources of AE are initiation and propagation of cracks, breakage of fibres, fracture of the matrix, friction between different surfaces, deformation, delamination, and impacts $[13,22]$. The detection of the AE waves is made by a surface sensor. The different failures in the structure can be detected depending on different characteristics of the emitted signal, i.e., counts, rise time, peak amplitude, arrival time, duration, and signal energy content [57]. This technique is commonly used in the industry for the control of composites [55,58,59], and allows steady-state wind turbine blade control [13]. This method is already protected with several patents [60-63]. Walsh et al. [64] studied the possible use of $\mathrm{AE}$ in the case of marine energies. Autonomous multichannel acoustic recorders were used to monitor a wave energy converter. The authors found that the ambient levels were negligible compared to the structure emission. They were also able to detect AE emissions in water with sensors $200 \mathrm{~m}$ away from the structure, while in air conditions the sensors were placed close to the structure. Michalcová and Kadlec [65] have used AE to detect crack length propagation in a carbon fibre reinforced polymers (CFRC) caused by the double cantilever beam with two extreme temperatures, $-55^{\circ} \mathrm{C}$ and $80^{\circ} \mathrm{C}$. They found an average error of the AE cumulative energy compared to the visual crack propagation of $3.49 \%$. In order to localise defects in a glass fibre reinforced polymers (GFRP) composite, Gómez Muñoz et al. [66] used a network of three sensors. Their position and distance from a defect led to various detections for each of them. Especially, the time of detection and the received amplitude were linked to the distance between the sensor and the defect. The correlation between all sensors enabled the defect localisation. The authors succeeded in detecting a fibre breakage with a maximum error of $9 \mathrm{~mm}$ for a $100 \times 79.5 \mathrm{~cm}^{2}$ inspected area. The AE limitations however include the interpretation of background noise, for example due to vibration of the structure or the electromagnetic interference. Furthermore, the size of the sensors seems prohibitive if considering their embedment in a structure, although some attempts were done in samples of small size $[67,68]$.

\subsubsection{Ultrasonic Measurements}

Unlike acoustic emission, which is a passive NDE, ultrasonic measurement (US) is an active monitoring technic. In addition to the received signal, an external excitation source is emitted. This signal propagates within the structure, is thus affected by the material which modified its characteristics (change of phase, defect, delamination, interfacial problems...) $[22,23,59,69]$. The use of ultrasonic waves enables to obtain information on the material's state. Three main techniques exist, named pulse-echo, thickness, and pitch-catch as illustrated in Figure 7. In echo-pulse mode, the wave is sent orthogonally to the material by a transducer which is attached to the surface. The reflection of the wave allows to obtain information on the various defects (type, depth). In thickness mode, the wave is sent through the thickness of the structure, and the reflected wave enables to collect similar information as that in the pulse-echo mode. Mouritz et al. [70] estimated the minimum delamination size for detection depending on the delamination depth in GFRP. They found an exponential relation where the minimum size was 5 and $10 \mathrm{~mm}$ for a depth of 25 and $100 \mathrm{~mm}$ respectively. In pitch-catch mode two sensors (one transmitter and one receiver) are positioned along the surface, and the transmitted wave provides information (location, type of defect) on the surface material state and slightly below [56]. Park et al. [71] have been able to estimate a porosity level of 0 to $6 \%$ in a CFRP specimen with the pitch-catch mode. The ultrasound technique is not affected by humidity or temperature [23]. But a minimal defect's size of few millimetres is required to be detected [22], and like acoustic emission, the sensor's size proscribes any embedding. 
(a)

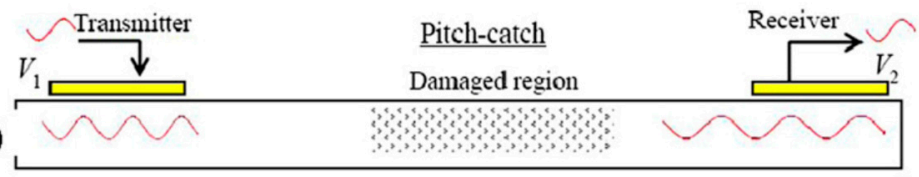

Transmitter-Receiver

$\sim \longrightarrow$ Pulse-echo

(b)

$V_{1} \quad \downarrow \uparrow V_{2}$

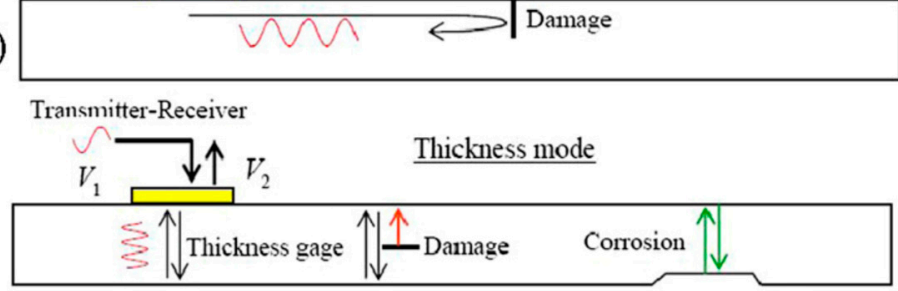

Figure 7. Damage detection with propagating and standing guided waves: (a) pitch-catch, (b) pulseecho, and (c) thickness mode [72].

\subsubsection{Vibrational Analysis}

The analysis of a structure vibrations parameters, such as the frequency, and their variation, enables to measure the structure deformation and the appearance and propagation of cracks $[23,69]$. Depending on the vibration frequencies, varying from $0.01 \mathrm{~Hz}$ to $100 \mathrm{kHz}$ [69], different sensors are used, from motion and speed sensors to accelerometers and emitted energy sensor. This technic has been identified as promising and patented in the field of wind blades [73]. The presence of a damage or change in the structure's properties modifies the measured vibration. Few years ago, Zhang et al. [74] have used three different inverse algorithms based on the shift of the measured frequency to detect and localise delamination in CFRP. Despite an easy identification of damage appearance, the error in the localisation was ranging from 0.08 to $26.95 \%$ and size was ranging from 0.27 and $13.82 \%$ respectively. At that time the authors concluded that the damage location and severity were still challenging. Additionally, it remains difficult to use sensors to detect low-frequency defects [29].

\subsubsection{Radiography}

Observation by X-ray in transmission provides an image of the state of the material [56]. Figure 8a, produced by Tan et al. [75], shows an X-ray images of a $6.1 \mathrm{~mm}$ thick CFRP laminate after a $6.7 \mathrm{~J} \mathrm{impact,} \mathrm{where} \mathrm{the} \mathrm{authors} \mathrm{have} \mathrm{identified} \mathrm{different} \mathrm{resulting} \mathrm{damages.}$ As shown in Figure $8 \mathrm{~b}$ with a 3D reconstruction of a GFRP sample, this technique enables to identify the presence of defects such as breaks, delaminations, lacks of adhesive, vacuums, or shifts in the fibres orientation $[22,23,69,76]$. The detection limit is about $10 \mu \mathrm{m}$, and this technique is sensitive to a variation of up to $1-2 \%$ of the material thickness. It is also possible to retrieve information on the variation of the materials' density from the backscattering of X-rays. This technique enables to quickly obtain a state of the structure because the set of images is obtained simultaneously. On the other hand, it is a complicated technique to implement because it requires greater security measures due to the X-rays hazard. It is therefore used to control the quality of the structure after manufacturing. Moreover, no parallel breaks to the X-ray beam are visible on a scan which limits the defects' detection. 


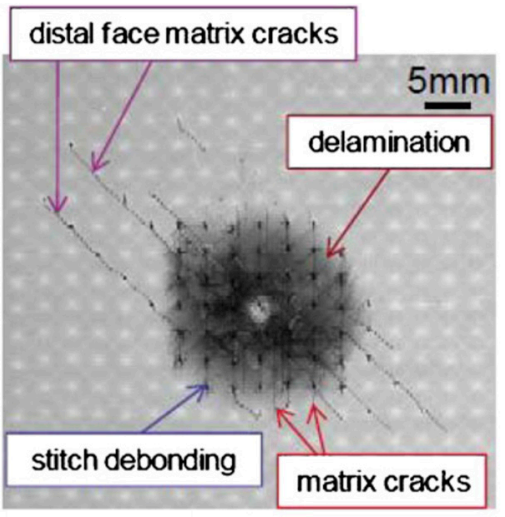

(a)

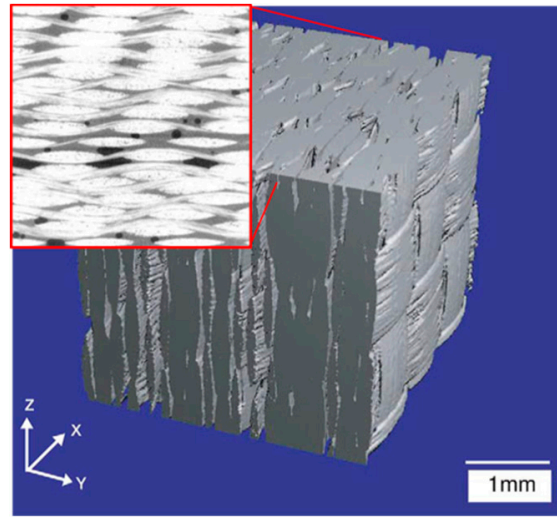

(b)

Figure 8. (a) X-ray radiography of a $6.1 \mathrm{~mm}$ thick CFRP laminate after a $6.7 \mathrm{~J}$ impact [75]. (b) 3Dreconstruction of a part of a GFRP sample by radiography. Insert shows a slice of the reconstruction where voids can be seen in black [76].

\subsubsection{Optical Fibres (OF)}

Optical fibres (OF) were originally used as a strain sensor for structures. The first appearance of OF to detect damages in composites was introduced by Hofer in 1987 [77]. In 2002, Takeda [40] studied the effect of cracks density on the reflected signal characteristics with a FBG. The author observed that an increase of the transverse cracks' density altered the reflected optical power. Without damage, a linear decrease of the optical power until $1 \% \varepsilon$ occurred. A nonlinear drop of the optical power then occurred with the appearance of damages. A drop of the normalised optical power is visible from 0.98 at $1 \% \varepsilon$ (starting of the damage) to $0.83 \% \varepsilon$ at the sample breakage, at $2.5 \% \varepsilon$. The author explained that this increase of small local defects changed the local strain distribution around the fibres. The reflection spectrum shape was therefore disturbed at the interval between two neighbouring cracks. In order to estimate the delamination length in CFRP, the author used afterwards lamb waves with FBG [41]. The researcher found that when the lamb waves were passing through the delamination, the amplitude of the signal decreased and a new wave mode was created. The measure of the amplitude loss ratio and the time of arrival of the new wave mode enabled to quantitatively estimate the delamination. More recently, FBG have been used to detect impact on composite, from low $[48,78]$ to high [79] energy impact. Rezayat et al. [48] used a 10 FBG sensors to localise the impact on a composite plate as schematically represented in Figure 9a. The authors mapped the studied surface with FBG sensors and further used a hammer to hit the surface on one of 20 determined nodes. With the use of a variable selective least squares' method, the authors were able to reconstruct the surface via the detected amplitude, noticing the lowest amplitude for the node that was hit, as shown in Figure $9 \mathrm{~b}$. The researchers were able to have a precision of the distance between each node, i.e., $10 \mathrm{~cm}$.

Tian et al. [80] experienced the damage detection on a $13.2 \mathrm{~m}$ length blade with a distributed FBG network along the blade during static load. Two damages were made in the blade, each $4 \mathrm{~cm}$ away from the closest node. To detect damages, the authors analysed the variation between all FBG strain measurements with two analytical methods. They reported the successful localisation of the closest nodes to the damages. Zhang and Bond [81] have estimated that the FBG current limitation laid in its too low frequency response characteristics. Readers interested in damage assessment in composites can also report to other reviews $[82,83]$.

An original use of optical fibres coated with manganese-doped zinc sulphide has been demonstrated by Okoli et al. [84]. They took benefit from the ability of ZnS:Mn to emit light upon friction to developed fibres able to detect shear failure in composites. 


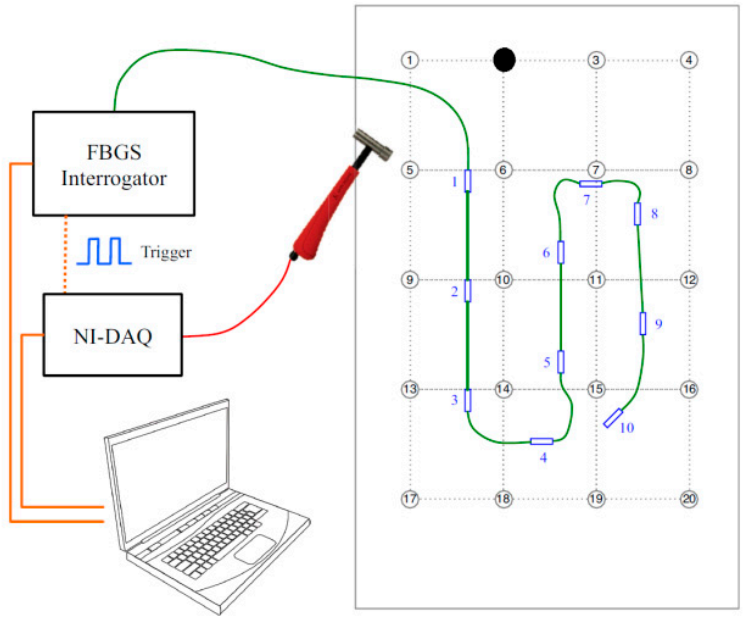

(a)

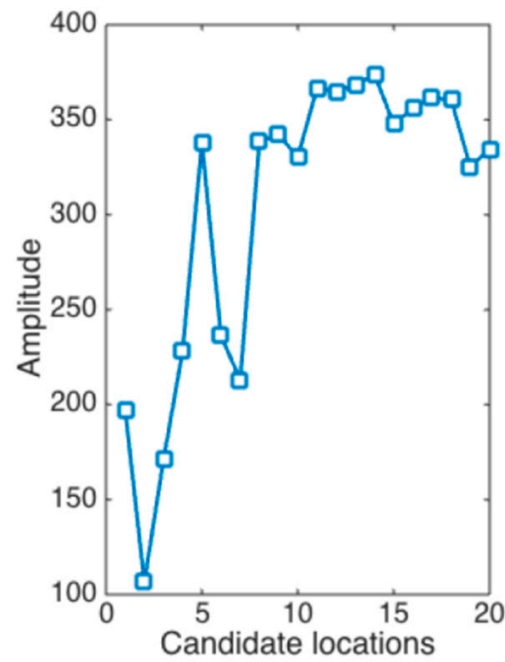

(b)

Figure 9. Identification of a force localization by a least squares' method on a $550 \times 350 \times 2.4 \mathrm{~mm}^{3}$ composite plate with a 10 FBG sensors network mapping [48]. (a) Experimental setup illustration with the FBG positions and the applied force on the node \#2. (b) Estimation of the force localization via the proposed method. The amplitude decreases with the assess force proximity. Sensor \#2 has the lower amplitude.

\section{Emerging Technics Based on Self-Sensing Thermoset Composites Filled with Carbon Materials}

The classical SHM and maintenance technics previously described have shown to be efficient methods for strain and damage detection. Nevertheless, most of them require either an extensive human involvement or expensive procedures. Moreover, they present partial information of the structure since they are only sensitive to strain or damage. Consequently, the combination of complementary technics appears compulsory for a suitable SHM system. To date, the use of optical fibres is the most promising technique, because firstly it can provide, at a laboratory scale, both strain and specific damages, and, secondly, unlike the other technics, the optical fibres could be embedded in the core of composite structures (their detrimental effects on the mechanical properties being acceptable). Nevertheless, their sensitivity remains lower than that of commercial metallic strain gauges, and a substantial equipment is required, as well for the fibres' deployment as for the in-service use. Consequently, in parallel with the previously mentioned strategies, there has been a growing interest for the development of "self-sensing materials". Those materials are prone to provide real-time information about themselves or their environment [14]. As seen in the literature, electrical resistance is the most frequently recorded parameter of sensing materials. A first possibility is to use the reinforcing conductive fibres, as long carbon fibres in of carbon fibres reinforced polymers (CFRP). Thanks to their good conductivity, the whole material can be used as a sensing element. In the case of insulating fibres, like glass fibre reinforced polymers (GFRP), alternatives strategies have been developed to modify the conductivity of the material by the addition of conductive carbon fillers. In such case, the addition of conducting fillers allows to create a conductive network inside the matrix, which turns out to be sensitive to external stimulus. The sensitivity of the percolated network is thus strongly dependents on the interfiller gap, itself being defined by the filler content and the process conditions [85]. The strategies discussed in the following section mainly involve carbon nanotubes (CNT) thanks to their high electrical, mechanical, thermal, optical properties [86-91], including the use of pristine CNT random network films called Bucky paper (BP), the bulk reinforcement of a polymer matrix, and the fibres' sizing. Other carbon fillers are used to create a conductive network into a thermoset based composite and will be presented thereafter, such as short carbon fibres [92], carbon nanoparticles 
(CNP) [93], graphite [94] and more recently fullerene $\left(\mathrm{C}_{60}\right)$ [95] or graphene (GNP) [96]. Hybrid fillers resulting from the combination of different carbon particles [97] has also been found to exhibit synergetic effects and could be valorised in future developments of self-sensing materials.

\subsection{Carbon Fibre Reinforced Epoxy (CF-EP) as Self-Sensing Materials}

In 1989, Schulte and Baron [98], while studying carbon fibres reinforced epoxy, were the first to report the direct use of carbon fibres' resistance change as piezo-resistive sensing strategy. The authors measured the resistance of tensile specimens from end to end. As observed in Figure 10a, the change of resistance was linear with the strain until the first fibre fracture at $0.7 \%$, followed by a larger change of resistance and finally infinite resistance at the breakage of the sample. They reported an initial resistivity of $332 \Omega \cdot \mathrm{m}(2.5 \mathrm{M} \Omega$ for a $19 \mathrm{~cm}$ long sample), and a $0.6 \%$ change of resistance at $1.0 \%$ of deformation. Similar results have been reported by Wang et al. [99] with a sample of epoxy reinforced with $5.5 \mathrm{vol} . \%$ of short carbon fibres, and Todoroki et al. $[100,101]$ mentioned that they could reach a gauge factor close to 2 with CF-EP samples, as shown in Figure 10b.

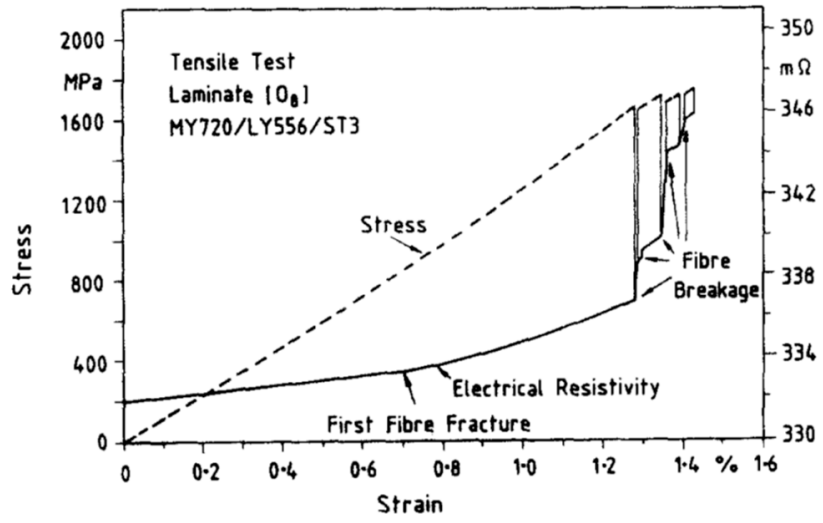

(a)

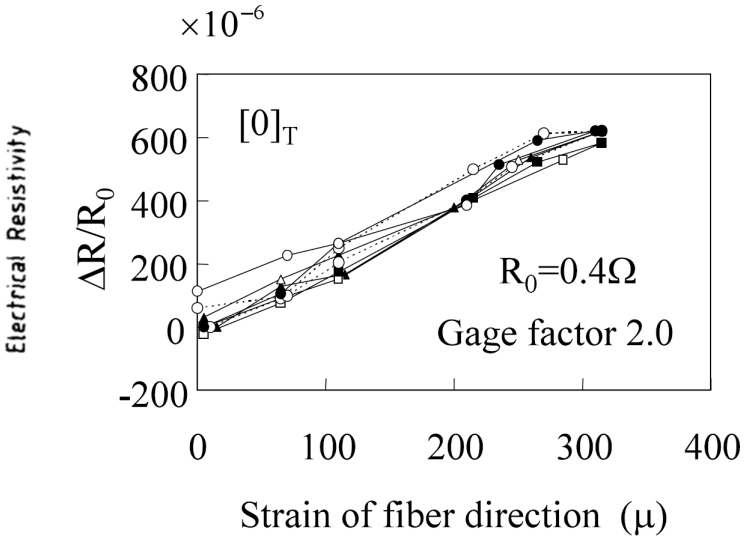

(b)

Figure 10. (a) Influence of strain on the resistance of a unidirectional Carbon fibre reinforced epoxy [98]. (b) Measured piezo-resistivity of a $0^{\circ}$ CFRP sample during a tensile test [100].

As illustrated in Figure 11, Chung et al. [102] had also investigated the change of resistance of a CF-EP sample under bending, looking at the surfaces subjected to compression or tension, and through the thickness. The researchers found that the change of resistance under compression was linear and opposite to the one submitted to tension or through the thickness. Moreover, at deflection below $0.2 \mathrm{~mm}$, the change of resistance through the thickness was not influenced by the deformation, whereas the electrical resistances of tension- and compression-side were immediately affected. The authors noticed that the transverse variation of resistance (through the thickness) was a good indicator of damage, whereas the surface resistances were better indicators of strain. Impacts are also responsible for a change of resistance on the surface of CF-EP samples, and Angelidis et al. [103,104] have followed the voltage change under constant intensity. This change of potential was maximal in the area of the damage and the change of resistance was decreasing when moving away from the damage zone. The authors reported, for an impact of $8 \mathrm{~J}$, a maximum damage length of $75 \mathrm{~mm}$ with a maximum resistance change of $30 \%$ and a minimal change of $2 \%$ of the potential $120 \mathrm{~mm}$ away from the centre of the impact. 

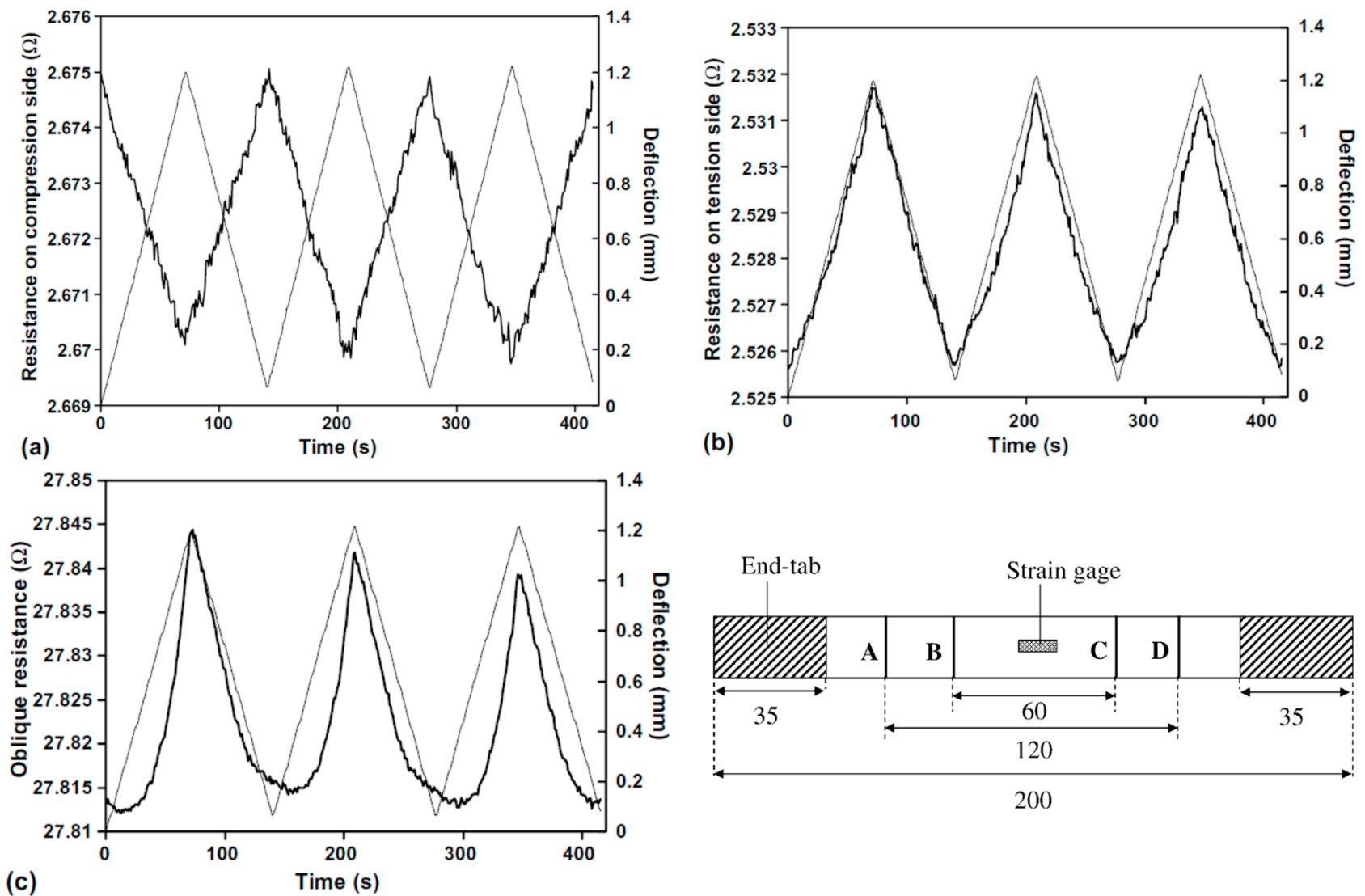

(d)

Figure 11. Influence of deflection on the electrical resistance of a CFEP sample: surface subjected to (a) compression, (b) tension and (c) through thickness. (d) Sample configuration with mm dimension for the self-sensing testing. In (d) the outer contacts between nodes $\mathbf{A}$ and $\mathbf{D}$ are for currant injection and the inner contacts (between nodes $\mathbf{B}$ and $\mathbf{C}$ ) are for voltage measurements [102].

Measuring the change of resistance of CF-EP samples has also been effective for detecting cracks in the matrix [105,106], delamination [107-109], as seen in Figure 12a, or during fatigue [110-112]. As illustrated in Figure 12b, Wang and Chung [110] have identified three stages in fatigue attributed to different damage mechanisms. The authors explained that in the first stage, the matrix cracking in the $90^{\circ}$ plies was leading to a decrease of the sample stiffness. One could add that the breakage of the interface of the fibres and the matrix in the $90^{\circ}$ plies may be responsible of this decrease of stiffness. In addition, the electrical resistance variation being mainly due to the breakage of $0^{\circ}$ fibres, it was not much visible during the first stage. The main resistance increase with gradual stiffness decrease was observed during the second stage with the initiation of $0^{\circ}$ fibres cracking. The last stage was the fibres fractures resulting in the stiffness drop and large resistance increase. Vavouliotis et al. [113] have also highlighted a decrease of the resistance during the first fatigue cycles, related to an increase of $0^{\circ}$ fibres alignment, to relaxation of pre-stressed fibres, and to the decrease of contacts resistance between fibres. 


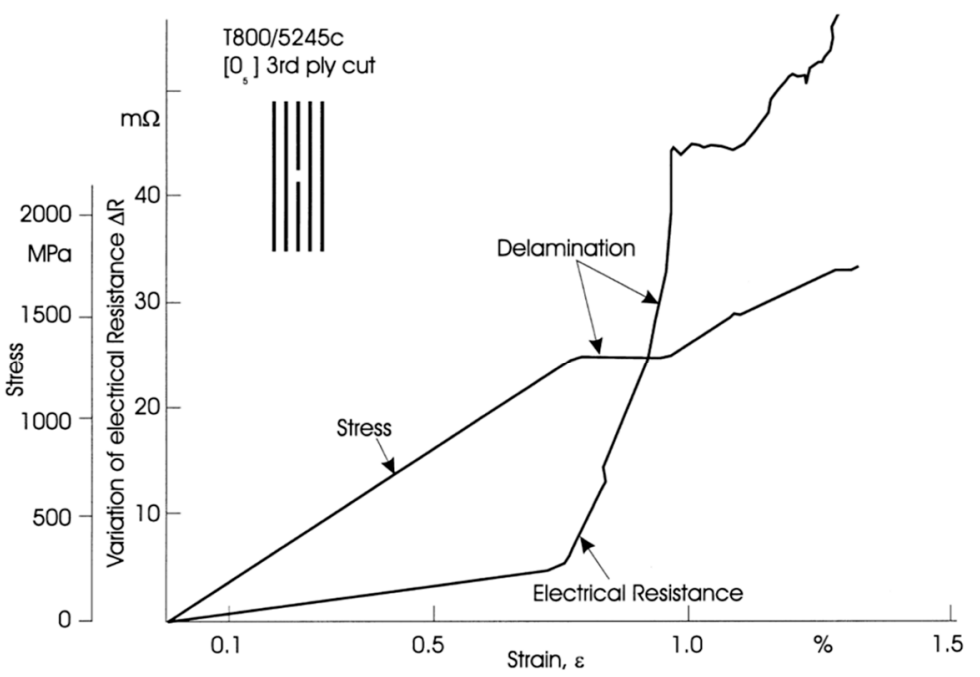

(a)

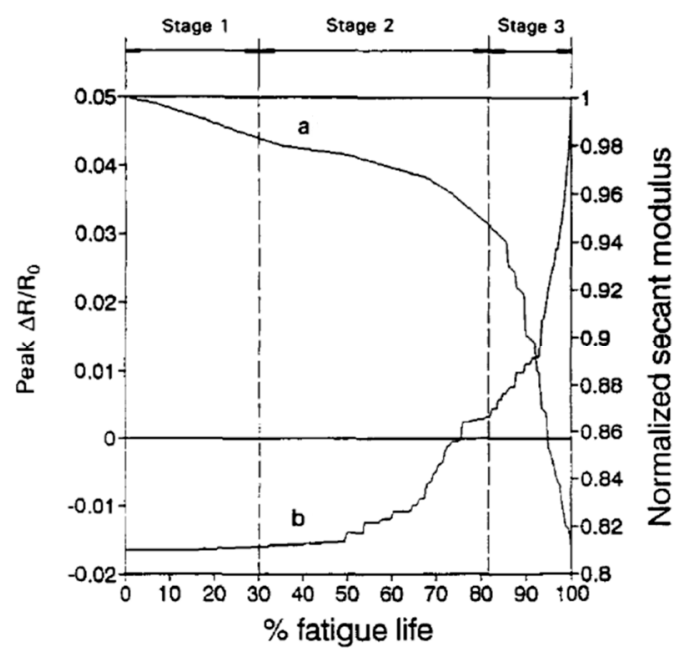

(b)

Figure 12. (a) Tensile test, at $1 \mathrm{~mm} \cdot \mathrm{min}^{-1}$, of a unidirectional CFEP laminate with the recording of the stress and electrical resistance of the sample. Centre ply was cut through to initiate delamination process [109]. (b) Evolution of the resistance and the modulus of CFEP during a fatigue test [110].

Abry et al. [114] and Kupke et al. [109] both studied the influence of the electrical mode $\mathrm{AC}$ or DC on the measured phenomenon. The researchers found that in DC measurements, the reinforcing fibres could be used as a resistance sensor, allowing the detection of fibres failure. Unlike in AC measurements, where the fibres and their connecting points were acting as resistances and the spaces between the fibres were similar to capacitors, which enabled detecting matrix cracking. An attempt to map the internal damages has also been proposed by positioning electrodes around the sample's area of interest [115-117]. To this end, Schueler et al. [115] have used the Electrical Impedance Tomography (EIT). A set of $\mathrm{N}$ electrodes were placed on the edge of the material. The current injection between two of them and the voltage measurement for all other electrodes provided $\mathrm{N}(\mathrm{N}-3) / 2$ measurements. Based on the assumption that there were no current sources in the sample, the internal potential and current densities could be obtained with a Finite Element Method (FEM). The sample was therefore represented as a network of resistances. The appearance of a defect in the sample was thus corresponding to an additional resistance at the defect location. The authors were consequently able to detect and localise a $5 \mathrm{~mm}$ hole with less than $2 \%$ of error.

As seen above, the use of the originally reinforcing carbon fibres as strain and damage sensors in a CF-EP can provide a lot of information on the sample's health. Nevertheless, most experiments were conducted with fibres oriented at $0^{\circ}$, where the composite conductivity is dominated by the longitudinal carbon fibre conductivity [115]. For other orientations of carbon fibres, the conductivity is decreasing until $90^{\circ}$ and is dominated by contact points between fibres. Therefore, the fibres' volume fraction [108] and the manufacturing process [115] are found to significantly impact the composite's resistance and its resulting piezo-resistive behaviour [118]. Regarding the mapping technic, the accuracy decreased with the increase of material's anisotropy [115]. Selvakumaran et al. [119,120] have studied the impact of the CF-EP anisotropy on the response to transverse cracks. The authors found that in the cross-ply section, the change of resistance was decreased of $40 \%$ compared to quasi-isotropic materials. Furthermore, they obtained a correlation between the anisotropy of the material, the accuracy of the measurements and the distance between the electrodes. The authors concluded that the localisation of electrodes with EIT is strongly related to the anisotropy of the material. Therefore, although the intrinsic resistivity of carbon fibres enabled to create a self-sensing CF-EP (with possible measurements of strain and damage localisation), this promising strategy still exhibited few drawbacks among 
which: (i) the precise localisation of the defects appeared to be time and calculation consuming; (ii) the signal mainly responded to fibre's fracture mechanism and not to matrix fracture mechanism; (iii) it favoured axial to transverse detection; (iv) it can be used only for intrinsically electrical conductive materials as CFEP, which does not represent the majority of the composite market [121].

\subsection{Carbon Nanoparticles and Their Associated Nanocomposites as Self-Sensing Systems}

To generate self-sensing composites from electrical insulating components, the most common way is to integrate conductive particles into the insulating matrix. CNT are thus good candidates thanks to their high electrical, mechanical, thermal, optical properties, and large aspect ratio [86-91]. The first studies, in which CNT were used to enhance the composites' mechanical properties [122], focused on the influence of both the filler content and the dispersion state. For instance, Gojny et al. [123] studied the mechanical properties of an epoxy resin filled with various CNT types ranging from 0.05 to $0.5 \mathrm{wt} \%$. They reported an enhancement of several performances for all CNT types and content, highlighting more particularly, the highest improvement $(+14.6 \%)$ of Young's modulus for the $\mathrm{NH}_{2}$ functionalized DWCNT. Along with improved mechanical properties, CNT were found to change the global electrical and thermal properties of the composites [123-152], thus revealing their self-sensing character. As stated earlier, a certain amount of conductive filler has to be added in the polymer matrix to provide electrical conductivity. Thus, in the following section the statistic percolation's theory to elaborate CNT based polymer conductive composites is described. Then the current main strategies developed for strain and damage sensing that includes CNT in the form of a pristine CNT film, as well as embedded in a matrix, or coated on a fibre, is then presented. Finally, the possible use of other carbon or hybrid fillers will be discussed.

\subsubsection{Electrical Behaviour of CNT-Filled Polymer: Theory of Statistic Percolation}

As stated earlier, the electrical conductivity of nanocomposites is obtained through the dispersion of conductive fillers into an insulating matrix. Increasing the amount of conductive fillers leads to an insulator-to-conductor transition, as illustrated in Figure 13. At low content of fillers dispersed in a matrix, no conductive pathway can be created inducing an insulating electrical behaviour [153]. When the first conductive pathway appears throughout the material, an insulator-to-conductor transition occurs with a sudden decrease of the material's resistivity [131,154]. This sharp transition is commonly referred as the percolation threshold. Above the percolation threshold, the matrix conductivity can be described by the Equation (2) [155]:

$$
\rho=\rho_{0}\left(\varphi-\varphi_{c}\right)^{-t}
$$

where $\varphi$ indicates the volume fraction of the conductive filler, $\varphi_{c}$ the volume fraction at the percolation threshold, $\rho$ and $\rho_{0}$ are the resistivity at $\varphi$ and for an infinite content of filler respectively, $t$ is the critical exponent comprises between 1.3 and 2.0. 


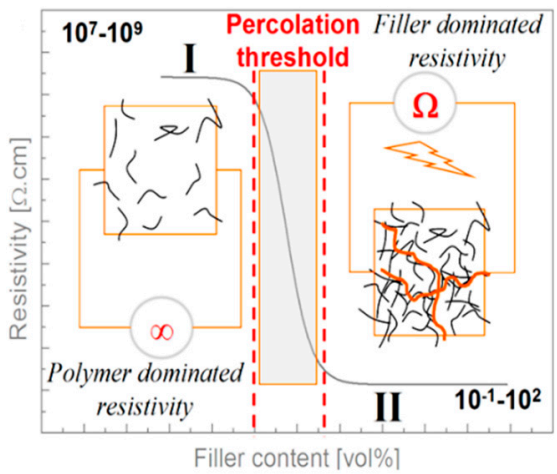

Figure 13. Resistivity behaviour of a polymer with the increase of filler volume content. The left inset, in region I, represents the fillers dispersion with no conductive pathway and a resulting nearly infinite resistivity. The central zone depicts the insulator-to-conductor transition with the formation of the first conductive path. The right inset, in region II, represents the fillers dispersion in a conductive matrix with several electrical pathways, resulting in low electrical resistance [156].

The electrical behaviour of epoxy-CNT composites has been extensively investigated by Bauhofer and Kovacs [157] who highlighted that the percolation threshold value strongly depends on the processing parameters. For instance, the authors studied the effect of the stirring rate during the CNT-epoxy mixing on the composite conductivity. They obtained a percolation threshold value after $5 \mathrm{~min}$ of stirring at 50 and $2000 \mathrm{rpm}$ of 0.01 and $0.1 \mathrm{wt} \%$ of $\mathrm{CNT}$, respectively. The authors explained that the increase of the stirring rate enhanced the CNT dispersion in the matrix, resulting in fewer available conductive paths. Above the percolation threshold, they also reported an equivalent electrically conductive behaviour regardless the processing parameters. Gojny et al. [138] have compared CNT with varying number of layers (single walled SW, double walled DW and multi walled MW) and their associated electrical behaviour in epoxy-based CNT composites. The authors found that the number of walls in CNT did not affect the composite's electrical properties for an equivalent mass of nanotubes. Yet, increasing the number of walls raised CNT density, and MWCNT therefore presented the lowest percolation threshold volume value, around $0.05 \mathrm{vol} \%$. They also explained that the lower specific surface of MWCNT compared to SW or DW enabled to reduce their attraction and their agglomeration. Thus, the best state of dispersion was reached for MWCNT without functionalization. Bai and Allaoui [158] studied the effect of CNT length on the percolation threshold in epoxy-based composites. While the CNT diameter was kept constant, the authors observed a decrease of the percolation threshold from 2 to $0.5 \mathrm{wt} \%$ with an increase of the CNT length from $10 \mu \mathrm{m}$ to $50 \mu \mathrm{m}$, respectively. They concluded that an increase of the CNT aspect ratio enhanced the probability of contact between nanotubes and, consequently, the composite's conductivity was increased from $10^{-11}$ to $10^{-5} \mathrm{~S} \cdot \mathrm{cm}^{-1}$ at $1 \mathrm{wt} \%$ for 10 and $50 \mu \mathrm{m}$, respectively. Another important parameter to be taken into account is the surface functionalization which has been intensively investigated [127,138,146,159-161]. Although it favours the dispersion of the CNT inside the matrix, functionalization may also alter the CNT structure, and eventually reduce the CNT length, which in turn can reduce the CNT inherent conductivity and increase the percolation threshold. In the case of amine functionalized DWCNT, Gojny et al. [138] observed a conductivity decrease of two decades compared to the pristine DWCNT with a filler content above the percolation threshold of $0.5 \mathrm{wt} \%$. The CNT alignment can also contribute to decrease the number of contacts between CNT making the nanocomposite more non-isotropic, thus increasing the average percolation threshold and decreasing the global conductivity of the composite [149-151,162-165]. In this context, Du et al. [166] have estimated the evolution of conductivity of CNT/polymer nanocomposite with the degree of alignment of the CNT. The authors observed that a CNT degree of alignment of $90^{\circ}$ in PMMA-SWCNT nanocomposite was leading to the highest conductivity for the lowest amount of CNT. For instance, the researchers measured the same conductivity 
for $19^{\circ}$ of alignment at $3 \mathrm{wt} \% \mathrm{CNT}$ and $75^{\circ}$ alignment at $0.38 \mathrm{wt} \% \mathrm{CNT}$. Therefore, a high degree of alignment tends to reduce the electrical conductivity of the composite. Meeuw et al. [164] have aligned $1000 \mu \mathrm{m}$ CNT in an epoxy matrix by an AC field and thus observed a decrease of the resistance by a factor of three.

As suggested by Hu et al. [151], in an epoxy-CNT composite, the overall electrical resistance can be assimilated to the CNT network, controlled by the intrinsic conductivity of each CNT, the junction between $\mathrm{CNT}$, and the tunnelling resistance between two consecutive CNT. The tunnelling resistance has been expressed as followed in the Equation (3)::

$$
R=\frac{h^{2} d}{A e^{2} \sqrt{2 m \lambda}} \exp \left(\frac{\pi 4 d}{h} \sqrt{2 m \lambda}\right)
$$

where $h$ is the Planck's constant, $d$ the distance between the two CNT, $A$ the cross-sectional area of tunnel, $e$ the quantum of electricity, $m$ the mass of electron, and $\lambda$ the height of barrier (epoxy 0.5-2.5 eV).

From Equation (3), one can notice that a deformation of the CNT network, that could be caused by strain, would break junctions between CNT, and increase the distance between them. The resulting change of electrical property of the composite is observed to be mainly ruled by the tunnelling resistance and its exponential relation with the gap between CNT. An increase of the CNT content in the matrix would (i) reduce the distance between nanotubes, (ii) increase the number of contact points, and (iii) decrease the strain effect on the overall composite change of resistance. To characterise the change of resistance during the deformation of a conductive system, as an epoxy-CNT composite, the gauge factor (GF) has been introduced, also called sensitivity, and described by the Equation (4):

$$
G F=\frac{R-R_{0}}{R_{0}} \frac{1}{\varepsilon}
$$

where $R$ indicates the sensor's resistance at the $\varepsilon$ strain, and $R_{0}$ the resistance at rest.

In a CNT-epoxy composite, the influence of the initial CNT loading on the resulting GF has been investigated by $\mathrm{Hu}$ et al. $[151,167]$. The composite was subjected to a tensile deformation, and above the percolation threshold the authors observed a decreasing in GF with increasing nanoparticles' content, starting from 20 to 5 at 1 to $5 \mathrm{wt} \%$, respectively. The increase of the CNT loading reduced the average distance between nanoparticles, which diminishes the influence of the tunnelling resistance upon the presence of strain, and therefore the GF.

\subsubsection{Bucky Paper as a Strain Sensing Element}

Dharap et al. $[32,168,169]$ were the first to use the electrical properties of CNT to develop a strain sensing device. They used a pure SWCNT film called Bucky paper (BP). The film was glued on the surface of a brass sample by a PVC film and epoxy. It allowed them to choose BP dimension and location and to use it as a strain sensor. The response of the film's voltage, obtained by a four-point probe method, as a function of the specimen strain was linear.

The authors observed a linear evolution of the tension with strain, about $0.5 \mathrm{~V} /(\mathrm{m} / \mathrm{m})$, mainly due to the change of resistivity of the BP, and further patented BP as a promising strain and stress sensor [169]. They suggested that the film could be placed on the surface or be embedded inside a sample. However, the addition of a pristine CNT film inside a composite may favour the creation of a new interface inside the sample as noticed by Rein et al. [170], and shown in Figure 14a. Actually, the presence of a weak interface may modify the electrical behaviour of the BP and the mechanical properties of the sample as shown by Pillin et al. [171] who have studied this phenomenon by coating or not a single glass fibre with CNT before deposition of a microdrop of epoxy for a micropullout test. Although this CNT film was less dense than a BP, the authors have observed that the low density of the CNT network avoided the epoxy matrix to diffuse through it, thus creating a weak 
interface. The measured interfacial shear strength was thus decreased from $45.2 \mathrm{MPa}$ to $40.5 \mathrm{MPa}$ in presence of a CNT coating layer on fibres. However, BP was found to reach the high stress at break of $9.6 \mathrm{Gpa}$ [172], i.e., whereas Liu et al. [173] have observed that for a thin Bucky paper, the mechanical properties of the composite could even be increased until $4 \%$. However, for film thickness above $40 \mu \mathrm{m}$ the mechanical properties were again shifted below the pristine composite as shown in Figure 14b. Aly et al. [174] have observed that an increase of BP thickness from 120 to $180 \mu \mathrm{m}$ in a glass fibre epoxy composite also decreased its sensitivity to strain by nearly half.
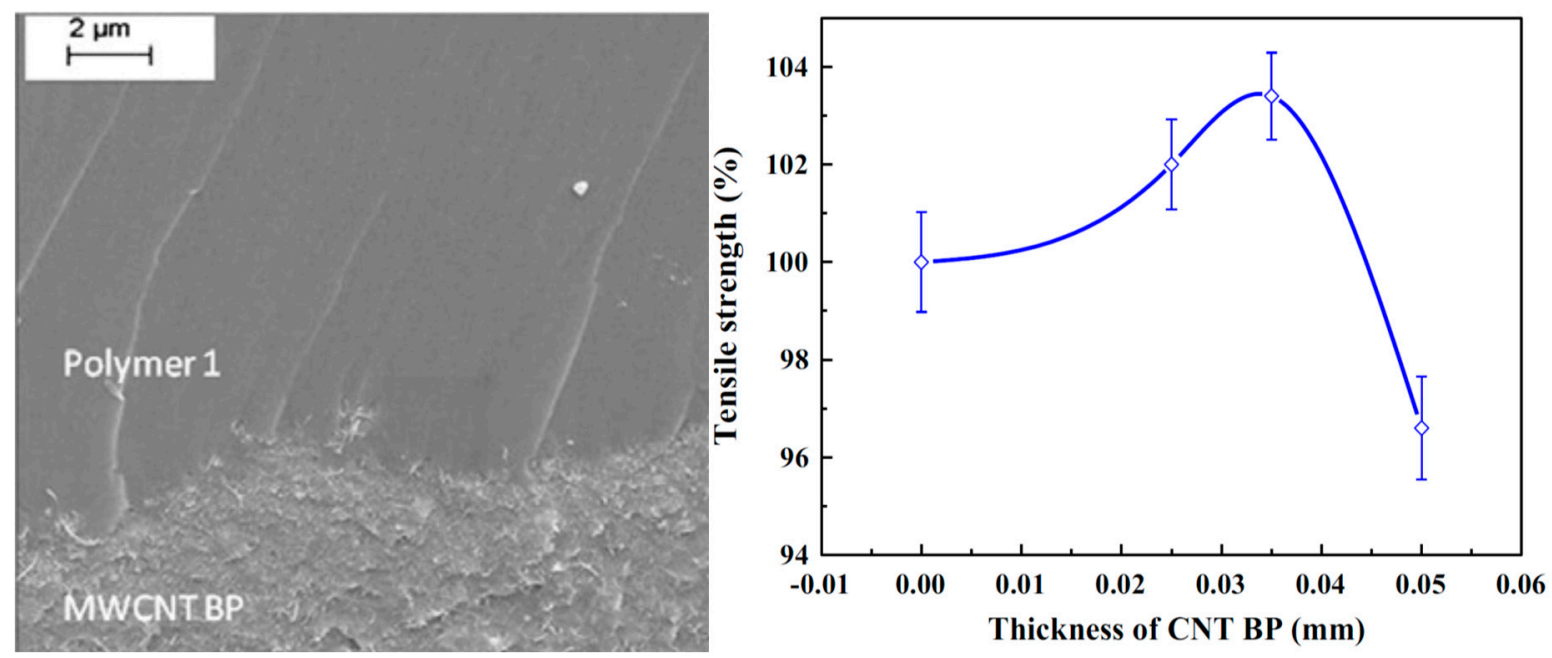

Figure 14. SEM observation of the edge boundary between a CNT Bucky paper and an epoxy matrix [170]. (b) Tensile strength of carbon fibre/epoxy composite with different thickness of Bucky paper embedded in the middle of the composite, which illustrates the possible sample weakening due to the addition of too thick BP [173].

The aforementioned authors have reported GF values of 20 for Liu et al. [173]. Nevertheless, their GF was observed not to be constant with the strain, with nearly no sensitivity at low deformation until $0.2 \%$ and a constant increase until breakage. Aly et al. [174,175] have characterised the GF value from low deformation until breakage. They reported a negative GF between 0 and $0.6 \%$ of strain, with a minimum of -0.8 at $0.5 \%$. The following gradual increase of the strain led to GF values of 4 at $1 \%$ and 10 at $1.5 \%$ of strain. In compression, the electrical behaviour was found opposite to the tension [174], as already found in other studies [176-178]. The inability of the resin to diffuse inside the film also affected the electrical response. In addition to the mechanical properties, Pillin et al. [171] observed a nonlinear electrical behaviour for their sample containing CNT coated fibres. The sensor's sensitivity was furthermore divided by 4 for the pristine CNT film, compared to their reference (EP-CNT). The authors suggested that this drift in the electrical response indicated that the sensor was less representative of the composite state of deformation compared to the EP-CNT film sensor.

The capability of BP to detect defects and damages has also been investigated. Indeed, the propagation of a delamination through the BP would break the CNT network, and therefore enhanced the resistance drastically as shown in Figure 15. The resistance was multiplied by 5 after $500 \mathrm{MPa}$ in the propagation stage (II) compared to the undamaged stage (I) [173]. While monitoring the fracture, the BP electrical resistance was found to be noisy and increasing until infinite value in the fracture stage (III). 


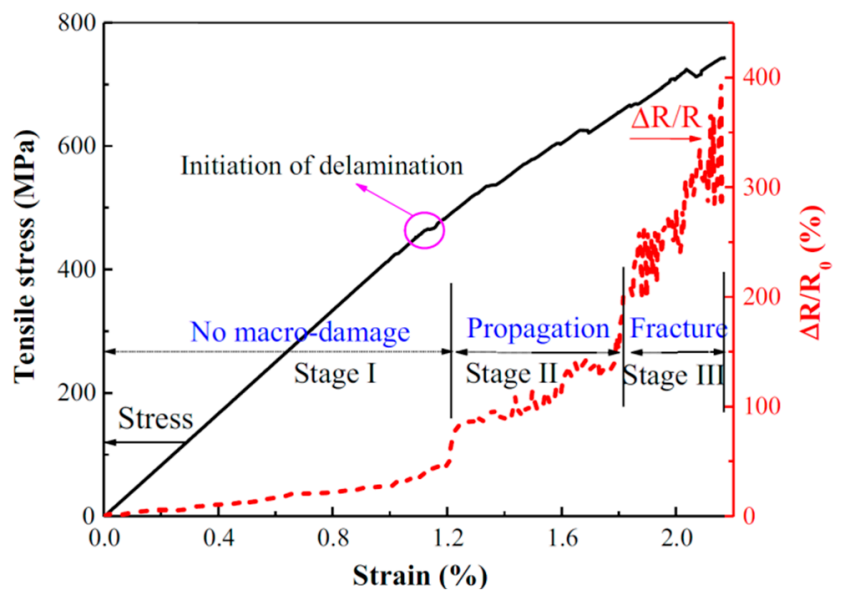

Figure 15. The completed stress-strain and corresponding $\Delta R / R_{0} \%$ response curve for a CNT BP embedded in a CFEP. Three areas are visible: the stage I until $500 \mathrm{MPa}$ where no macro-damage occurs, the stage II until $600 \mathrm{MPa}$ corresponding to the propagation of damage after the first appearance, and stage III with the final fracture [173].

\subsubsection{CNT Dispersed in a Matrix as a Sensing Element}

Sensing with a CNT Nanocomposite Matrix

A second possibility of preparing self-sensing materials was proposed by Fiedler et al. [179] in 2004. They introduced nanotubes inside the composite epoxy matrix to create a percolated network. Therefore, the whole matrix (and thus the whole composite part) became an electrically sensing element, in which strain would induce a network change and consequently a change of its resistance. Thostenson et al. [130,180-188] added $0.5 \mathrm{wt} \%$ of MWCNT into the resin of a glass fibre epoxy (GF-EP) laminate and monitored real-time strain applied to the composite. They linked the changes in the resistance's slope with strain to the composite intrinsic events. Figure 16a presents the electrical behaviour when the laminate is subjected to increasing cycling loading. Three electrical behaviours have been associated to specific events by the authors, i. e. the opening of previous cracks, the elastic deformation of the sample, and the accumulation of new damage in the laminate. The authors further related this accumulation of damage to the drift of resistance at rest, as shown in Figure 16b. They noticed that the decrease of Young's Modulus from 28 to $26 \mathrm{Gpa}$ in the elastic region below $0.4 \%$ did not affect the electrical resistance, while a further strain increase above $1.5 \%$ reduced the modulus to $23 \mathrm{Gpa}$ and the residual resistance reached $5500 \Omega \cdot \mathrm{cm}^{-1}$.

The authors suggested that the accumulation of new damages modified the network of CNT, which resulted in the increase of the resistance at rest. Additionally, they compared the resistance change with acoustic emission to monitor the propagation of damages in laminates [188]. While the CNT network was sensitive to matrix damages like micro-cracking, with a resistance variation of $5000 \Omega \cdot \mathrm{cm}^{-1}$ due to cracks reopening, the AE method was able to sense delamination after fibre breaking, with the detection of more than 8000 counts during the sample final failure, thus illustrating the complementarity of the two methods. However, the resin's viscosity was also shown to be strongly affected by the presence of CNT, making subsequent processing of large-scale sensors very difficult [189]. Moreover, this strategy implied a global change of the sample's resistance, avoiding therefore the localisation of damage.

In addition to the measure of the resistance, Bekas and Paipetis [190,191] have investigated the evolution of the sensor's impedance during a tensile test. They found that the CNT network is equivalent to a resistance and a capacitance in parallel, as shown in Figure 17a. They estimated that the resistance and capacitance variation during a deformation were induced by the distance's change between CNT [192]. The authors reported Figure 17b four regions during mechanical testing of GF-EP (EP filled with $0.5 \mathrm{wt} \%$ of 
$\mathrm{CNT}$ ): the elastic domain (region I), the damage initiation with matrix microcracking (II) until $40 \%$ of the ultimate tensile strength (UTS), the saturation of the matrix cracking (III) until $80 \%$ of UTS and the final fibre fracture (IV). They observed a $0.881 \mathrm{nF}$ relative capacitance reduction and a $500 \mathrm{M} \Omega$ relative resistance increase in region II. In region III, the variations were reduced with a relative capacitance decrease of $0.003 \mathrm{nF}$ and resistance increase of $100 \mathrm{M} \Omega$. The fibres fracture and the resulting specimen's failure (region IV) led to a more pronounced change of slope in both capacitance and resistance due to the breakage of the matrix, with a decrease of $0.005 \mathrm{nF}$ and an increase of $450 \mathrm{M} \Omega$, respectively. The destruction of the CNT network during the breakage of the matrix may at the same time reduce the number of conductive paths, increasing the global resistance, and the available segments, reducing the global capacitance.

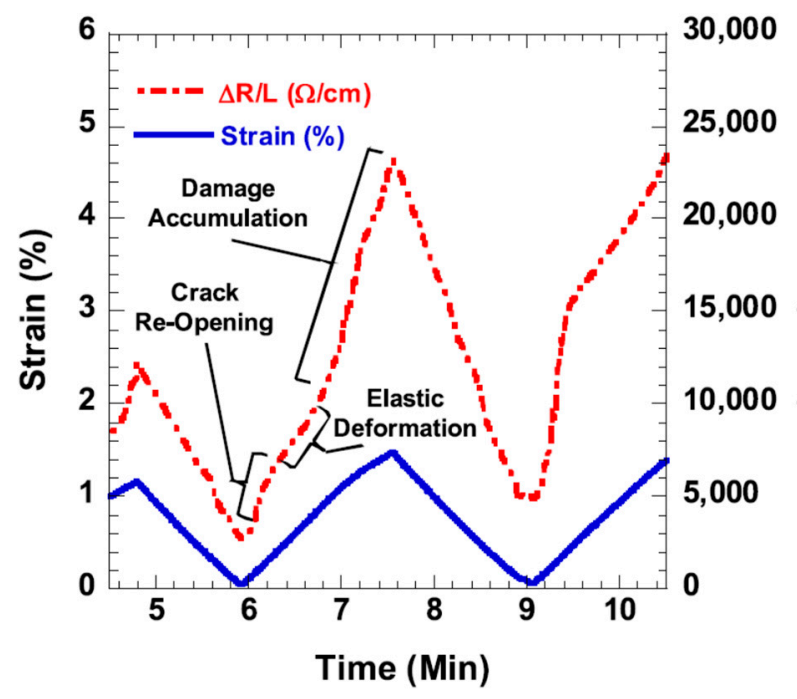

(a)

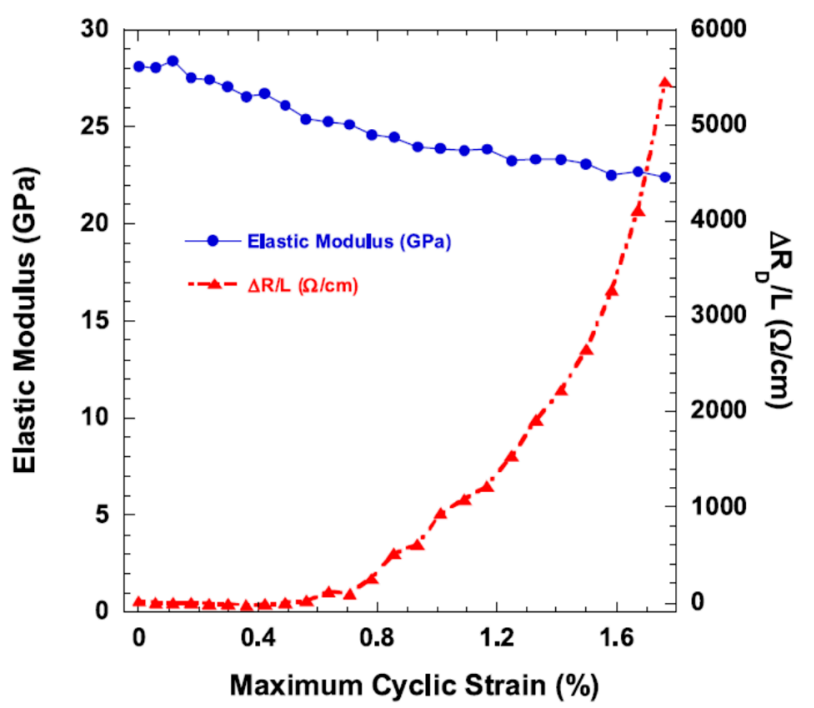

(b)

Figure 16. (a) Cyclic loading of a cross-ply glass fibre CNT-epoxy laminate showing resistance and strain response. During the tensile part, three electrical behaviours are noticeable by the change of slope: crack reopening, elastic deformation and damage accumulation [186]. (b) Evolution with the cyclic loading of the elastic modulus and resistance at rest due the damage in a cross-ply glass fibre CNT-epoxy laminate [186].

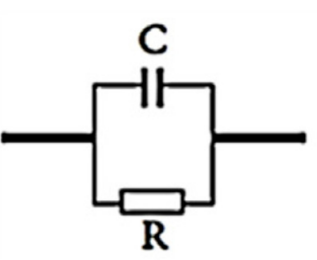

(a)

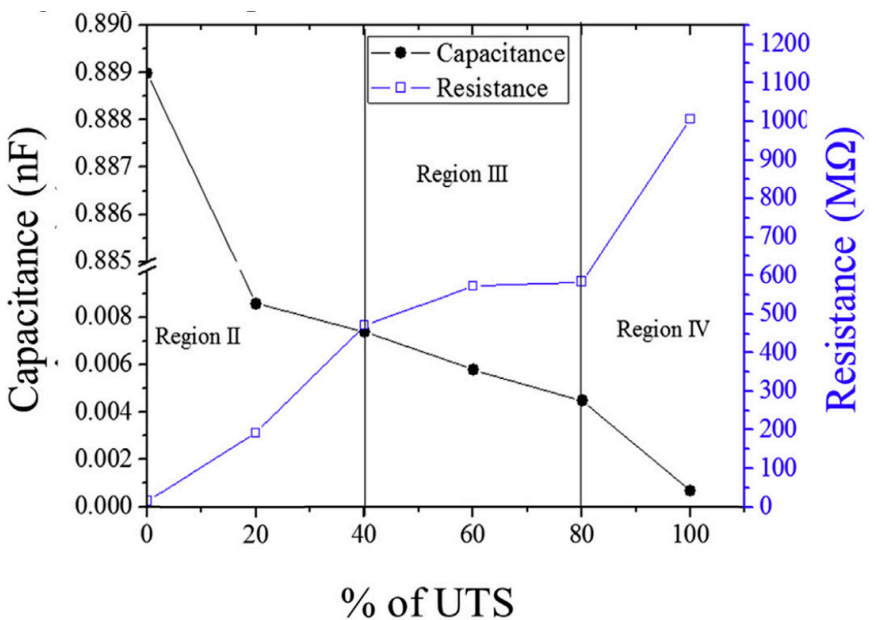

(b)

Figure 17. (a) Equivalent RC circuit representing the epoxy CNT system and (b) resistance and capacitance's evolution of a $0.5 \mathrm{wt} \% \mathrm{CNT}$ in epoxy sample during a tensile test as a function of the applied load (\% of Ultimate Tensile Strength). Three regions are represented with damage initiation and matrix microcracking (II), saturation of matrix damage (III) and final failure (IV) [190]. 
To overcome the issue of damage localisation, Baltopoulos et al. [193,194] introduced in 2014, the electrical resistance tomography (ERT) by connecting the samples' edges with regularly spaced electrodes, as shown in Figure 18.

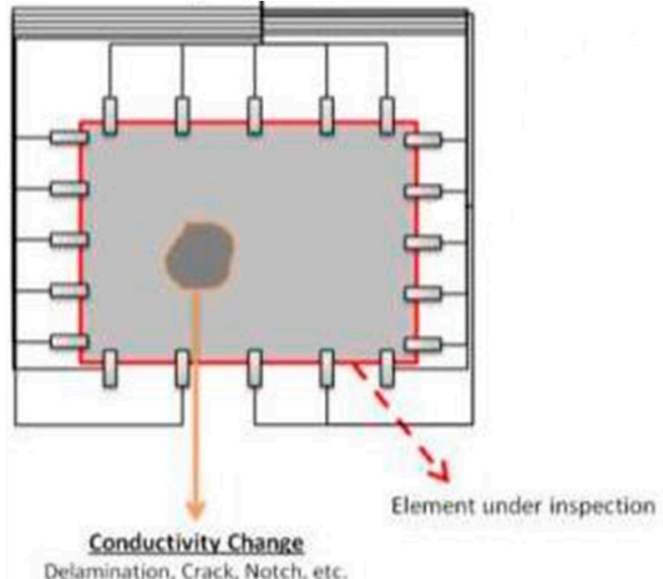

(a)

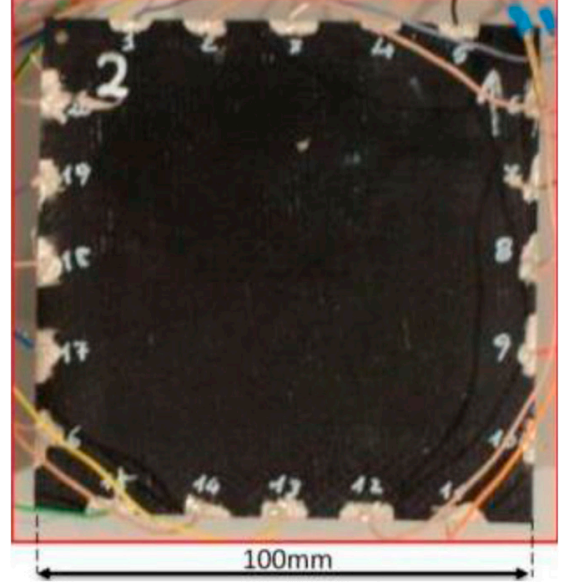

(b)

Figure 18. (a) Principle of electrical resistance tomography (ERT), current is injected between pairs of electrodes and the voltage measured allows to calculate the resistances at the intersections. The scanning of all electrode pairs allows to mesh the sample and estimate the local strain and damage. (b) ERT sample made of GF-EP with $0.5 \mathrm{wt} \% \mathrm{CNT}$ in the matrix [194].

The intensity applied between two electrodes allowed to measure the voltage for all the others electrodes. This operation was repeated consecutively for every pair of electrodes. The scanning of all pairs of electrodes in the sample, enabled to mesh the whole CNT film. The local conductivity of the network measured by the tension at each electrode was affected by the modification of the CNT network, due to an applied strain on the sample, or the presence of a defect. Based on the voltage measurements, the CNT network was modelled and the damage was identified. Compared to the EIT method, the created network was more isotropic than the carbon fibres network in a CF-EP. The number of required measurements was therefore less important [115]. The authors reported a sensitivity to damage smaller than $0.1 \%$ of the total inspected area and a localisation error around $10 \%$. The defects localisation precision was linked to the number of electrodes, as well as the time of calculation to model the CNT network. For a 32 electrodes sample, the number of voltage measurements was above 1000 [195] and the time of calculation was about 5 min [196], illustrating the limitation of ERT to detect punctual event and for real-time monitoring.

Pursuing efforts on the localisation issue, Naghaspour et al. [197-201] proposed the use of electric potential measurement (EPM). The authors mapped the whole surface of a CFEP with 0.3 wt \% CNT in the matrix with electrodes and continuously measured the change of resistance between each pair of electrodes.

The researchers studied the effect of the hole size and the impact energy on the variation of resistance. They reported that the change of resistance between two electrodes in the presence of a hole was proportional to the hole's volume [199]. They were also able to detect and localise barely visible impacts of $1 \mathrm{~J}$. The precision of the EPM method was directly linked to the number of electrodes applied on the surface and their inter-distance. Compared to the ERT method, on the one hand the number of electrodes needed to map the surface of the sample was higher because only the resistance between two consecutives electrodes was measured. On the other hand, the number of electrodes allowed recording the local resistance without any additional calculation. The resulting mapping of the sample was instantaneous compared to the ERT method. The authors have therefore patented this method [202]. Instead of using local electrodes, Viets et al. [203] used a GF-EP filled with $0.3 \mathrm{wt} \%$ CNT on which the mapping consisted of parallel silver ink lines drown on 
both surfaces perpendicularly, as illustrated in Figure 19. Through this configuration, the authors created a "through thickness" mapping device. They consequently reported the detection of $7.65 \mathrm{~J}$ impacts on the surface and the induced delamination of the sample by recording the resistance. Therefore, for the current different localisation technics, a precise localisation of the strain or damage induced an important calculation time (ERT) or a large amount of electrodes for the mapping of the sample (EPM).

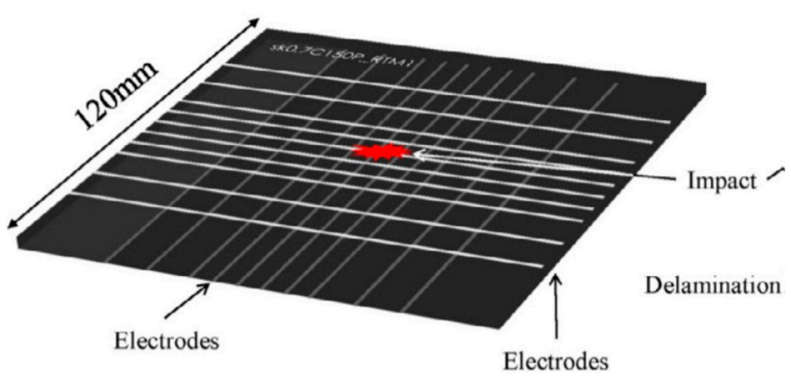

Figure 19. Schematic illustration of a GF-EP reinforced with $0.3 \mathrm{wt} \%$ of CNT. Parallel silver ink are drawn on each surface perpendicularly for through thickness mapping [203].

Sensing with a Patch of CNT Nanocomposites

Instead of dispersing CNT in the whole sample matrix, the alternative solution of introducing locally a patch of matrix-CNT nanocomposite has been studied. This local sensor could be deposited on the surface of the composite specimen by resin casting [164,204], spraying [205] as shown in Figure 20 (left), or printing [192,206-208]. The ply is inserted prior the epoxy infusion process, thus after fabrication, the sensors are embedded in the sample's core Figure 20 (right). The sensor's sensitivity can be furthermore adjusted with the filler content in the matrix according to the percolation law [209]. The use of an epoxyCNT nanocomposite, closely above it's percolation threshold at $0.5 \mathrm{wt} \%$, allowed reaching a very high GF value of 78 [207], while at $0.7 \mathrm{wt} \%$ the GF was about 3.2 [164]. Such sensors have a typical thickness ranging from $1 \mu \mathrm{m}$ [205] to $100 \mu \mathrm{m}$ [164]. Michelis et al. [210] also proposed a CNT based strain gauge made by inkjet printing of CNT on a polymer substrate that allowed them to make a strain gauge with a GF of 0.98 . A similar process has been used by Kaiyan et al. [211] with the addition of epoxy in the sensor, reaching a GF of 50 and 20 for 0.3 and 0.5 wt \% CNT composite, respectively. Nevertheless, one could argue that the sensor is still located on the surface of the sample, which avoids in situ core measurements. As for other industrial sensors, this sensor would also be affected by moisture and temperature. Another strategy is to embed the CNT based epoxy sensor in the core of the structure. Feller et al. $[171,209]$ have sprayed layer by layer (sLbL) CNT-epoxy solutions on the dry glass fibres from the reinforcement textile prior to epoxy infusion and final curing of the composite, as illustrated in Figure 20.

In this example the "on-demand" dimensions of the sensing multilayer film were fixed to $10 \mathrm{~mm} \times 5 \mathrm{~mm} \times 1 \mu \mathrm{m}$. The so-prepared quantum resistive sensor (QRS), were made with additive manufacturing and reached the same level of crosslinking as the GF-EP part. Conveniently, the resulting gauge factor could be adjusted by changing the filler content as well as the number of sprayed layers. They obtained GF from 4 and 12 for QRS made of 30 layers of EP-3 wt \% CNT and 10 layers of EP-1 wt \% CNT, respectively. The authors showed that sensors were sensitive to the strain and damage inside the structure until its final failure, as already presented in another study [204]. During fatigue tests, a clear drift of resistance was also visible for a strain level above the elastic limit, while the average resistance was constant for lower strain. The degradation of the structure therefore affected the electrical performance of the sensor, thus supporting the statement that the sensor's state was in agreement with the structure's state. Finally, Dai et al. [189] have developed strain sensors with an aramid nonwoven fabric. They coated the fabric, made of $90 \%$ of voids, with CNT using a solution casting process, and finally obtained a sheet with about $1.5 \mathrm{wt} \%$ of CNT on the fibres. The infusion and curing of epoxy resin inside the sheet 
enabled them to fabricate a final sensor with about $1.0 \mathrm{wt} \%$ of CNT and a thickness of $470 \mu \mathrm{m}$. The so-prepared sensor was then glued on the surface of a metallic sample for the electro-mechanical characterization. The obtained gauge factor was ranging from 3.64 to 5.34 for $0.75 \mathrm{wt} \%$ and $1.0 \mathrm{wt} \%$ of CNT, respectively. All those sensors enabled to provide local information, as well on the surface or in the core of the sample. However, in the case of a conductive substrate, the insulation of the sensor is compulsory to avoid any short-cut.
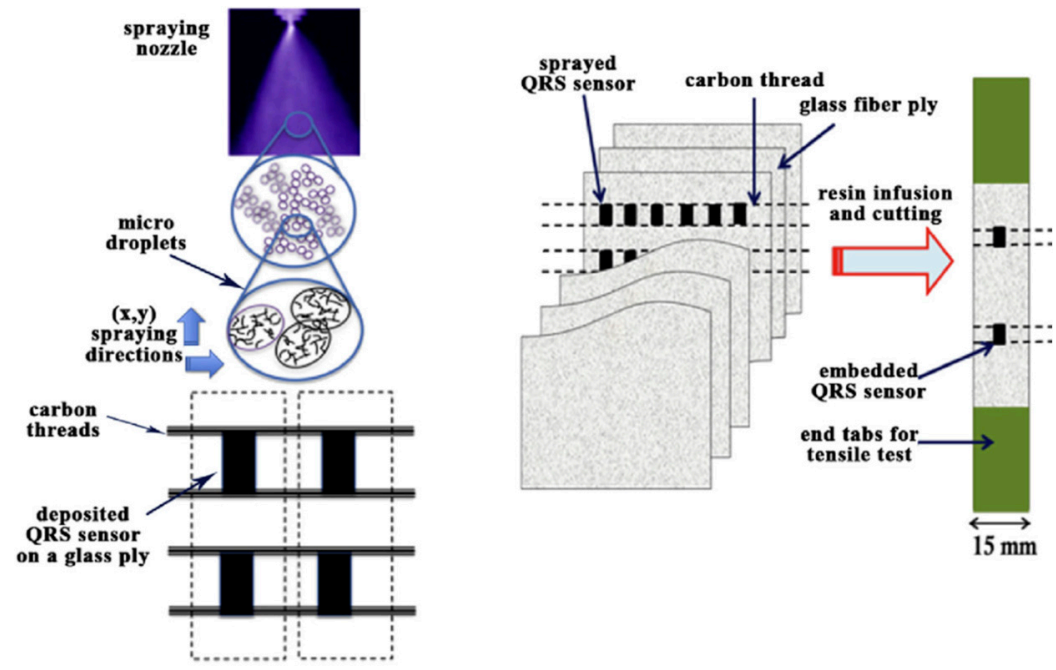

Figure 20. Fabrication steps of composite samples equipped with two embedded sprayed nanocomposites SQRS. A liquid solution containing the epoxy-CNT mixture is sprayed layer by layer directly on the glass fibre fabric (left). The ply is inserted prior the epoxy infusion process. Thus, after fabrication, the sensors are embedded in the sample's core (right) [209].

\subsubsection{CNT Coated Reinforcing Fibres as a Sensing Element}

Another way to trigger the sensitivity of a composite has been investigated in the literature through the coating of fibres with CNT, later on inserted in the laminate, thus called "fuzzy fibre". Zhang et al. [212] showed that this strategy allowed the monitoring of the piezo-resistive behaviour at the interface between a single fuzzy fibre and the polymer matrix. Mäder et al. [213-216] made the surface of glass fibres conductive by electrophoretic deposition (EPD) [217] and dip-coating in a nanotubes solution prior to embedding it into an epoxy matrix. The authors performed tensile deformation on the laminate with an in-situ electrical measurement, as shown in Figure 21a, and identified three stages in the electrical response. At first, the resistance variation was linear with the applied strain, as caused by dimensional changes of MWCNT network in the interphase. At $1 \%$ of strain, they measured a GF close to 1. Then, an exponentially increase of the slope was observed. The authors related it to the stress concentration at interphases, the increasing distance between CNT and the loss of contact points. Finally, the propagation of cracks in the composite disconnected the network, inducing the resistance value to suddenly increase to infinite. In this way, the authors suggested that CNT coated glass fibre could be used as a mechanical sensor, and this CNT-fibre architecture has ensued interest in the fibres manufacturer community [218]. The authors have also investigated the use of a CNT network as a temperature and humidity sensor as shown in Figure 21c,d [214]. They found an exponential relation with humidity, i.e., the resistance was increased by $50 \%$ from 20 to $80 \mathrm{RH} \%$. 


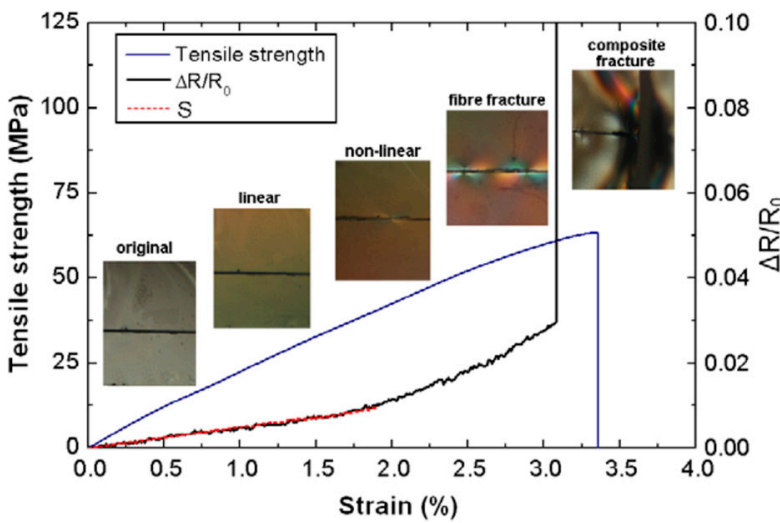

(a)

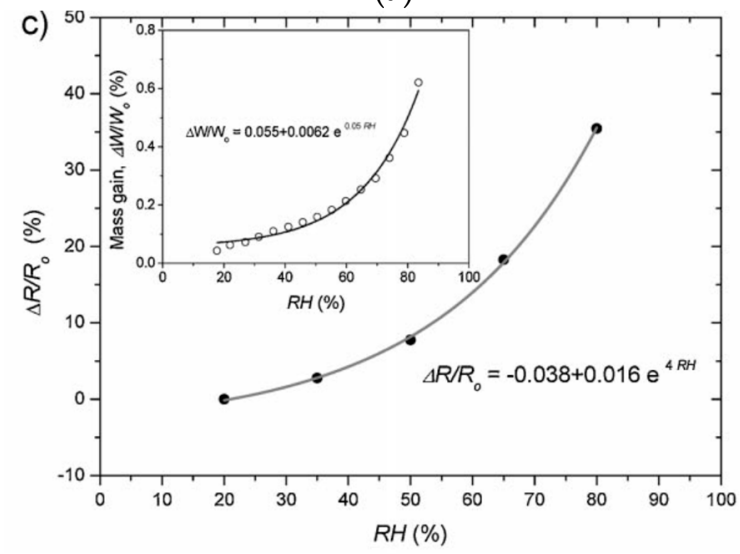

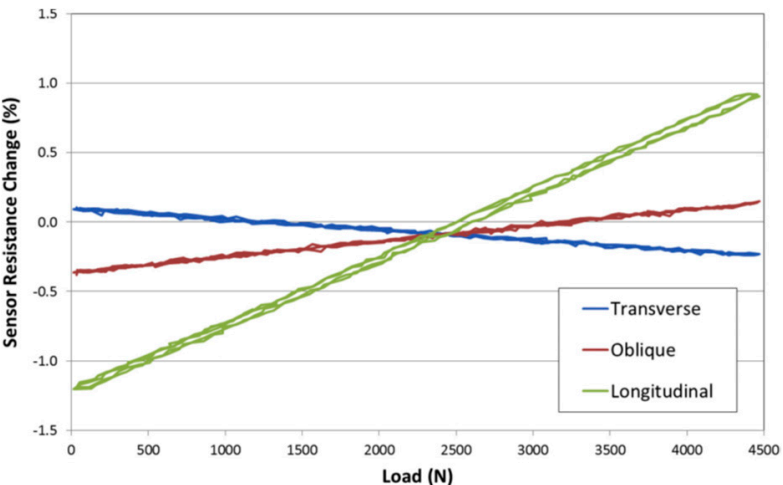

(b)

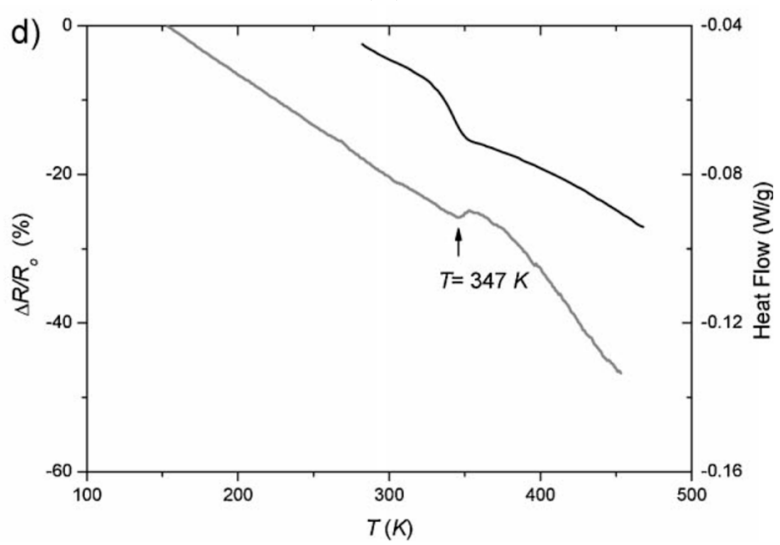

Figure 21. (a) Simultaneous change of electrical resistance and stress as a function of strain for single coated fibre/epoxy composite. Inset figures correspond to the sample profiles at different stages [213]. (b) Fuzzy fibre's resistance variation with load for different orientations [219]. Relative (c) humidity and (d) temperature dependence of a fuzzy fibre [214].

They also reported that the CNT network had a negative temperature coefficient effect (NTC), however disturbed at the glass transition temperature of the polymer matrix. The change of relative resistance was up to $40 \%$ on a $300 \mathrm{~K}$ range, thus illustrating that the CNT resistivity was not limited to strain and damage, but also to environmental parameters like temperature and humidity. Another attempt has been done to coat fibres by in-situ growth of the carbon nanotubes [220], thus creating sensing fibres for strain and damage monitoring [221]. Lafdi et al. [219,222,223] have studied the influence of the orientation of such sensitive glass fibre in a glass fibre epoxy laminate, as observed in Figure 21b. The change of resistance was affected by the orientation of the fibre relatively to the strain direction, with a maximum of sensitivity when the fibre was longitudinal $(\mathrm{GF}=2.5)$, and a negative sensitivity when the fibre was in the transverse direction. The authors attributed the variation of sensitivity to the Poisson's ratio. Other authors have also found that the Poisson's ratio directly affects the piezo-resistive properties of the sensor when CNT were deposited on a substrate having a tuneable Poisson's ratio [224] or by simulation [225]. Because the fibre aspect ratio (\#1000) was very high for Lafdi et al. [219], the deformation of the fibre was principally possible along it's axis, which enhanced the on-axis sensitivity in addition to the Poisson's ratio [225]. Therefore, Lafdi et al. succeeded to create a fibre sensitive to the orientation of the strain. This property was not reached by the Bucky paper or the bulk dispersion strategies because the aspect ratios of those sensors were at least 1000 times smaller than the fibre's one. Similar results were obtained by Luo et al. [226] with a spraying technic used to coat the fibre with pristine SWCNT which led to a GF value of 1.25 during tensile test. The authors have patented their technic to create a flexible motion sensor [227]. 


\subsubsection{Self-Sensing Materials Based on Hybrid Fillers}

Besides CNT, others nano-carbon based fillers have been studied to tune the electrical properties of insulating composites, like carbon nanoparticles (CNP), graphite and graphene nano-platelets (GNP), as shown in Figure 22. CNP are nearly spherical particles from 10 to $100 \mathrm{~nm}$ welded together during their synthesis into aggregates of 200 to $800 \mathrm{~nm}$ [228]. GNP are planar sheets about $1 \mathrm{~nm}$ thick and several micron length [229]. CNT are made of graphene sheets shaped into the form of a tube with one to 20 walls. For commercial multi-walled CNT, the external diameter and the length are about $10 \mathrm{~nm}$ and $1 \mu \mathrm{m}$ respectively [230]. As for CNT, those carbon-based fillers can also be used to improve the mechanical [231-234], thermal [233-236], or electrical properties of nanocomposites [204,228,237-243] and often led to modified rheological [244,245] and crystallization behaviours [246,247].

(A)

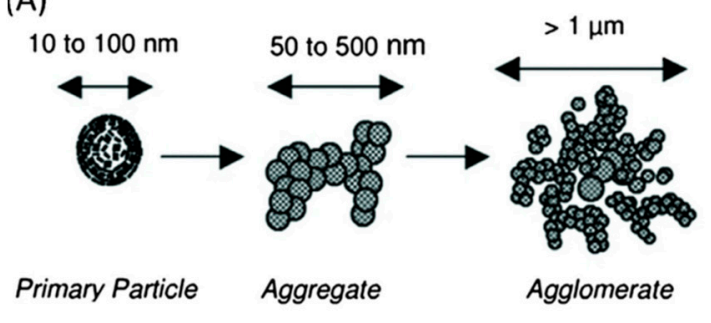

(C)

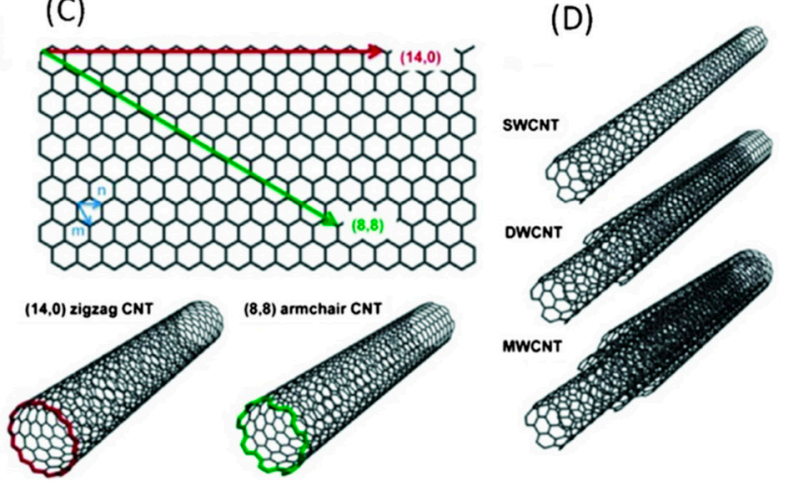

(B)

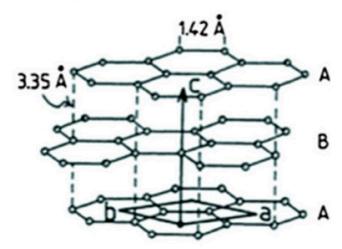

(D)

Figure 22. Schematic structure of (A) carbon black primary particles fused together to form aggregates and agglomerates; (B) hexagonal graphite showing the $\mathrm{ABAB}$ stacking of honeycomb carbon layers; (C) structural variety of $\mathrm{CNT}$ and orientation of the carbon network in armchair $(\mathrm{n}, \mathrm{n})$ and zigzag configuration (n, 0); (D) Single, double and multi-walled CNT [248].

The first filler used to provide elastomers with piezo-resistive capability was carbon black, i.e., aggregated nanoparticules (CNP) [249-253]. Using the same processing conditions for CNP and CNT in epoxy composites, Shen et al. [237] observed a similar percolation threshold value of $0.025 \mathrm{wt} \%$ for both fillers. Yet the resulting conductivity was 10 times lower with CNP because of the lower aspect ratio. Wichmann et al. [240] have found similar electrical behaviour for CNP and CNT reinforced epoxy when subjected to tensile deformation. The CNP-filled system displayed an increase of sensitivity by a factor 2 and a one-decade higher initial resistance. The authors explained it by the lower number of contacts and the larger gap between particles. On another side, Novak and Krupa [238] studied the evolution of the electrical conductivity of epoxy and poly(urethane) based composites reinforced with raw graphite powder. The authors found a percolation threshold value of 22 vol. \% in both matrices, which was about 100 times higher than systems filled with CNT. An attempt to reduce the percolation threshold was done, through the exfoliation of graphite, enabling the dissociation of some graphite sheets [254]. They succeeded and finally reached a percolation threshold of $1 \mathrm{wt} \%[255,256]$. Other authors went further in the graphite exfoliation and obtained GNP that lowered the threshold down to $0.3 \mathrm{wt} \%[257,258]$, while maintaining the final conductivity 4 decades higher than 
the pristine epoxy one [259]. In laminates, GNP have a preferential localisation along the fibres. Due to the high aspect ratio of GNP, the conductivity along the fibres direction was about 10 times higher than through the thickness [259]. The use of GNP as a strain and damage sensor inside composites has been the object of fewer studies than CNT-based ones [204,239,260-266]. Urena et al. [239] presented the use of GNP filled epoxy matrix as a strain sensor. As it has been previously observed for CNT (Figure 21a), for a sample subjected to a tensile deformation, the resistance of the network is first showing a linear increase, followed by an exponential one, as shown in Figure 23a. Interestingly increasing the GNP content from 2 to $5 \mathrm{wt} \%$, converts the exponential shape of electrical response into a linear one. However, the sensitivity was also decreased accordingly, i.e., with a change of resistance at 0.020 strain of 1.2 and 0.35 for 2 to $5 \mathrm{wt} \%$, respectively (Figure 23b). The authors explained this reduction of sensitivity by the decrease of distance between GNP and the associated lower resistance.

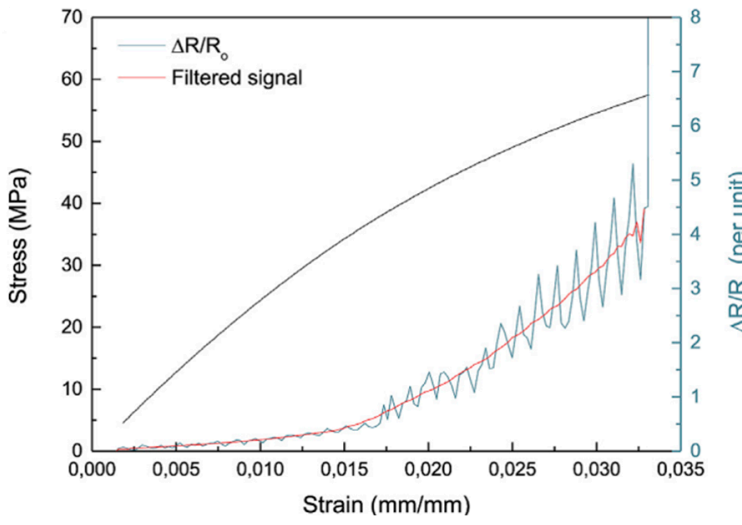

(a)

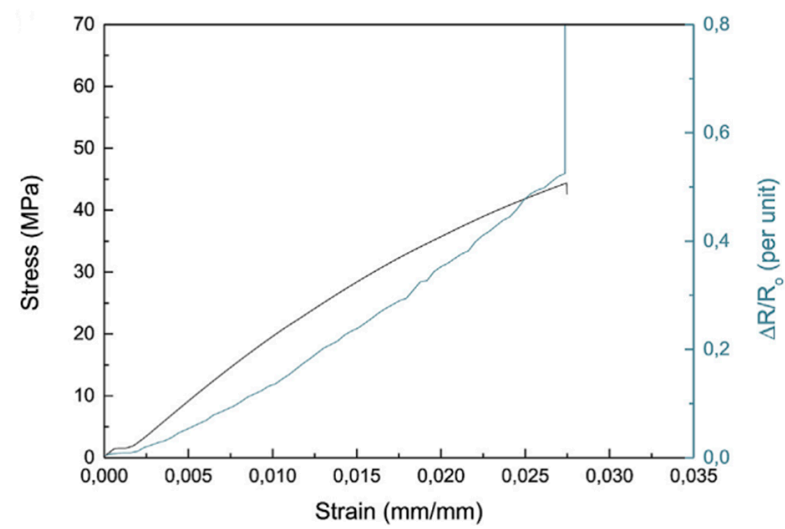

(b)

Figure 23. Electrical and stress responses of epoxy nano-composites samples, reinforced with (a) 2 and (b) 5 wt \% GNP, under tensile test. A first linear resistance increase with strain occurs, followed by an exponential rise. The filler loading increase favours the linear response overs the exponential [239].

Chiacchiarelli et al. [204] have observed the response of a $2 \mathrm{wt} \%$ GNP filled epoxy sensor on the surface of a composite under increasing cyclic bending loadings. They evidenced a decrease of the initial change of resistance with strain under damaging of samples. After 7 cycles, at $6 \times 10^{-3}$ strain, the change of resistance was measured at $40 \%$ while estimated at $65 \%$ for an undamaged sample. The authors linked this change in sensitivity to the progression of damage in the matrix resulting in a measurable irreversible change of resistance during the successive loadings. Lately, graphene interleave has also been used to detect delamination in CF-EP composites by Du et al. [267]. The addition of $1.0 \mathrm{wt} \%$ GNP interleave in the delamination area led to an increase of the critical energy release rate $\left(\mathrm{G}_{\mathrm{IC}}\right)$ by a factor 2 and to a rise of the sensor's resistance with the crack's propagation. Individually, all those carbon fillers have shown some interest for strain and damage monitoring. The combination of two or more of them allowed creating hybrid materials with potential synergistic effect [268]. The impact of hybrids, including CNT, $\mathrm{CNP}$ and GNP, on the composite's electrical properties has been studied mostly in the aim of lowering the percolation threshold. In 2009, Ma et al. [269] have studied the combination of MWCNT and CNP in epoxy resin. The percolation thresholds of CNT and CNP alone were $0.3 \mathrm{wt} \%$ and $0.5 \mathrm{wt} \%$, respectively. The addition of CNP in epoxy already filled with $0.2 \mathrm{wt} \%$ of CNT (below percolation) allowed the authors to reach instantaneously the percolation threshold. Above percolation, the addition of CNP into CNT filled epoxy had no measurable effect. The authors proposed two situations as shown schematically in Figure 24 [270]. 


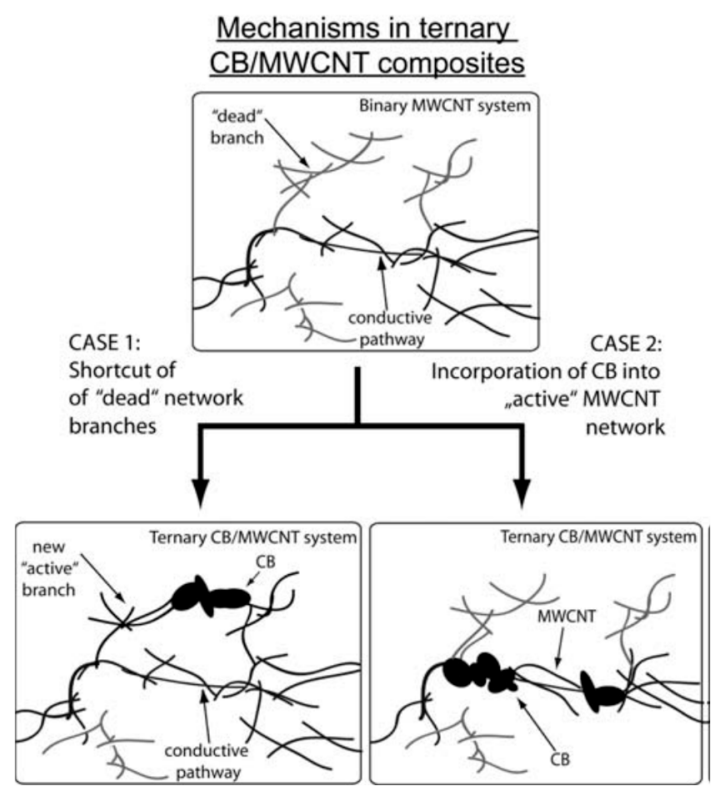

Figure 24. Two cases of conductive pathway formation in ternary CNP-MWCNT/epoxy systems. Addition of bridging CNP particles to create new conductive paths and increase the electrical conductivity, or CNP aggregate around an existing path to conserve or lowered the conductivity [248].

Firstly, they claimed that CNP particles could create new conductive paths by bridging some branches that were not yet connected, thus leading to an instantaneous increase of the material's conductivity. Secondly, the CNP particles could aggregate themselves around an existing conductive path. The enhancement of the conductivity should be preserved, but if $\mathrm{CNP}$ replace $\mathrm{CNT}$, the resistance might increase because of the higher intrinsic conductivity of the latter. The percolation synergy between CNP and CNT fillers has been described by the Equation (5) [271]:

$$
\frac{V_{C N T}}{\phi_{C N T}}+\frac{V_{C N P}}{\phi_{C N P}}=1
$$

where $V_{C N T}$ and $V_{C N P}$ are the actual volume fractions of CNT and CNP particles, and $\phi_{C N T}$ and $\phi_{C N P}$ their respective volume percolation threshold value. Below 1, no percolation of the system is occurring, and above 1 conductive paths are made.

From a mechanical point of view, Ma et al. [269] highlighted a 20\% improvement of fracture strength for CNP $0.2 \mathrm{wt} \% / \mathrm{CNT} 0.2 \mathrm{wt} \%$ filled samples compared to neat epoxy. The value was also higher compared to CNP or CNT at $0.2 \mathrm{wt} \%$ or $0.4 \mathrm{wt} \%$ in epoxy, thus illustrating the synergistic effect.

Later, Wei et al. [272] studied the effect of the introduction of CNP in a GNP-epoxy composite. For a $1 \mathrm{wt} \%$ filled nanocomposite (total content of carbon nano fillers), the authors reached the highest conductivity of $10^{-4} \mathrm{~S} \cdot \mathrm{cm}^{-1}$ with $0.9 \mathrm{wt} \%$ of CNP and $0.1 \mathrm{wt} \%$ of GNP, which was 3 decades larger than the $1 \mathrm{wt} \%$ GNP filled epoxy. It is assumed that CNP particles were able to fill the gap between GNP, therefore avoiding their agglomeration as proposed by the authors in Figure 25 and allowing an easier disconnection of the conducting architecture as also noticed by Tung et al. [96] who used magnetite nanoparticles as nano spacers to enhance the sensitivity of graphene based piezo-resistive nano composites. 


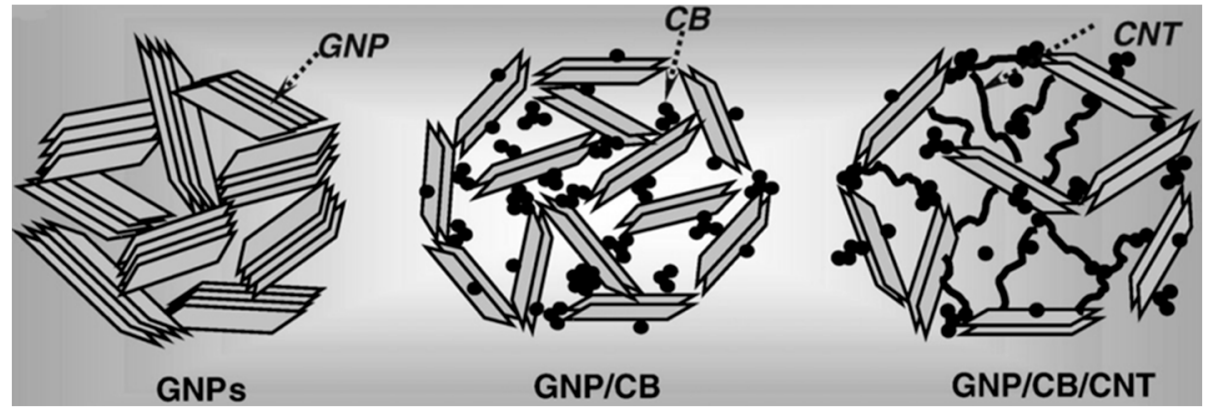

(a)

(b)

(c)

Figure 25. Possible morphologies explaining the synergistic effect between GNP, CNP and CNT: (a) GNP alone, (b) bridging and separation of GNP with CNP particles, (c) enhancement of the bridging by CNT [272].

Wei et al. [272] also studied the effect of adding CNT in the previous mix, and finally observed the lowest percolation threshold at $0.2 \mathrm{wt} \%$ with a ratio in 7:1:2 of GNP/CNP/CNT specimen. In the later formulation, CNT were claimed to bridge GNP thus creating more conductive paths. The elongated shapes of CNT facilitated the development of the conductive network. Finally, thanks to their various shapes, the addition of CNP, CNT and GNP allowed improving the structure of 3D network, the particles dispersion, increased the conductivity, and enhanced crack deflection and bridging [248].

Li et al. [273] first studied in 2008 the introduction of up to $2 \mathrm{wt} \%$ of CNT/GNP in epoxy with CNT amounts ranging from 0.1 to $1 \mathrm{wt} \%$. The authors reached the highest conductivity of $10^{-2} \mathrm{~S} \cdot \mathrm{cm}^{-1}$ with $1 \mathrm{wt} \%$ of $\mathrm{CNT}$, this value being two orders of magnitude higher than for $2 \mathrm{wt} \%$ GNP. However, they didn't notice any enhancement of the mechanical properties (Young's modulus, flexural strength). Highly filled CNT/GNP-epoxy nano composites were studied by $\mathrm{Yu}$ et al. [274], who used total nano filler contents ranging from 5 to $40 \mathrm{wt} \%$. They reported no visible synergistic effect, possibly due to a too high amount of fillers. The optimization of the GNP/CNT ratio for mechanical properties showed nevertheless various results $[275,276]$. For relatively similar total fillers content, the optimal GNP/CNT ratio obtained was 1:9 and 9:1 for 0.5 and $1 \mathrm{wt} \%$ filled sample, respectively. Indeed, for slightly filled composites, the addition of GNP enabled creating a higher surface contact than with CNT alone. On the other hand, for highly filled composites, CNT contributed to the bridging of GNP. Unfortunately, and to the best of our knowledge, no similar information on the electrical synergy between CNT and GNP has been found so far in the literature.

Regarding the use of hybrid nano fillers in piezo-resistive sensors, only few studies were found in the literature. Zhao and Bai [277], in 2015, have grown aligned CNT by CVD onto GNP with a final mass ratio of $1 / 1$. The hybrid fillers were then dispersed in PDMS to form a 3D network. The authors estimated the percolation threshold at 0.64 vol. \%, which was below usual values in PDMS. The resulting nano composite was used as a pressure and human motion sensor. Due to the low particle's concentration, the transverse strain with the applied pressure favored the disconnection of the network and thus led to an increase of the resistance, as shown in Figure 26a. The variation of the filler content from 0.8 to 1.5 vol. \% showed a decrease of the sensor's sensitivity of nearly two decades. The authors assumed that the increase of the filler content could favor the creation of a "hub" structure, thus enhancing the interfacial area and extending the effective contact space between fillers. 


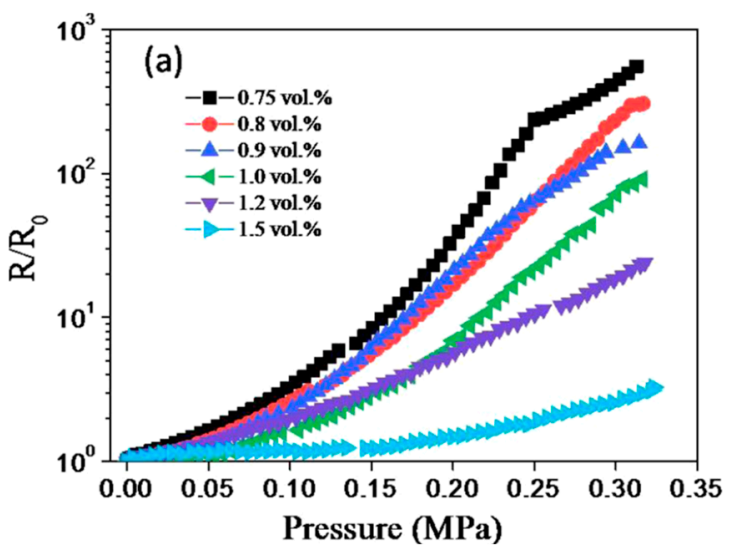

(a)

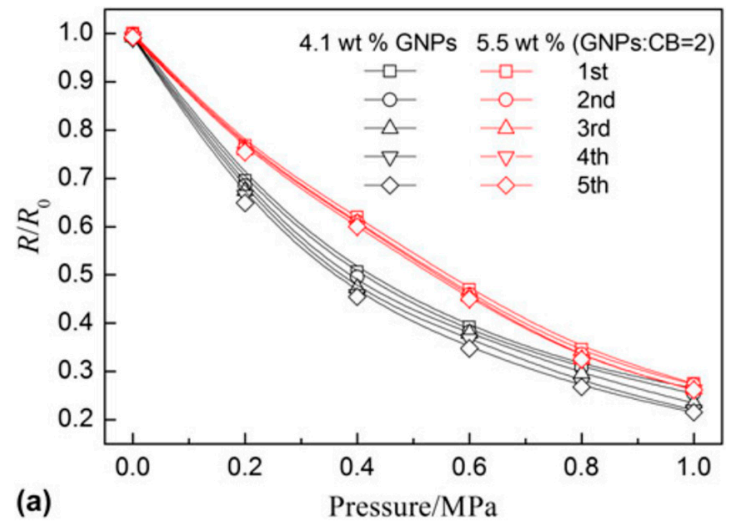

(b)

Figure 26. (a) Typical pressure-resistance behaviour variation of GNP-CNT/PDMS composites [278]. (b) Repeatability of the piezo-resistive characteristics of GNP/SR at 4.1 wt \% and $\mathrm{GNP} / \mathrm{CNP} / \mathrm{SR}_{(\mathrm{GNP}: \mathrm{CNP}=2)}$ at $5.5 \mathrm{wt} \%$ [278].

Inversely, at high filler percentage, despite the sample's high deformation, the connected fillers were therefore able to maintain the pathways conductive, explaining the lower observed sensitivity. In their study, Liu et al. [278] have chosen to use carbon nanoparticles and graphene to enhance the pressure piezo-resistive performance of a silicone rubber graphene sensor. The addition of CNP led to a more stable electrical signal with repeated loadings, with a more constant relative resistance decrease down to $75 \%$ at $1 \mathrm{MPa}$ loading, as shown in Figure 26b. More recently Tran et al. found interesting to use thermoplastic poly(urethane) (TPU) as an insulating host for the development of a conducting architecture made of $\mathrm{pG} 2 \% / \mathrm{CNT} 4 \%$ hybrid. This piezo-resistive transducer was found to exhibit a linear response in compression from 0 to $4 \mathrm{MPa}$, the highest range ever obtained with a sensitivity as high as $11.310^{-5} \mathrm{kPa}^{-1}$. Moreover, these hybrid $\mathrm{pQRS}$ were found to be able to get rid of the double peak usually obtained at high compression due to Poisson's effect [279]. Reader interested by additional information about the topic can refer to the following recent review on in the interest of using hybrids to improve the piezo-resistive response of polymer nanocomposites [280].

\section{Conclusions}

In the light of the growing demands for electrical green energy, which is boosting the development of wind turbines equipped with huge composite blades, the objective of this review was to give an overview of the different strategies used to develop self-sensing materials for structural health monitoring (SHM) in order to reduce the maintenance costs.

Among all routes, the creation of conductive networks inside the insulating epoxy matrix by the percolation of nano carbon fillers, especially CNT, seemed the most promising. The simple monitoring of the nano composite's resistance allows to correlate strain and damage with the matrix piezo-resistive behaviour. However, the state of dispersion, as well as the CNT content in the matrix appear to be primordial parameters to control, in order to obtain nanocomposite strain sensors with reproducible performances.

Three approaches have been discussed for different kind of CNT networks: Bucky paper (random network of CNT), matrix reinforcement (CNT percolated into the polymer) and fuzzy fibres (CNT coating an insulating fibre). All strategies proved to be effective in measuring strain and detecting damages. Nevertheless, some lockers to their industrialisation remain, such as for instance, the weakening of the interface between the CNT and the matrix resulting from the use of Bucky papers that may decrease the composite mechanical properties.

While, the localisation of strain and damage in a matrix completely filled with CNT has been demonstrated with both ERT and EPM technics, a reduction of the calculation time (ERT) or the number of electrodes (EPM) should still be improved for real time monitoring 
and some issues remain for their insertion in the core of parts. In the case of fuzzy fibres, a sensitivity to the orientation of strain can be obtained thanks to the high aspect ratio of fibres.

Finally, the possible synergistic effect between carbon nanofillers in epoxy-based hybrid composites has been confirmed to optimize their electrical behaviour. Thanks to the different particles' geometry the bridging effect and the creation of hub like interconnection can enhance specific electrical parameters such stability of responses during cyclic deformation, partial disappearance of double peaks in compression due to the Poisson's effect.

The state of the art on existing structural health monitoring (SHM) for turbine blades made of composite structures has allowed to list the different techniques used: metallic strain gauge and optical fibres for strain measurement, and acoustic emission, ultrasonic measurements and optical fibres for failure analysis. Among these technics, only optical fibres can detect both strain and failure, but their use for in situ measurements in the core of composites is still controversial, as their handling during processing is tricky and their integration susceptible to weaken the composite depending on the structure of its plies.

Consequently, the development of "self-sensing" composites appears to provide a credible alternative to overcome those issues. Actually, these materials proved to be able to give a real-time information about their mechanical behaviour and their environment. By simply analysing the resistance variations of their carbon network, it is possible to evidence delamination, fibre's fracture, and eventually locate structural defects.

Future development of self-sensing sensors will certainly include hybrid nanocomposites obtained by the combination of various nano carbon fillers such as CNP, CNT, or graphene, which proved a synergistic effect able to enhance their sensitivity and stabilize their signals.

However, an increase of the technological readiness level (TRL) of piezo-resistive nanocomposite sensors for structural health monitoring (SHM) still requires the implementation in the data treatment, of the influence of environmental parameters such as temperature and moisture for example. It is also likely that the massive acquisition of data in use conditions and their fusion with data from other classical surface technics like acoustic emission (AE), will allow to perform sharper diagnostics.

Author Contributions: Conceptualization, M.C., J.-F.F.; methodology, A.L., M.C., J.-F.F.; validation, A.L., M.C., J.-F.F., O.F.; formal analysis, A.L., M.C., J.-F.F.; investigation, A.L., M.C., J.-F.F.; resources M.C., J.-F.F.; writing—original draft preparation, A.L.; writing—review and editing, A.L., M.C., J.-F.F.; visualization, A.L., M.C., J.-F.F.; supervision, M.C.; project administration, O.F., J.-C.D.-L., J.-F.F.; funding acquisition, J.-C.D.-L., J.-F.F. All authors have read and agreed to the published version of the manuscript.

Funding: This research was funded by EVEREST research program, grant number CED 2014/011.

Acknowledgments: The authors thank Hervé Bellégou, Isabelle Pillin, the University of South Brittany (UBS), and the Jules Verne Technological Research Institute (IRT) for their contribution to this work.

Conflicts of Interest: The authors declare no conflict of interest.

\section{References}

1. Martinez-Luengo, M.; Kolios, A.; Wang, L. Structural health monitoring of offshore wind turbines: A review through the Statistical Pattern Recognition Paradigm. Renew. Sustain. Energy Rev. 2016, 64, 91-105. [CrossRef]

2. Thresher, R.W.; Robinson, M.C.; Veers, P. Wind Energy Technology: Current Status and R \& D future. In Proceedings of the Physics of Sustainable Energy Conference, Berkeley, CA, USA, 1-2 March 2008.

3. Thresher, R.W.; Robinson, M.C.; Veers, P. The Future of Wind Energy Technology in the United States. In Proceedings of the 2008 World Renewable Energy Congress, Glasgow, Scotland, 19-25 July 2008.

4. Wind Power by Country, Wikipedia 2020. Available online: https://en.wikipedia.org/wiki/Wind_power_by_country (accessed on 25 November 2021).

5. Lyons, J.P.; Robinson, M.C.; Veers, P.; Thresher, R.W. Wind Turbine Technology-The Path to 20\% US Electrical Energy. In Proceedings of the 2008 IEEE Power and Energy Society General Meeting-Conversion and Delivery of Electrical Energy in the 21st Century, Pittsburgh, PA, USA, 20-24 July 2008; IEEE: Pittsburgh, PA, USA, 2008; pp. 1-4. 
6. Commission, E. Renewable Energy Directive 2018/2001/EU; 2018; Available online: https:/ / euagenda.eu/upload/publications / eprs-bri2021662619-en.pdf (accessed on 25 November 2021).

7. Jones, R.M. Mechanics of Composite Materials; CRC Press: Boca Raton, FL, USA, 1998; ISBN 978-1560327127.

8. Shohag, M.A.S.; Hammel, E.C.; Olawale, D.O.; Okoli, O.I. Damage mitigation techniques in wind turbine blades: A review. Wind Eng. 2017, 41, 185-210. [CrossRef]

9. Syndicat des Énergies Renouvelables. Etat des Coûts de Production de L'éolien Terrestre en France Analyse Économique de la Commission Eolienne du SER. 2014. Available online: https:/ / www.syndicat-energies-renouvelables.fr/keywordsdocs/etatcouts-de-production-eolien-terrestre/ (accessed on 25 November 2021).

10. Windpower Offshore. The Tide Turns on Offshore Maintenance Costs. Available online: https://www.windpowermonthly.com/ article/1314299/tide-turns-offshore-maintenance-costs (accessed on 25 November 2021).

11. Castro-Santos, L.; Diaz-Casas, V. Green Energy and Technology. In Floating Offshore Wind Farms; Castro-Santos, L., Diaz-Casas, V., Eds.; Springer International Publishing: Cham, Germany, 2016; ISBN 978-3-319-27970-1.

12. Union of Concerned Scientists How Wind Energy Works. Available online: https://www.ucsusa.org/resources/how-windenergy-works (accessed on 25 November 2021).

13. Schubel, P.J.; Crossley, R.J.; Boateng, E.K.G.; Hutchinson, J.R. Review of structural health and cure monitoring techniques for large wind turbine blades. Renew. Energy 2013, 51, 113-123. [CrossRef]

14. Balageas, D.; Fritzen, C.-P.; Güemes, A. Structural Health Monitoring; ISTE: Newport Beach, CA, USA, 2006; ISBN 978-1-905209-01-9.

15. Huston, D. Structural Sensing, Health Monitoring, and Performance Evaluation (Series in Sensors); CRC Press: Boca Raton, FL, USA, 2011; ISBN 9781420012354.

16. Farrar, C.R.; Worden, K. An introduction to structural health monitoring. Philos. Trans. R. Soc. A Math. Phys. Eng. Sci. 2007, 365, 303-315. [CrossRef]

17. Mcgugan, M.; Ostachowicz, W.; Schröder-Hinrichs, J.-U.; Luczak, M. Mare-Wint; Ostachowicz, W., McGugan, M., SchröderHinrichs, J.-U., Luczak, M., Eds.; Springer International Publishing: Cham, Germany, 2016; ISBN 978-3-319-39094-9.

18. Sørensen, B.F.; Jørgensen, E.; Debel, C.P.; Jensen, F.M.; Jensen, H.M.; Jacobsen, T.K.; Halling, K.M. Improved Design of Large Wind Turbine Blade of Fibre Composites Based on Studies of Scale Effects (Phase 1)—Summary Report; Risø-R-139: Roskilde, Denmark, 2004; Volume 1390, ISBN 87-550-3176-5/87-550-3177-3.

19. Chen, X.; Zhao, X.; Xu, J. Revisiting the structural collapse of a $52.3 \mathrm{~m}$ composite wind turbine blade in a full-scale bending test. Wind Energy 2017, 20, 1111-1127. [CrossRef]

20. Dransfield, K.; Baillie, C.; Mai, Y.-W. Improving the delamination resistance of CFRP by stitching-a review. Compos. Sci. Technol. 1994, 50, 305-317. [CrossRef]

21. Wymore, M.L.; Van Dam, J.E.; Ceylan, H.; Qiao, D. A survey of health monitoring systems for wind turbines. Renew. Sustain. Energy Rev. 2015, 52, 976-990. [CrossRef]

22. Ciang, C.C.; Lee, J.-R.; Bang, H.-J. Structural health monitoring for a wind turbine system: A review of damage detection methods. Meas. Sci. Technol. 2008, 19, 122001. [CrossRef]

23. Takoutsing, P.; Wamkeue, R.; Ouhrouche, M.; Slaoui-Hasnaoui, F.; Tameghe, T.; Ekemb, G. Wind turbine condition monitoring: State-of-the-art review, new trends, and future challenges. Energies 2014, 7, 2595-2630. [CrossRef]

24. de Azevedo, H.D.M.; Araújo, A.M.; Bouchonneau, N. A review of wind turbine bearing condition monitoring: State of the art and challenges. Renew. Sustain. Energy Rev. 2016, 56, 368-379. [CrossRef]

25. Crabtree, C.J.; Zappalá, D.; Tavner, P.J. Survey of Commercially Available Condition Monitoring Systems for Wind Turbines; Durham University School of Engineering and Computing Sciences and the SUPERGEN Wind Energy Technologies Consortium: Durham, UK, 2014.

26. Chen, B.; Zappalá, D.; Crabtree, C.J.; Tavner, P.J. Survey of Commercially Available SCADA Data Analysis Tools for Wind Turbine Health Monitoring; Durham University School of Engineering and Computing Sciences: Durham, UK, 2014.

27. Yang, B.; Sun, D. Testing, inspecting and monitoring technologies for wind turbine blades: A survey. Renew. Sustain. Energy Rev. 2013, 22, 515-526. [CrossRef]

28. Cooperman, A.; Martinez, M. Load monitoring for active control of wind turbines. Renew. Sustain. Energy Rev. 2015, 41, 189-201. [CrossRef]

29. Hameed, Z.; Hong, Y.S.; Cho, Y.M.; Ahn, S.H.; Song, C.K. Condition monitoring and fault detection of wind turbines and related algorithms: A review. Renew. Sustain. Energy Rev. 2009, 13, 1-39. [CrossRef]

30. Hoffmann, K. An Introduction to Stress Analysis and Transducer Design using Strain Gauges. Academia 2012, 127-133.

31. Nanolike, Monitor Your Industrial Assets. Available online: http:/ /www.nanolike.com/ (accessed on 25 November 2021).

32. Dharap, P.; Li, Z.; Nagarajaiah, S.; Barrera, E.V. Nanotube film based on single-wall carbon nanotubes for strain sensing. Nanotechnology 2004, 15, 379-382. [CrossRef]

33. Eisler, P. Electric Resistance Devices. US Patent US2441960A, 1952. Available online: https://patents.google.com/patent/US244 1960A/en (accessed on 25 November 2021).

34. Rs Components. Available online: http://fr.rs-online.com/web/c/automatisme-et-controle-de-process/capteurs-ettransducteurs/jauges-de-contraintes/ (accessed on 25 November 2021).

35. Strain Gauges, HBM Technical Sheet. Available online: https://www.hbm.com/en/2122/strain-gauge-datasheets / (accessed on 25 November 2021). 
36. Ettouney, M.; Alampalli, S. Infrastructure Health in Civil Engineering; CRC Press: Boca Raton, FL, USA, 2012; ISBN 9780849320408.

37. Majumder, M.; Gangopadhyay, T.K.; Chakraborty, A.K.; Dasgupta, K.; Bhattacharya, D.K. Fibre Bragg gratings in structural health monitoring-Present status and applications. Sens. Actuators A Phys. 2008, 147, 150-164. [CrossRef]

38. Li, H.-N.; Li, D.-S.; Song, G.-B. Recent applications of fiber optic sensors to health monitoring in civil engineering. Eng. Struct. 2004, 26, 1647-1657. [CrossRef]

39. Ramakrishnan, M.; Rajan, G.; Semenova, Y.; Farrell, G. Overview of fiber optic sensor technologies for strain/temperature sensing applications in composite materials. Sensors 2016, 16, 99. [CrossRef]

40. Takeda, N. Characterization of microscopic damage in composite laminates and real-time monitoring by embedded optical fiber sensors. Int. J. Fatigue 2002, 24, 281-289. [CrossRef]

41. Takeda, N.; Okabe, Y.; Kuwahara, J.; Kojima, S.; Ogisu, T. Development of smart composite structures with small-diameter fiber Bragg grating sensors for damage detection: Quantitative evaluation of delamination length in CFRP laminates using Lamb wave sensing. Compos. Sci. Technol. 2005, 65, 2575-2587. [CrossRef]

42. Li, C.; Ning, T.; Li, J.; Pei, L.; Zhang, C.; Zhang, C.; Lin, H.; Wen, X. Simultaneous measurement of refractive index, strain, and temperature based on a four-core fiber combined with a fiber Bragg grating. Opt. Laser Technol. 2017, 90, 179-184. [CrossRef]

43. Mieloszyk, M.; Ostachowicz, W. Moisture contamination detection in adhesive bond using embedded FBG sensors. Mech. Syst. Signal Process. 2017, 84, 1-14. [CrossRef]

44. Mieloszyk, M.; Ostachowicz, W. An application of Structural Health Monitoring system based on FBG sensors to offshore wind turbine support structure model. Mar. Struct. 2017, 51, 65-86. [CrossRef]

45. Kinet, D.; Mégret, P.; Goossen, K.; Qiu, L.; Heider, D.; Caucheteur, C. Fiber Bragg grating sensors toward structural health monitoring in composite materials: Challenges and solutions. Sensors 2014, 14, 7394-7419. [CrossRef] [PubMed]

46. Rodriguez-Cobo, L.; Cobo, A.; Lopez-Higuera, J.-M. Embedded compaction pressure sensor based on Fiber Bragg Gratings. Measurement 2015, 68, 257-261. [CrossRef]

47. Tennyson, R.C.; Mufti, A.A.; Rizkalla, S.; Tadros, G.; Benmokrane, B. Structural health monitoring of innovative bridges in Canada with fiber optic sensors. Smart Mater. Struct. 2001, 10, 560-573. [CrossRef]

48. Rezayat, A.; De Pauw, B.; Lamberti, A.; El-Kafafy, M.; Nassiri, V.; Ertveldt, J.; Arroud, G.; Vanlanduit, S.; Guillaume, P. Reconstruction of impacts on a composite plate using fiber Bragg gratings (FBG) and inverse methods. Compos. Struct. 2016, 149, 1-10. [CrossRef]

49. Zohari, M.H.; Yusof, M.; Siregar, J.P.; Sin, L.K. The Applications of FBG sensor for Realtime Strain Mapping of Thin Composite Plate under Point Loading. In Proceedings of the International Conference on Advanced Mechanics, Power and Energy 2015 (AMPE2015), Kuala Lumpur, Malaysia, 5-6 December 2015.

50. Webb, G.T.; Vardanega, P.J.; Middleton, C.R. Categories of SHM Deployments: Technologies and Capabilities. J. Bridg. Eng. 2014, 20, 04014118. [CrossRef]

51. Nicolas, M.; Sullivan, R.; Richards, W. Large Scale Applications Using FBG Sensors: Determination of In-Flight Loads and Shape of a Composite Aircraft Wing. Aerospace 2016, 3, 18. [CrossRef]

52. Huang, C.Y.; Trask, R.S.; Bond, I.P. Characterization and analysis of carbon fibre-reinforced polymer composite laminates with embedded circular vasculature. J. R. Soc. Interface 2010, 7, 1229-1241. [CrossRef]

53. Luyckx, G.; Voet, E.; Lammens, N.; Degrieck, J. Strain measurements of composite laminates with embedded fibre Bragg gratings: Criticism and opportunities for research. Sensors 2010, 11, 384-408. [CrossRef] [PubMed]

54. Yang, R.; He, Y.; Zhang, H. Progress and trends in non-destructive testing and evaluation for wind turbine composite blade. Renew. Sustain. Energy Rev. 2016, 60, 1225-1250. [CrossRef]

55. Juengert, A. Damage Detection in Wind Turbine Blades using two Different Acoustic Techniques. E-J. Nondestruct. Test. 2008, 1-10. Available online: https://www.ndt.net/article/v13n12/juengert.pdf (accessed on 25 November 2021).

56. García Márquez, F.P.; Tobias, A.M.; Pinar Pérez, J.M.; Papaelias, M. Condition monitoring of wind turbines: Techniques and methods. Renew. Energy 2012, 46, 169-178. [CrossRef]

57. Beganovic, N.; Söffker, D. Structural health management utilization for lifetime prognosis and advanced control strategy deployment of wind turbines: An overview and outlook concerning actual methods, tools, and obtained results. Renew. Sustain. Energy Rev. 2016, 64, 68-83. [CrossRef]

58. Signaltech, Capteurs d'émission Acoustique. Available online: http://www.signaltech.fr/capteurs/emisacoust.html (accessed on 25 November 2021).

59. Juengert, A.; Grosse, C.U. Inspection techniques for wind turbine blades using ultrasound and sound waves. In Proceedings of the NDTCE'09, Non-Destructive Testing in Civil Engineering, Nantes, France, 30 June-3 July 2009.

60. John, W.N. Method and Apparatus for Monitoring Wind Turbine Blades during Operation. 2013. Available online: https: / / patents.google.com/patent/US9194843B2/en (accessed on 25 November 2021).

61. John, W.N. Nondestructive Testing of Wind Turbine Blades from the Ground during Operation. 2014. Available online: https:/ / patentimages.storage.googleapis.com/09/64/e0/226b5cebac2bb6/EP2984337B1.pdf (accessed on 25 November 2021).

62. Frey, A.; Roark, F.; Gonzalez, M. Early Detection of Wind Turbine Degradation Using Acoustical Monitoring. 2013. Available online: https:/ / patentimages.storage.googleapis.com/2c/49/e6/83c174d186ad4d/CA2891326A1.pdf (accessed on 25 November 2021). 
63. Method and Apparatus for Monitoring Wind Turbine Blades during Operation. US Patent US2014260634A1, 2014. Available online: https: / / patents.google.com/patent/US20140260634?oq=2014260634A1 (accessed on 25 November 2021).

64. Walsh, J.; Bashir, I.; Garrett, J.K.; Thies, P.R.; Blondel, P.; Johanning, L. Monitoring the condition of Marine Renewable Energy Devices through underwater Acoustic Emissions: Case study of a Wave Energy Converter in Falmouth Bay, UK. Renew. Energy 2017, 102, 205-213. [CrossRef]

65. Michalcová, L.; Kadlec, M. Carbon/epoxy composite delamination analysis by acoustic emission method under various environmental conditions. Eng. Fail. Anal. 2016, 69, 88-96. [CrossRef]

66. Gómez Muñoz, C.; García Márquez, F. A New Fault Location Approach for Acoustic Emission Techniques in Wind Turbines. Energies 2016, 9, 40. [CrossRef]

67. Masmoudi, S.; El Mahi, A.; Turki, S. Fatigue behaviour and structural health monitoring by acoustic emission of E-glass/epoxy laminates with piezoelectric implant. Appl. Acoust. 2016, 108, 50-58. [CrossRef]

68. Masmoudi, S.; El Mahi, A.; Turki, S. Use of piezoelectric as acoustic emission sensor for in situ monitoring of composite structures. Compos. Part B Eng. 2015, 80, 307-320. [CrossRef]

69. Raišutis, R.; Jasi, E.; Šliteris, R.; Vladišauskas, A.; Jasiūnienė, E.; Šliteris, R.; Vladišauskas, A. The review of non-destructive testing techniques suitable for inspection of the wind turbine blades. Ultragarsas 2008, 63, 26-30.

70. Mouritz, A.P.; Townsend, C.; Shah Khan, M.Z. Non-destructive detection of fatigue damage in thick composites by pulse-echo ultrasonics. Compos. Sci. Technol. 2000, 60, 23-32. [CrossRef]

71. Park, J.-W.; Im, K.-H.; Hsu, D.K.; Jung, J.-A.; Yang, I.-Y. Pitch-catch ultrasonic study on unidirectional CFRP composite laminates using Rayleigh wave transducers. J. Mech. Sci. Technol. 2012, 26, 2147-2150. [CrossRef]

72. Giurgiutiu, V. 7.19 Smart Materials and Health Monitoring of Composites. In Comprehensive Composite Materials II; Beaumont, P.W.R., Zweben, C.H., Eds.; Elsevier: Amsterdam, The Netherlands, 2018; pp. 364-381. ISBN 9780128035818.

73. Wind Turbine Blade with Strain Sensing Means, Wind Turbine Block Sensor Unit and Uses Hereof. WO Patent WO2008101496A3, 2011. Available online: https:/ / patents.google.com/patent/WO2008101496A3/en (accessed on 25 November 2021).

74. Zhang, Z.; Shankar, K.; Ray, T.; Morozov, E.V.; Tahtali, M. Vibration-based inverse algorithms for detection of delamination in composites. Compos. Struct. 2013, 102, 226-236. [CrossRef]

75. Tan, K.T.; Watanabe, N.; Iwahori, Y. X-ray radiography and micro-computed tomography examination of damage characteristics in stitched composites subjected to impact loading. Compos. B Eng. 2011, 42, 874-884. [CrossRef]

76. Schell, J.S.U.; Renggli, M.; van Lenthe, G.H.; Müller, R.; Ermanni, P. Micro-computed tomography determination of glass fibre reinforced polymer meso-structure. Compos. Sci. Technol. 2006, 66, 2016-2022. [CrossRef]

77. Hofer, B. Fibre optic damage detection in composite structures. Composites 1987, 18, 309-316. [CrossRef]

78. Shin, C.-S.; Liaw, S.-K.; Yang, S.-W. Post-Impact Fatigue Damage Monitoring Using Fiber Bragg Grating Sensors. Sensors 2014, 14, 4144-4153. [CrossRef] [PubMed]

79. Petrovic, M.; Mihailovic, P.; Brajovic, L.; Petricevic, S.; Zivkovic, I.; Kojovic, A.; Radojevic, V. Intensity Fiber-optic Sensor for Structural Health Monitoring Calibrated by Impact Tester. IEEE Sens. J. 2016, 16, 3047-3053. [CrossRef]

80. Tian, S.; Yang, Z.; Chen, X.; Xie, Y. Damage Detection Based on Static Strain Responses Using FBG in a Wind Turbine Blade. Sensors 2015, 15, 19992-20005. [CrossRef] [PubMed]

81. Zhang, C.; Bond, L.J. Performance evaluation of the fiber Bragg grating (FBG) sensing device and comparison with piezoelectric sensors for AE detection. AIP Conf. Proc. 2017, 1806, 070007. [CrossRef]

82. Duchene, P.; Chaki, S.; Ayadi, A.; Krawczak, P. A review of non-destructive techniques used for mechanical damage assessment in polymer composites. J. Mater. Sci. 2018, 53, 7915-7938. [CrossRef]

83. Tuloup, C.; Harizi, W.; Aboura, Z.; Meyer, Y.; Khellil, K.; Lachat, R. On the use of in-situ piezoelectric sensors for the manufacturing and structural health monitoring of polymer-matrix composites: A literature review. Compos. Struct. 2019, 215, 127-149. [CrossRef]

84. Shohag, M.A.; Dessureault, Y.S.; Joshi, K.; Ndebele, T.; Olawale, D.O.; Dickens, T.; Okoli, O. Enhanced fabrication process for in situ triboluminescent optical fiber sensor for multifunctional composites. Measurement 2018, 121, 240-248. [CrossRef]

85. Feller, J.F. 6.10 Electrically Conductive Nanocomposites. In Comprehensive Composite Materials II; Beaumont, P.W.R., Zweben, C.H., Eds.; Elsevier: Amsterdam, The Netherlands, 2018; pp. 248-314.

86. Thostenson, E.T.; Ren, Z.; Chou, T.W. Advances in the science and technology of carbon nanotubes and their composites: A review. Compos. Sci. Technol. 2001, 61, 1899-1912. [CrossRef]

87. Kim, P.; Shi, L.; Majumdar, A.; McEuen, P.L. Thermal Transport Measurements of Individual Multiwalled Nanotubes. Phys. Rev. Lett. 2001, 87, 215502. [CrossRef]

88. Asai, S.; Sumita, M. Effect of interfacial energy and viscosity on percolation time of carbon black-filled poly(methyl methacrylate). J. Macromol. Sci. Part B 1995, 34, 283-294. [CrossRef]

89. Yao, Z.; Kane, C.L.; Dekker, C. High-Field Electrical Transport in Single-Wall Carbon Nanotubes. Phys. Rev. Lett. 2000, 84, 2941-2944. [CrossRef]

90. Ebbesen, T.W.; Lezec, H.J.; Hiura, H.; Bennett, J.W.; Ghaemi, H.F.; Thio, T. Electrical conductivity of individual carbon nanotubes. Nature 1996, 382, 54-56. [CrossRef]

91. Treacy, M.M.J.; Ebbesen, T.W.; Gibson, J.M. Exceptionally high Young's modulus observed for individual carbon nanotubes. Nature 1996, 381, 678-680. [CrossRef] 
92. Feller, J.F.; Linossier, I.; Grohens, Y. Conductive polymer composites: Comparative study of poly(ester)-short carbon fibres and poly(epoxy)-short carbon fibres mechanical and electrical properties. Mater. Lett. 2002, 57, 64-71. [CrossRef]

93. Luheng, W.; Tianhuai, D.; Peng, W. Influence of carbon black concentration on piezoresistivity for carbon-black-filled silicone rubber composite. Carbon 2009, 47, 3151-3157. [CrossRef]

94. Kumar, S.K.; Castro, M.; Saiter, A.; Delbreilh, L.; Feller, J.F.; Thomas, S.; Grohens, Y. Development of poly(isobutylene-coisoprene)/reduced graphene oxide nanocomposites for barrier, dielectric and sensing applications. Mater. Lett. 2013, 96, 109-112. [CrossRef]

95. Wudl, F. Fullerene materials. J. Mater. Chem. 2002, 12, 1959-1963. [CrossRef]

96. Tung, T.T.; Robert, C.; Castro, M.; Feller, J.F.; Kim, T.Y.; Suh, K.S. Enhancing the sensitivity of graphene/polyurethane nanocomposite flexible piezo-resistive pressure sensors with magnetite nano-spacers. Carbon 2016, 108, 450-460. [CrossRef]

97. Nag, S.; Castro, M.; Choudhary, V.; Feller, J.F. Sulfonated poly(ether ether ketone) [SPEEK] nanocomposites based on hybrid nanocarbons for the detection and discrimination of some lung cancer VOC biomarkers. J. Mater. Chem. B Biol. Med. 2017, 5, 348-359. [CrossRef] [PubMed]

98. Schulte, K.; Baron, C. Load and failure analyses of CFRP laminates by means of electrical resistivity measurements. Compos. Sci. Technol. 1989, 36, 63-76. [CrossRef]

99. Wang, X.; Chung, D.D.L. Short-carbon-fiber-reinforced epoxy as a piezoresistive strain sensor. Smart Mater. Struct. 1995, 4, 363-367. [CrossRef]

100. Todoroki, A.; Yoshida, J. Electrical resistance change of unidirectional CFRP due to applied load. JSME Int. J. Ser. A 2004, 47, 357-364. [CrossRef]

101. Todoroki, A.; Ueda, M.; Hirano, Y. Strain and damage monitoring of CFRP laminates by means of electrical resistance measurement. J. Solid Mech. Mater. Eng. 2007, 1, 947-974. [CrossRef]

102. Wang, S.; Chung, D.D.L. Self-sensing of flexural strain and damage in carbon fiber polymer-matrix composite by electrical resistance measurement. Carbon 2006, 44, 2739-2751. [CrossRef]

103. Angelidis, N.; Irving, P.E. Detection of impact damage in CFRP laminates by means of electrical potential techniques. Compos. Sci. Technol. 2007, 67, 594-604. [CrossRef]

104. Angelidis, N.; Khemiri, N.; Irving, P.E. Experimental and finite element study of the electrical potential technique for damage detection in CFRP laminates. Smart Mater. Struct. 2005, 14, 147-154. [CrossRef]

105. Todoroki, A.; Tanaka, M.; Shimamura, Y.; Kobayashi, H. Effects with a matrix crack on monitoring by electrical resistance method. Adv. Compos. Mater. 2004, 13, 107-120. [CrossRef]

106. Todoroki, A.; Omagari, K.; Shimamura, Y.; Kobayashi, H. Matrix crack detection of CFRP using electrical resistance change with integrated surface probes. Compos. Sci. Technol. 2006, 66, 1539-1545. [CrossRef]

107. Wang, X.; Chung, D.D.L. Sensing delamination in a carbon fiber polymer-matrix composite during fatigue by electrical resistance measurement. Polym. Compos. 1997, 18, 692-700. [CrossRef]

108. Todoroki, A.; Tanaka, M.; Shimamura, Y. Measurement of orthotropic electric conductance of CFRP laminates and analysis of the effect on delamination monitoring with an electric resistance change method. Compos. Sci. Technol. 2002, 62, 619-628. [CrossRef]

109. Kupke, M.; Schulte, K.; Schüler, R. Non-destructive testing of FRP by d.c. and a.c. electrical methods. Compos. Sci. Technol. 2001, 61, 837-847. [CrossRef]

110. Wang, X.; Chung, D.D.L. Self-monitoring of fatigue damage and dynamic strain in carbon fiber polymer-matrix composite. Compos. B Eng. 1998, 29, 63-73. [CrossRef]

111. Seo, D.; Lee, J. Damage detection of CFRP laminates using electrical resistance measurement and neural network. Compos. Struct. 1999, 47, 525-530. [CrossRef]

112. Irving, P.E.; Thiagarajan, C. Fatigue damage characterization in carbon fibre composite materials using an electrical potential technique. Smart Mater. Struct. 1998, 7, 456-466. [CrossRef]

113. Vavouliotis, A.; Paipetis, A.; Kostopoulos, V. On the fatigue life prediction of CFRP laminates using the Electrical Resistance Change method. Compos. Sci. Technol. 2011, 71, 630-642. [CrossRef]

114. Abry, J.C.; Choi, Y.K.; Chateauminois, A.; Dalloz, B.; Giraud, G.; Salvia, M. In-situ monitoring of damage in CFRP laminates by means of AC and DC measurements. Compos. Sci. Technol. 2001, 61, 855-864. [CrossRef]

115. Schueler, R.; Joshi, S.P.; Schulte, K. Damage detection in CFRP by electrical conductivity mapping. Compos. Sci. Technol. 2001, 61, 921-930. [CrossRef]

116. Kwon, D.-J.; Shin, P.-S.; Kim, J.-H.; Wang, Z.-J.; DeVries, K.L.; Park, J.-M. Detection of damage in cylindrical parts of carbon fiber/epoxy composites using electrical resistance (ER) measurements. Compos. Part B Eng. 2016, 99, 528-532. [CrossRef]

117. Todoroki, A. The effect of number of electrodes and diagnostic tool for monitoring the delamination of CFRP laminates by changes in electrical resistance. Compos. Sci. Technol. 2001, 61, 1871-1880. [CrossRef]

118. Abry, J.C.; Bochard, S.; Chateauminois, A.; Salvia, M.; Giraud, G. In situ detection of damage in CFRP laminates by electrical resistance measurements. Compos. Sci. Technol. 1999, 59, 925-935. [CrossRef]

119. Selvakumaran, L.; Long, Q.; Prudhomme, S.; Lubineau, G. On the detectability of transverse cracks in laminated composites using electrical potential change measurements. Compos. Struct. 2015, 121, 237-246. [CrossRef]

120. Selvakumaran, L.; Lubineau, G. Effect of voltage measurement on the quantitative identification of transverse cracks by electrical measurements. Sensors 2016, 16, 427. [CrossRef] 
121. Witten, E.; Kraus, T.; Kühnel, M. Composites Market Report 2015 Market Developments, Trends, Outlook and Challenges; Industrievereinigung Verstärkte Kunststoffe e.V., 2015; Available online: https:/ / eucia.eu/userfiles/files/Composites_Market\%20Report_2015 .pdf (accessed on 25 November 2021).

122. Gong, X.; Liu, J.; Baskaran, S.; Voise, R.D.; Young, J.S. Surfactant-assisted processing of carbon nanotube/polymer composites. Chem. Mater. 2000, 12, 1049-1052. [CrossRef]

123. Gojny, F.H.; Wichmann, M.; Fiedler, B.; Schulte, K. Influence of different carbon nanotubes on the mechanical properties of epoxy matrix composites-A comparative study. Compos. Sci. Technol. 2005, 65, 2300-2313. [CrossRef]

124. Gojny, F.H.; Wichmann, M.H.G.; Köpke, U.; Fiedler, B.; Schulte, K. Carbon nanotube-reinforced epoxy-composites: Enhanced stiffness and fracture toughness at low nanotube content. Compos. Sci. Technol. 2004, 64, 2363-2371. [CrossRef]

125. An, Q.; Rider, A.N.; Thostenson, E.T. Electrophoretic deposition of carbon nanotubes onto carbon-fiber fabric for production of carbon/epoxy composites with improved mechanical properties. Carbon 2012, 50, 4130-4143. [CrossRef]

126. Li, R.; Lachman, N.; Florin, P.; Wagner, H.D.; Wardle, B.L. Hierarchical carbon nanotube carbon fiber unidirectional composites with preserved tensile and interfacial properties. Compos. Sci. Technol. 2015, 117, 139-145. [CrossRef]

127. Spitalsky, Z.; Tasis, D.; Papagelis, K.; Galiotis, C. Carbon nanotube-polymer composites: Chemistry, processing, mechanical and electrical properties. Prog. Polym. Sci. 2010, 35, 357-401. [CrossRef]

128. Špitalský, Z.; Krontiras, C.A.; Georga, S.N.; Galiotis, C. Effect of oxidation treatment of multiwalled carbon nanotubes on the mechanical and electrical properties of their epoxy composites. Compos. Part A Appl. Sci. Manuf. 2009, 40, 778-783. [CrossRef]

129. Domun, N.; Hadavinia, H.; Zhang, T.; Sainsbury, T.; Liaghat, G.H.; Vahid, S. Improving the fracture toughness and the strength of epoxy using nanomaterials-a review of the current status. Nanoscale 2015, 7, 10294-10329. [CrossRef]

130. Li, C.; Thostenson, E.T.; Chou, T.W. Dominant role of tunneling resistance in the electrical conductivity of carbon nanotube-based composites. Appl. Phys. Lett. 2007, 91, 223114. [CrossRef]

131. Martin, C.A.; Sandler, J.K.W.; Shaffer, M.S.P.; Schwarz, M.K.; Bauhofer, W.; Schulte, K.; Windle, A.H. Formation of percolating networks in multi-wall carbon-nanotube-epoxy composites. Compos. Sci. Technol. 2004, 64, 2309-2316. [CrossRef]

132. Kim, H.S.; Jang, J.; Yu, J.; Kim, S.Y. Thermal conductivity of polymer composites based on the length of multi-walled carbon nanotubes. Compos. Part B Eng. 2015, 79, 505-512. [CrossRef]

133. Oliva-Avilés, A.I.; Avilés, F.; Seidel, G.D.; Sosa, V. On the contribution of carbon nanotube deformation to piezoresistivity of carbon nanotube/polymer composites. Compos. Part B Eng. 2013, 47, 200-206. [CrossRef]

134. Nam, T.H.; Goto, K.; Yamaguchi, Y.; Premalal, E.V.A.; Shimamura, Y.; Inoue, Y.; Naito, K.; Ogihara, S. Effects of CNT diameter on mechanical properties of aligned CNT sheets and composites. Compos. Part A Appl. Sci. Manuf. 2015, 76, 289-298. [CrossRef]

135. Ma, P.C.; Mo, S.Y.; Tang, B.Z.; Kim, J.K. Dispersion, interfacial interaction and re-agglomeration of functionalized carbon nanotubes in epoxy composites. Carbon 2010, 48, 1824-1834. [CrossRef]

136. Nam, T.H.; Goto, K.; Yamaguchi, Y.; Premalal, E.V.A.; Shimamura, Y.; Inoue, Y.; Arikawa, S.; Yoneyama, S.; Ogihara, S. Improving mechanical properties of high volume fraction aligned multi-walled carbon nanotube/epoxy composites by stretching and pressing. Compos. Part B Eng. 2016, 85, 15-23. [CrossRef]

137. Gardea, F.; Lagoudas, D.C. Characterization of electrical and thermal properties of carbon nanotube/epoxy composites. Compos. Part B Eng. 2014, 56, 611-620. [CrossRef]

138. Gojny, F.H.; Wichmann, M.H.G.; Fiedler, B.; Kinloch, I.A.; Bauhofer, W.; Windle, A.H.; Schulte, K. Evaluation and identification of electrical and thermal conduction mechanisms in carbon nanotube/epoxy composites. Polymer 2006, 47, 2036-2045. [CrossRef]

139. Gojny, F.H.; Wichmann, M.H.G.; Fiedler, B.; Bauhofer, W.; Schulte, K. Influence of nano-modification on the mechanical and electrical properties of conventional fibre-reinforced composites. Compos. A Appl. Sci. Manuf. 2005, 36, 1525-1535. [CrossRef]

140. Fidelus, J.D.; Wiesel, E.; Gojny, F.H.; Schulte, K.; Wagner, H.D. Thermo-mechanical properties of randomly oriented carbon/epoxy nanocomposites. Compos. Part A Appl. Sci. Manuf. 2005, 36, 1555-1561. [CrossRef]

141. Bautista-Quijano, J.R.; Pötschke, P.; Brünig, H.; Heinrich, G. Strain sensing, electrical and mechanical properties of polycarbonate/multiwall carbon nanotube monofilament fibers fabricated by melt spinning. Polymer 2016, 82, 181-189. [CrossRef]

142. Alexopoulos, N.D.; Jaillet, C.; Zakri, C.; Poulin, P.; Kourkoulis, S.K. Improved strain sensing performance of glass fiber polymer composites with embedded pre-stretched polyvinyl alcohol-carbon nanotube fibers. Carbon 2013, 59, 65-75. [CrossRef]

143. Alexopoulos, N.D.; Bartholome, C.; Poulin, P.; Marioli-Riga, Z. Structural health monitoring of glass fiber reinforced composites using embedded carbon nanotube (CNT) fibers. Compos. Sci. Technol. 2010, 70, 260-271. [CrossRef]

144. Zamora-Ledezma, C.; Blanc, C.; Puech, N.; Maugey, M.; Zakri, C.; Anglaret, E.; Poulin, P. Conductivity anisotropy of assembled and oriented carbon nanotubes. Phys. Rev. E 2011, 84, 062701. [CrossRef] [PubMed]

145. Robert, C.; Pillin, I.; Castro, M.; Feller, J.F. Multifunctional carbon nanotubes enhanced structural composites with improved toughness and damage monitoring. J. Compos. Sci. 2019, 3, 109. [CrossRef]

146. Ma, P.C.; Siddiqui, N.A.; Marom, G.; Kim, J.K. Dispersion and functionalization of carbon nanotubes for polymer-based nanocomposites: A review. Compos. Part A Appl. Sci. Manuf. 2010, 41, 1345-1367. [CrossRef]

147. Hong, S.; Kim, D.; Lee, S.; Kim, B.-W.; Theilmann, P.; Park, S.-H. Enhanced thermal and mechanical properties of carbon nanotube composites through the use of functionalized CNT-reactive polymer linkages and three-roll milling. Compos. Part A Appl. Sci. Manuf. 2015, 77, 142-146. [CrossRef]

148. Geng, Y.; Liu, M.Y.; Li, J.; Shi, X.M.; Kim, J.K. Effects of surfactant treatment on mechanical and electrical properties of CNT/epoxy nanocomposites. Compos. Part A Appl. Sci. Manuf. 2008, 39, 1876-1883. [CrossRef] 
149. Ladani, R.B.; Wu, S.; Kinloch, A.J.; Ghorbani, K.; Zhang, J.; Mouritz, A.P.; Wang, C.H. Improving the toughness and electrical conductivity of epoxy nanocomposites by using aligned carbon nanofibres. Compos. Sci. Technol. 2015, 117, 146-158. [CrossRef]

150. Mecklenburg, M.; Mizushima, D.; Ohtake, N.; Bauhofer, W.; Fiedler, B.; Schulte, K. On the manufacturing and electrical and mechanical properties of ultra-high wt.\% fraction aligned MWCNT and randomly oriented CNT epoxy composites. Carbon 2015, 91, 275-290. [CrossRef]

151. Hu, N.; Karube, Y.; Arai, M.; Watanabe, T.; Yan, C.; Li, Y.; Liu, Y.; Fukunaga, H. Investigation on sensitivity of a polymer/carbon nanotube composite strain sensor. Carbon 2010, 48, 680-687. [CrossRef]

152. Liu, P.; Lam, A.; Fan, Z.; Tran, T.Q.; Duong, H.M. Advanced multifunctional properties of aligned carbon nanotube-epoxy thin film composites. Mater. Des. 2015, 87, 600-605. [CrossRef]

153. Feller, J.F.; Kumar, B.; Castro, M. Conductive biopolymer nanocomposites for sensors. In Nanocomposites with Biodegradable Polymers: Synthesis, Properties \& Future Perspectives; Mital, V., Ed.; Oxford University Press: Oxford, UK, 2011; pp. 368-399. ISBN 978-0-19-958192-4.

154. Ambrosetti, G.; Grimaldi, C.; Balberg, I.; Maeder, T.; Danani, A.; Ryser, P. Solution of the tunneling-percolation problem in the nanocomposite regime. Phys. Rev. B 2010, 81, 155434. [CrossRef]

155. Stauffer, D.; Aharony, A. Introduction to Percolation Theory; Taylor \& Francis: Abingdon-on-Thame, UK, 1994; Volume 6, ISBN 1420074792.

156. Feller, J.F.; Castro, M.; Kumar, B. Polymer-carbon nanotube conductive nanocomposites for sensing. In Polymer-Carbon Nanotube Composites: Preparation, Properties \& Applications; McNally, T., Pötschke, P., Eds.; Woodhead Publishing Limited: Swaston, UK, 2011; pp. 760-803. ISBN 9781845697617.

157. Bauhofer, W.; Kovacs, J.Z. A review and analysis of electrical percolation in carbon nanotube polymer composites. Compos. Sci. Technol. 2009, 69, 1486-1498. [CrossRef]

158. Bai, J.B.; Allaoui, A. Effect of the length and the aggregate size of MWNTs on the improvement efficiency of the mechanical and electrical properties of nanocomposites-experimental investigation. Compos. Part A Appl. Sci. Manuf. 2003, 34, 689-694. [CrossRef]

159. Kim, Y.J.; Shin, T.S.; Choi, H.D.; Kwon, J.H.; Chung, Y.C.; Yoon, H.G. Electrical conductivity of chemically modified multiwalled carbon nanotube/epoxy composites. Carbon 2005, 43, 23-30. [CrossRef]

160. Ma, P.C.; Kim, J.K.; Tang, B.Z. Effects of silane functionalization on the properties of carbon nanotube/epoxy nanocomposites. Compos. Sci. Technol. 2007, 67, 2965-2972. [CrossRef]

161. Theodore, M.; Hosur, M.; Thomas, J.; Jeelani, S. Influence of functionalization on properties of MWCNT-epoxy nanocomposites. Mater. Sci. Eng. A 2011, 528, 1192-1200. [CrossRef]

162. Xie, X.; Mai, Y.; Zhou, X. Dispersion and alignment of carbon nanotubes in polymer matrix: A review. Mater. Sci. Eng. Reports 2005, 49, 89-112. [CrossRef]

163. Rosca, I.D.; Hoa, S.V. Highly conductive multiwall carbon nanotube and epoxy composites produced by three-roll milling. Carbon 2009, 47, 1958-1968. [CrossRef]

164. Meeuw, H.; Viets, C.; Liebig, W.V.; Schulte, K.; Fiedler, B. Morphological influence of carbon nanofillers on the piezoresistive response of carbon nanoparticle/epoxy composites under mechanical load. Eur. Polym. J. 2016, 85, 198-210. [CrossRef]

165. Fernández Sánchez-Romate, X.X.; Jiménez-Suárez, A.; Sánchez, M.; Güemes, A.; Ureña, A. Novel approach to percolation threshold on electrical conductivity of carbon nanotube reinforced nanocomposites. RSC Adv. 2016, 6, 43418-43428. [CrossRef]

166. Du, F.; Fischer, J.E.; Winey, K.I. Effect of nanotube alignment on percolation conductivity in carbon nanotube/polymer composites. Phys. Rev. B 2005, 72, 121404. [CrossRef]

167. Hu, N.; Karube, Y.; Yan, C.; Masuda, Z.; Fukunaga, H. Tunneling effect in a polymer/carbon nanotube nanocomposite strain sensor. Acta Mater. 2008, 56, 2929-2936. [CrossRef]

168. Li, Z.; Dharap, P.; Nagarajaiah, S.; Barrera, E.V.; Kim, J.D. Carbon Nanotube Film Sensors. Adv. Mater. 2004, 16, 640-643. [CrossRef]

169. Barrera, E.V.; Nagarajaiah, S.; Dharap, P.; Zhiling, L.; Kim, J.D. Smart Materials: Strain Sensing and Stress Determination by Means of Nanotube Sensing Systems, Composites, and Devices. 2010. Available online: https:/ / patentimages.storage.googleapis. com/86/cd/4e/901c7b0b2dc158/US7730547.pdf (accessed on 25 November 2021).

170. Rein, M.D.; Breuer, O.; Wagner, H.D. Sensors and sensitivity: Carbon nanotube buckypaper films as strain sensing devices Compos. Sci. Technol. 2011, 71, 373-381. [CrossRef]

171. Pillin, I.; Castro, M.; Nag-Chowdhury, S.; Feller, J.F. Robustness of carbon nanotube-based sensor to probe composites' interfacial damage in situ. J. Compos. Mater. 2016, 50, 109-113. [CrossRef]

172. Xu, W.; Chen, Y.; Zhan, H.; Wang, J.N. High-Strength Carbon Nanotube Film from Improving Alignment and Densification. Nano Lett. 2016, 16, 946-952. [CrossRef]

173. Liu, L.; Wu, J.; Zhou, Y. Enhanced delamination initiation stress and monitoring sensitivity of quasi-isotropic laminates under in-plane tension by interleaving with CNT buckypaper. Compos. Part A Appl. Sci. Manuf. 2016, 89, 10-17. [CrossRef]

174. Aly, K.; Li, A.; Bradford, P.D. Compressive piezoresistive behavior of carbon nanotube sheets embedded in woven glass fiber reinforced composites. Compos. Part B Eng. 2016, 116, 459-470. [CrossRef]

175. Aly, K.; Li, A.; Bradford, P.D. Strain sensing in composites using aligned carbon nanotube sheets embedded in the interlaminar region. Compos. Part A Appl. Sci. Manuf. 2016, 90, 536-548. [CrossRef] 
176. Wang, X.; Lu, S.; Ma, K.; Xiong, X.; Zhang, H.; Xu, M. Tensile strain sensing of buckypaper and buckypaper composites. Mater. Des. 2015, 88, 414-419. [CrossRef]

177. Hoang, P.T.; Liu, T. Diazonium salt treated single-walled carbon nanotube thin films with high piezoresistive sensitivity. Sensors Actuators A Phys. 2016, 250, 106-113. [CrossRef]

178. Liu, W.; Wei, B.; Xu, F. Investigation on the mechanical and electrical properties of carbon nanotube/epoxy composites produced by resin transfer molding. J. Compos. Mater. 2017, 51, 2035-2043. [CrossRef]

179. Fiedler, B.; Gojny, F.H.; Wichmann, M.H.G.; Bauhofer, W.; Schulte, K. Can carbon nanotubes be used to sense damage in composites? Ann. Chim. Sci. Matériaux 2004, 29, 81-94. [CrossRef]

180. Thostenson, E.T.; Chou, T.W. Processing-structure-multi-functional property relationship in carbon nanotube/epoxy composites. Carbon 2006, 44, 3022-3029. [CrossRef]

181. Gao, L.; Chou, T.W.; Thostenson, E.T.; Zhang, Z.; Coulaud, M. In situ sensing of impact damage in epoxy/glass fiber composites using percolating carbon nanotube networks. Carbon 2011, 49, 3382-3385. [CrossRef]

182. Gao, L.; Chou, T.W.; Thostenson, E.T.; Zhang, Z. A comparative study of damage sensing in fiber composites using uniformly and non-uniformly dispersed carbon nanotubes. Carbon 2010, 48, 3788-3794. [CrossRef]

183. Li, C.; Chou, T.W. Modeling of damage sensing in fiber composites using carbon nanotube networks. Compos. Sci. Technol. 2008, 68, 3373-3379. [CrossRef]

184. Ahmed, S.; Doshi, S.; Schumacher, T.; Thostenson, E.T.; McConnell, J. Development of a novel integrated strengthening and sensing methodology for steel structures using CNT-based composites. J. Struct. Eng. 2017, 143, 04016202. [CrossRef]

185. Thostenson, E.T.; Chou, T.W. Carbon nanotube-based health monitoring of mechanically fastened composite joints. Compos. Sci. Technol. 2008, 68, 2557-2561. [CrossRef]

186. Thostenson, E.T.; Chou, T.W. Real-time in situ sensing of damage evolution in advanced fiber composites using carbon nanotube networks. Nanotechnology 2008, 19, 215713. [CrossRef]

187. Gao, L.; Thostenson, E.T.; Zhang, Z.; Chou, T.W. Sensing of damage mechanisms in fiber-reinforced composites under cyclic loading using carbon nanotubes. Adv. Funct. Mater. 2009, 19, 123-130. [CrossRef]

188. Gao, L.; Thostenson, E.T.; Zhang, Z.; Chou, T.W. Coupled carbon nanotube network and acoustic emission monitoring for sensing of damage development in composites. Carbon 2009, 47, 1381-1388. [CrossRef]

189. Dai, H.; Thostenson, E.T.; Schumacher, T. Processing and characterization of a novel distributed strain sensor using carbon nanotube-based nonwoven composites. Sensors 2015, 15, 17728-17747. [CrossRef] [PubMed]

190. Bekas, D.G.; Paipetis, A.S. Damage monitoring in nanoenhanced composites using impedance spectroscopy. Compos. Sci. Technol. 2016, 134, 96-105. [CrossRef]

191. Bekas, D.G.; Paipetis, A.S. Study of the Effect of Damage on the Electrical Impedance of Carbon Nanotube Reinforced Epoxy Nanocomposites. J. Sens. 2015, 2015, 805303. [CrossRef]

192. Sanli, A.; Müller, C.; Kanoun, O.; Elibol, C.; Wagner, M.F.X. Piezoresistive characterization of multi-walled carbon nanotube-epoxy based flexible strain sensitive films by impedance spectroscopy. Compos. Sci. Technol. 2016, 122, 18-26. [CrossRef]

193. Baltopoulos, A.; Vavouliotis, A.; Kostopoulos, V. Exploiting carbon nanotube networks for damage assessment of structural composites. In Proceedings of the ECCM16-16th European Conference on Composite Materials, Seville, Spain, 22-27 June 2014; pp. 22-26.

194. Baltopoulos, A.; Polydorides, N.; Pambaguian, L.; Vavouliotis, A.; Kostopoulos, V. Exploiting carbon nanotube networks for damage assessment of fiber reinforced composites. Compos. B Eng. 2015, 76, 149-158. [CrossRef]

195. Gallo, G.J.; Thostenson, E.T. Spatial damage detection in electrically anisotropic fiber-reinforced composites using carbon nanotube networks. Compos. Struct. 2016, 141, 14-23. [CrossRef]

196. Dai, H.; Gallo, G.J.; Schumacher, T.; Thostenson, E.T. A novel methodology for spatial damage detection and imaging using a distributed carbon nanotube-based composite sensor combined with electrical impedance tomography. J. Nondestruct. Eval. 2016, 35, 26. [CrossRef]

197. Naghashpour, A.; Van Hoa, S. Motion of carbon nanotubes based polymer nanocomposites subjected to multi-directional deformation. Polym. Test. 2016, 55, 109-114. [CrossRef]

198. Sarvestani, H.Y.; Naghashpour, A. Investigation of Through-Thickness Stresses in Composite Laminates Using Layerwise Theory method and the integral equation theory were used by. Int. J. Eng. Math. 2013, 2013, 11. [CrossRef]

199. Naghashpour, A.; Van Hoa, S. A technique for real-time detecting, locating, and quantifying damage in large polymer composite structures made of carbon fibers and carbon nanotube networks. Struct. Health Monit. An. Int. J. 2015, 14, 35-45. [CrossRef]

200. Naghashpour, A.; Hoa, S. Van In situ monitoring of through-thickness strain in glass fiber/epoxy composite laminates using carbon nanotube sensors. Compos. Sci. Technol. 2013, 78, 41-47. [CrossRef]

201. Naghashpour, A.; Van Hoa, S. A technique for real-time detection, location and quantification of damage in large polymer composite structures made of electrically non-conductive fibers and carbon nanotube networks. Nanotechnology 2013, $24,455502$. [CrossRef]

202. Van Hoa, S.; Naghashpour, A. Method and System for Detecting and Locating Damages in Composite Structures. 20 June 2013 , p. 81. Available online: https:/ / patentimages.storage.googleapis.com/30/d2/15/faf0102a4c2638/WO2013086626A1.pdf (accessed on 25 November 2021). 
203. Viets, C.; Kaysser, S.; Schulte, K. Damage mapping of GFRP via electrical resistance measurements using nanocomposite epoxy matrix systems. Compos. B Eng. 2014, 65, 80-88. [CrossRef]

204. Chiacchiarelli, L.M.; Rallini, M.; Monti, M.; Puglia, D.; Kenny, J.M.; Torre, L. The role of irreversible and reversible phenomena in the piezoresistive behavior of graphene epoxy nanocomposites applied to structural health monitoring. Compos. Sci. Technol. 2013, 80, 73-79. [CrossRef]

205. Robert, C.; Feller, J.F.; Castro, M. Sensing skin for strain monitoring made of PC-CNT conductive polymer nanocomposite sprayed layer by layer. ACS Appl. Mater. Interfaces 2012, 4, 3508-3516. [CrossRef]

206. Kanoun, O.; Benchirouf, A.; Sanli, A.; Bouhamed, A.; Bu, L. Potential of Flexible Carbon Nanotube Films for High Performance Strain and Pressure Sensors. In Nanotechnology for Optics and Sensors; One Central Press: Altrincham, UK, $2014 ;$ pp. 148-183.

207. Sanli, A.; Benchirouf, A.; Müller, C.; Kanoun, O. Piezoresistive performance characterization of strain sensitive multi-walled carbon nanotube-epoxy nanocomposites. Sens. Actuators A Phys. 2017, 254, 61-68. [CrossRef]

208. Bouhamed, A.; Müller, C.; Choura, S.; Kanoun, O. Processing and characterization of MWCNTs/epoxy nanocomposites thin films for strain sensing applications. Sens. Actuators A Phys. 2017, 257, 65-72. [CrossRef]

209. Nag-Chowdhury, S.; Bellégou, H.; Pillin, I.; Castro, M.; Longrais, P.; Feller, J.F. Non-intrusive health monitoring of infused composites with embedded carbon quantum piezo-resistive sensors. Compos. Sci. Technol. 2016, 123, 286-294. [CrossRef]

210. Michelis, F.; Bodelot, L.; Bonnassieux, Y.; Lebental, B. Highly reproducible, hysteresis-free, flexible strain sensors by inkjet printing of carbon nanotubes. Carbon 2015, 95, 1020-1026. [CrossRef]

211. Kaiyan, H.; Weifeng, Y.; Shuying, T.; Haidong, L. A fabrication process to make CNT/EP composite strain sensors. High Perform. Polym. 2018, 30, 224-229. [CrossRef]

212. Zhang, H.; Bilotti, E.; Peijs, T. The use of carbon nanotubes for damage sensing and structural health monitoring in laminated composites: A review. Nanocomposites 2015, 1, 177-194. [CrossRef]

213. Zhang, J.; Zhuang, R.; Liu, J.; Mäder, E.; Heinrich, G.; Gao, S. Functional interphases with multi-walled carbon nanotubes in glass fibre/epoxy composites. Carbon 2010, 48, 2273-2281. [CrossRef]

214. Gao, S.L.; Zhuang, R.C.; Zhang, J.; Liu, J.W.; Mäder, E. Glass fibers with carbon nanotube networks as multifunctional sensors Adv. Funct. Mater. 2010, 20, 1885-1893. [CrossRef]

215. Siddiqui, N.A.; Li, E.L.; Sham, M.; Zhong, B.; Lin, S.; Mäder, E.; Kim, J. Tensile strength of glass fibres with carbon nanotubeepoxy nanocomposite coating: Effects of CNT morphology and dispersion state. Compos. Part A 2010, 41, 539-548. [CrossRef]

216. Zhang, J.; Liu, J.; Zhuang, R.; Mäder, E.; Heinrich, G.; Gao, S. Single MWNT-Glass Fiber as Strain Sensor and Switch. Adv. Mater. 2011, 23, 3392-3397. [CrossRef] [PubMed]

217. Sarkar, P.; Nicholson, P.S. Electrophoretic Deposition (EPD): Mechanisms, Kinetics, and Application to Ceramics. J. Am. Ceram. Soc. 1996, 79, 1987-2002. [CrossRef]

218. Nguyen, F.N.; Yoshioka, K. Conductive Fiber Reinforced Polymer Composite and Multifunctional Composite. Patent $\mathrm{n}^{\circ}$ TW201443120 (A), 11 October 2017.

219. Sebastian, J.; Schehl, N.; Bouchard, M.; Boehle, M.; Li, L.; Lagounov, A.; Lafdi, K. Health monitoring of structural composites with embedded carbon nanotube coated glass fiber sensors. Carbon 2014, 66, 191-200. [CrossRef]

220. He, D.; Fan, B.; Zhao, H.; Lu, X.; Yang, M.; Liu, Y.; Bai, J. Design of electrically conductive structural composites by modulating aligned CVD-grown carbon nanotube length on glass fibers. ACS Appl. Mater. Interfaces 2017, 9, 2948-2958. [CrossRef]

221. Mehdikhani, M.; Matveeva, A.; Aravand, M.A.; Wardle, B.L.; Lomov, S.V.; Gorbatikh, L. Strain mapping at the micro-scale in hierarchical polymer composites with aligned carbon nanotube grafted fibers. Compos. Sci. Technol. 2016, 137, 24-34. [CrossRef]

222. Boehle, M.; Pianca, P.; Lafdi, K.; Chinesta, F. Modeling of an embedded carbon nanotube based composite strain sensor. Adv. Aircr. Spacecr. Sci. 2015, 2, 263-273. [CrossRef]

223. Boehle, M.; Jiang, Q.; Li, L.; Lagounov, A.; Lafdi, K. Carbon nanotubes grown on glass fiber as a strain sensor for real time structural health monitoring. Int. J. Smart Nano Mater. 2012, 3, 162-168. [CrossRef]

224. Li, Y.; Luo, S.; Yang, M.-C.; Liang, R.; Zeng, C. Poisson Ratio and Piezoresistive Sensing: A New Route to High-Performance 3D Flexible and Stretchable Sensors of Multimodal Sensing Capability. Adv. Funct. Mater. 2016, 26, 201505070. [CrossRef]

225. Gong, S.; Zhu, Z.H.; Meguid, S.A. Carbon nanotube agglomeration effect on piezoresistivity of polymer nanocomposites. Polymer 2014, 55, 5488-5499. [CrossRef]

226. Luo, S.; Obitayo, W.; Liu, T. SWCNT-thin-film-enabled fiber sensors for lifelong structural health monitoring of polymeric composites-From manufacturing to utilization to failure. Carbon 2014, 76, 321-329. [CrossRef]

227. Luo, S.; Liu, T. Piezoresistive Sensors and Methods. US20150248159A1, 2015. Available online: https://patents.google.com/ patent/US20150248159A1/en (accessed on 25 November 2021).

228. Accorsi, J.V. The Impact of Carbon Black Morphology and Dispersion on the Weatherability of polyethylene. Kautsch. Gummi Kunstst. 2001, 54, 321-326.

229. Available online: http:/ / www.angstronmaterials.com (accessed on 25 November 2021).

230. Available online: http:/ / www.nanocyl.com (accessed on 25 November 2021).

231. Frasca, D.; Schulze, D.; Wachtendorf, V.; Huth, C.; Schartel, B. Multifunctional multilayer graphene/elastomer nanocomposites. Eur. Polym. J. 2015, 71, 99-113. [CrossRef]

232. Jia, J.; Du, X.; Chen, C.; Sun, X.; Mai, Y.; Kim, J. 3D network graphene interlayer for excellent interlaminar toughness and strength in fiber reinforced composites. Carbon 2015, 95, 978-986. [CrossRef] 
233. Yasmin, A.; Daniel, I.M. Mechanical and thermal properties of graphite platelet/epoxy composites. Polymer 2004, 45, 8211-8219. [CrossRef]

234. Saleem, H.; Edathil, A.; Ncube, T.; Pokhrel, J.; Khoori, S.; Abraham, A.; Mittal, V. Mechanical and thermal properties of thermoset-graphene nanocomposites. Macromol. Mater. Eng. 2016, 301, 231-259. [CrossRef]

235. Kumar, P.; Yu, S.; Shahzad, F.; Hong, S.M.; Kim, Y.-H.; Koo, C.M. Ultrahigh electrically and thermally conductive self-aligned graphene/polymer composites using large-area reduced graphene oxides. Carbon 2016, 101, 120-128. [CrossRef]

236. Debelak, B.; Lafdi, K. Use of exfoliated graphite filler to enhance polymer physical properties. Carbon 2007, 45, 1727-1734. [CrossRef]

237. Shen, J.T.; Buschhorn, S.; De Hosson, J.T.M.; Schulte, K.; Fiedler, B. Pressure and temperature induced electrical resistance change in nano-carbon/epoxy composites. Compos. Sci. Technol. 2015, 115, 1-8. [CrossRef]

238. Novák, I.; Krupa, I. Electro-conductive resins filled with graphite for casting applications. Eur. Polym. J. 2004, 40, 1417-1422. [CrossRef]

239. Moriche, R.; Sánchez, M.; Jiménez-Suárez, A.; Prolongo, S.G.; Ureña, A. Strain monitoring mechanisms of sensors based on the addition of graphene nanoplatelets into an epoxy matrix. Compos. Sci. Technol. 2016, 123, 65-70. [CrossRef]

240. Wichmann, M.H.G.; Buschhorn, S.T.; Gehrmann, J.; Schulte, K. Piezoresistive response of epoxy composites with carbon nanoparticles under tensile load. Phys. Rev. B 2009, 80, 245437. [CrossRef]

241. Nanni, F.; Ruscito, G.; Puglia, D.; Terenzi, A.; Kenny, J.M.; Gusmano, G. Effect of carbon black nanoparticle intrinsic properties on the self-monitoring performance of glass fibre reinforced composite rods. Compos. Sci. Technol. 2011, 71, 1-8. [CrossRef]

242. Nanni, F.; Auricchio, F.; Sarchi, F.; Forte, G.; Gusmano, G. Self-sensing CF-GFRP rods as mechanical reinforcement and sensors of concrete beams. Smart Mater. Struct. 2006, 15, 182-186. [CrossRef]

243. Nanni, F.; Ruscito, G.; Forte, G.; Gusmano, G. Design, manufacture and testing of self-sensing carbon fibre-glass fibre reinforced polymer rods. Smart Mater. Struct. 2007, 16, 2368-2374. [CrossRef]

244. Feller, J.F.; Linossier, I. Mechanical and rheological properties of poly(ethylene-co-ethyl acrylate) as a function of carbon black content. Macromol. Symp. 2003, 203, 317-324. [CrossRef]

245. Droval, G.; Feller, J.F.; Salagnac, P.; Glouannec, P. Rheological properties of conductive polymer composite (CPC) filled with double percolated network of carbon nanoparticles and boron nitride powder. e-Polymers 2009, 9, 1-17. [CrossRef]

246. Lagrève, C.; Feller, J.F.; Linossier, I.; Levesque, G. Poly(butylene terephthalate)/ poly(ethylene-co-alkyl acrylate)/ carbon black conductive composites: Influence of composition and morphology on electrical properties. Polym. Eng. Sci. 2001, 41, 1124-1132. [CrossRef]

247. Pillin, I.; Feller, J.F. Influence of carbon-black nanoparticles on poly (butylene terephthalate) fractionated crystallization in bicomponent poly (butylene terephthalate)/poly (ethylene-co-ethyl acrylate) blends. Macromol. Mater. Eng. 2006, 291, 1375-1387. [CrossRef]

248. Szeluga, U.; Kumanek, B.; Trzebicka, B. Synergy in hybrid polymer/nanocarbon composites: A review. Compos. Part A Appl. Sci. Manuf. 2015, 73, 204-231. [CrossRef]

249. Flandin, L.; Chang, A.; Nazarenko, S.; Hiltner, A.; Baer, E. Effect of strain on the properties of an ethylene-octene elastomer with conductive carbon fillers. J. Appl. Polym. Sci. 2000, 76, 894-905. [CrossRef]

250. Zavickis, J.; Knite, M.; Podins, G.; Linarts, A.; Orlovs, R. Polyisoprene-nanostructured carbon composite-A soft alternative for pressure sensor application. Sens. Actuators A Phys. 2011, 171, 38-42. [CrossRef]

251. Knite, M.; Teteris, V.; Kiploka, A.; Kaupuzs, J. Polyisoprene-carbon black nanocomposites as tensile strain and pressure sensor materials. Sensors Actuators A Phys. 2004, 110, 142-149. [CrossRef]

252. Wang, P.; Ding, T. Conductivity and piezoresistivity of conductive carbon black filled polymer composite. J. Appl. Polym. Sci. 2010, 116, 2035-2039. [CrossRef]

253. Huang, M.; Tunnicliffe, L.B.; Zhuang, J.; Ren, W.; Yan, H.; Busfield, J.J.C. Strain-dependent dielectric behavior of carbon black reinforced natural rubber. Macromolecules 2016, 49, 2339-2347. [CrossRef]

254. Sengupta, R.; Bhattacharya, M.; Bandyopadhyay, S.; Bhowmick, A.K. A review on the mechanical and electrical properties of graphite and modified graphite reinforced polymer composites. Prog. Polym. Sci. 2011, 36, 638-670. [CrossRef]

255. Jia, W.; Tchoudakov, R.; Narkis, M.; Siegmann, A. Performance of expanded graphite and expanded milled-graphite fillers in thermosetting resins. Polym. Compos. 2005, 26, 526-533. [CrossRef]

256. Zheng, G.; Wu, J.; Wang, W.; Pan, C. Characterizations of expanded graphite/polymer composites prepared by in situ polymerization. Carbon 2004, 42, 2839-2847. [CrossRef]

257. Chandrasekaran, S.; Seidel, C.; Schulte, K. Preparation and characterization of graphite nano-platelet (GNP)/epoxy nanocomposite: Mechanical, electrical and thermal properties. Eur. Polym. J. 2013, 49, 3878-3888. [CrossRef]

258. Li, J.; Kim, J.-K. Percolation threshold of conducting polymer composites containing 3D randomly distributed graphite nanoplatelets. Compos. Sci. Technol. 2007, 67, 2114-2120. [CrossRef]

259. Moriche, R.; Sánchez, M.; Jiménez-Suárez, A.; Prolongo, S.G.; Ureña, A. Electrically conductive functionalized-GNP/epoxy based composites: From nanocomposite to multiscale glass fibre composite material. Compos. Part B Eng. 2016, 98, 49-55. [CrossRef]

260. Li, H.B.; Wang, X. Nonlinear dynamic characteristics of graphene/piezoelectric laminated films in sensing moving loads. Sensors Actuators A Phys. 2016, 238, 80-94. [CrossRef] 
261. Zha, J.-W.; Zhang, B.; Li, R.K.Y.; Dang, Z.-M. High-performance strain sensors based on functionalized graphene nanoplates for damage monitoring. Compos. Sci. Technol. 2016, 123, 32-38. [CrossRef]

262. Liu, Y.; Zhang, D.; Wang, K.; Liu, Y.; Shang, Y. A novel strain sensor based on graphene composite films with layered structure. Compos. Part A Appl. Sci. Manuf. 2016, 80, 95-103. [CrossRef]

263. Moriche, R.; Sánchez, M.; Prolongo, S.G.; Jiménez-Suárez, A.; Ureña, A. Reversible phenomena and failure localization in self-monitoring GNP/epoxy nanocomposites. Compos. Struct. 2016, 136, 101-105. [CrossRef]

264. Liu, H.; Li, Y.; Dai, K.; Zheng, G.; Liu, C.; Shen, C.; Yan, X.; Guo, J.; Guo, Z. Electrically conductive thermoplastic elastomer nanocomposites at ultralow graphene loading levels for strain sensor applications. J. Mater. Chem. C 2016, 4, 157-166. [CrossRef]

265. Sanchez, M.; Moriche, R.; Prolongo, S.G.; Rams, J.; Ureña, A. Graphene Nanocomposites as Strain-Damage Sensor. In Proceedings of the Eccm16-16th European Conference on Composite Materials, Seville, Spain, 22-26 June 2014.

266. Rinaldi, A.; Proietti, A.; Tamburrano, A.; Ciminello, M.; Sarto, M.S. Graphene-Based Strain Sensor Array on Carbon Fiber Composite Laminate. IEEE Sens. J. 2015, 15, 7295-7303. [CrossRef]

267. Du, X.; Zhou, H.; Sun, W.; Liu, H.-Y.; Zhou, G.; Zhou, H.; Mai, Y.-W. Graphene/epoxy interleaves for delamination toughening and monitoring of crack damage in carbon fibre/epoxy composite laminates. Compos. Sci. Technol. 2017, 140, 123-133. [CrossRef]

268. Ashby, M.F.; Bréchet, Y.J.M. Designing hybrid materials. Acta Mater. 2003, 51, 5801-5821. [CrossRef]

269. Ma, P.-C.; Liu, M.-Y.; Zhang, H.; Wang, S.-Q.; Wang, R.; Wang, K.; Wong, Y.-K.; Tang, B.-Z.; Hong, S.-H.; Paik, K.-W.; et al. Enhanced Electrical Conductivity of Nanocomposites Containing Hybrid Fillers of Carbon Nanotubes and Carbon Black. ACS Appl. Mater. Interfaces 2009, 1, 1090-1096. [CrossRef] [PubMed]

270. Sumfleth, J.; Adroher, X.C.; Schulte, K. Synergistic effects in network formation and electrical properties of hybrid epoxy nanocomposites containing multi-wall carbon nanotubes and carbon black. J. Mater. Sci. 2009, 44, 3241-3247. [CrossRef]

271. Sun, Y.; Bao, H.D.H.-D.; Guo, Z.X.Z.-X.; Yu, J. Modeling of the Electrical Percolation of Mixed Carbon Fillers in Polymer-Based Composites. Macromolecules 2009, 42, 459-463. [CrossRef]

272. Wei, T.; Song, L.; Zheng, C.; Wang, K.; Yan, J.; Shao, B.; Fan, Z.J. The synergy of a three filler combination in the conductivity of epoxy composites. Mater. Lett. 2010, 64, 2376-2379. [CrossRef]

273. Li, J.; Wong, P.-S.; Kim, J.-K. Hybrid nanocomposites containing carbon nanotubes and graphite nanoplatelets. Mater. Sci. Eng. A 2008, 483-484, 660-663. [CrossRef]

274. Yu, A.; Ramesh, P.; Sun, X.; Bekyarova, E.; Itkis, M.E.; Haddon, R.C. Enhanced Thermal Conductivity in a Hybrid Graphite Nanoplatelet-Carbon Nanotube Filler for Epoxy Composites. Adv. Mater. 2008, 20, 4740-4744. [CrossRef]

275. Yang, S.-Y.; Lin, W.-N.; Huang, Y.-L.; Tien, H.-W.; Wang, J.-Y.; Ma, C.C.; Li, S.-M.; Wang, Y.-S. Synergetic effects of graphene platelets and carbon nanotubes on the mechanical and thermal properties of epoxy composites. Carbon 2011, 49, 793-803. [CrossRef]

276. Chatterjee, S.; Nafezarefi, F.; Tai, N.H.; Schlagenhauf, L.; Nüesch, F.A.; Chu, B.T.T. Size and synergy effects of nanofiller hybrids including graphene nanoplatelets and carbon nanotubes in mechanical properties of epoxy composites. Carbon 2012, 50, 5380-5386. [CrossRef]

277. Zhao, H.; Bai, J. Highly sensitive piezo-resistive graphite nanoplatelet-carbon nanotube hybrids/polydimethylsilicone composites with improved conductive network construction. ACS Appl. Mater. Interfaces 2015, 7, 9652-9659. [CrossRef]

278. Liu, P.; Huang, Y.; Liu, C.; Wang, Y.; Guo, X.; Zhang, Y.; Ge, Y. Enhanced electrical conductivity and mechanical stability of flexible pressure-sensitive GNPs/CB/SR composites: Synergistic effects of GNPs and CB. J. Mater. Res. 2015, 30, 3394-3402. [CrossRef]

279. Tran, M.T.; Tung, T.T.; Sachan, A.; Losic, D.; Castro, M.; Feller, J.F. 3D sprayed polyurethane functionalized graphene/carbon nanotubes hybrid architectures to enhance the piezo-resistive response of quantum resistive pressure sensors. Carbon 2020, 168, 564-579. [CrossRef]

280. Ke, K.; Yue, L.; Shao, H.; Yang, M.; Yang, W.; Manas-Zloczower, I. Boosting electrical and piezoresistive properties of polymer nanocomposites via hybrid carbon fillers: A review. Carbon 2020, 173, 1020-1040. [CrossRef] 